\title{
Money Well Spent? Operations, Mainstreaming, and Fairness of Fair Trade
}

\author{
Michael K. Lim ${ }^{a}$, Ho-Yin $\mathrm{Mak}^{b}$, Seung Jae Park \\ a SNU Business School, Seoul National University, Seoul 08826, South Korea, milim@snu.ac.kr; \\ ${ }^{b}$ Saïd Business School, University of Oxford, Oxford OX1 1HP, United Kingdom, ho-yin.mak@sbs.ox.ac.uk; \\ ${ }^{c}$ School of Business, Ewha Womans University, Seoul 03760, South Korea, park.s@ewha.ac.kr
}

\begin{abstract}
We examine the operations, fairness, and social implications of fair trade certified products. We consider the market for fair trade certified products, which may serve as a substitute to a regular product. A fair trade organization chooses standards for the certification, namely, the (unit) premium and minimum fraction of fair trade raw materials, to maximize the total premium transferred to farmers. We analyze the operations of various stakeholders in the fair trade value chain, as well as the role and social welfare of fair trade organizations with different philosophies. We characterize the firms' entry decision in the fair trade market as well as the resulting market equilibrium. Furthermore, we examine the impact of mainstreaming, i.e., whether to allow large-scale plantations (often owned by large corporates) to be eligible for fair trade certification or not, which is one of the most discussed topics in the fair trade movement. We also identify the welfare allocation among various stakeholders in the value chain under different certification policies, and thereby address the fairness issue of the fair trade market as well as its resulting social welfare implications. Finally, we obtain a number of policy insights and suggestions to support this nascent marketplace.
\end{abstract}

Key words: fair trade certification; sustainable operations; farmer premium; smallholders; value chain

Acknowledgements: The authors would like to thank Mr. Jean-Jacques Grauhar, the President of Fairtrade International Europe-Korea Foundation, for providing various information and perspective on the fair trade market practice. We also appreciate various help and comments provided by the Fairtrade International office during the development of this study.

\section{Introduction}

The retail coffee market in the U.S. is estimated to be $\$ 48$ billion in 2015 , and fair trade ${ }^{1}$ coffee is one of the fastest growing specialty coffees comprising about $5 \%$ value share (USDA 2015). If you have purchased one of the fair trade coffees recently, then you might have wondered: How does the

\footnotetext{
${ }^{1}$ We use the term "fair trade" as a general term indicating a certified fair-trading practice of products sourced from producers in developing countries. We note that "Fair Trade" and "Fairtrade" are registered certification labels of particular organizations, which are examples of fair trade certifications considered in this paper.
} 
fair trade marketplace work? How does the premium we pay for a fair trade coffee pass along the value chain to the poor farmers in developing countries?

Fair trade is an alternative to conventional forms of trade that supports sustainable development of marginalized farmers, especially in developing countries. Fair trade standards and contract offer better terms to producers to reduce poverty, provide good working conditions, and encourage environmentally- and socially-responsible practices. Fair Trade USA (FTUSA), the largest fair trade organization in the U.S., describes fair trade as:

Fair Trade is a global trade model and certification allows shoppers to quickly identify products that were produced in an ethical manner. For consumers, Fair Trade offers a powerful way to reduce poverty through their everyday shopping. For farmers and workers in developing countries, Fair Trade offers better prices, improved terms of trade, and the business skills necessary to produce high-quality products that can compete in the global marketplace (FTUSA 2017b).

To carry the fair trade certification label on a product, a firm must procure fair trade certified raw materials from farmers. Such raw materials are produced by following the fair trade standards, which include International Labor Organization (ILO) conventions (e.g., no child labor) and sustainable farming practices (e.g., no use of genetically modified organisms). The two common instruments employed by the fair trade organizations, such as Fairtrade Labelling Organizations International (FLO) and Fair Trade USA (FTUSA), are premium and minimum fraction of certified raw materials (e.g., see FLO 2017b). To purchase the fair trade raw materials, the firm must pay a premium to farmers in addition to regular selling price. For example, FLO stipulates that the fair trade procurement price must be set at least 20 cents per pound (the premium) above the commodity coffee price (or a fixed minimum price). In addition, a fair trade product must contain at least a certain amount of fair trade certified raw material. This, referred to as the minimum fraction of certified raw materials, may vary depending on the type of the product; for example, the minimum fraction of fair trade certified raw materials including cocoa in a chocolate bar is $20 \%$ of its weight (FTUSA 2017d).

Other major fair trade products - bananas, cane sugar, flowers and plants, and tea, which, including coffee and cocoa, account for well over $90 \%$ of fair trade sales volume, number of involved farmers, and producer income in 2016 (FLO 2016) - are also procured in similar manners providing favorable terms and various benefits to marginalized farmers. As shown in Figure 1, the sales of fair trade certified products have grown rapidly in recent years, and about $59 \%$ of consumers now recognize the fair trade certified logos in the marketplace (FTUSA 2016). Despite making such progress, however, the market share of fair trade certified products still remains to be low in general. The market share of fair trade products in 2015 was typically ranging between $1 \%$ to $5 \%$ (FTUSA 2015). For example, the market shares of fair trade certified cocoa and sugar in the global 
market are about $1.2 \%$ and less than 1\%, respectively (Fairtrade Foundation 2017). In addition, according to Elliott (2012), the income of fair trade producers accounts for less than 1\% of global exports of the corresponding products. Thus, to nurture the growth of this nascent market, we aim to establish understanding of the fair trade marketplace by examining the question of how does fair trade work? In particular, we analyze the decisions of the fair trade organization as well as the firms to characterize the resulting equilibrium of the fair trade market in $\S 4$.

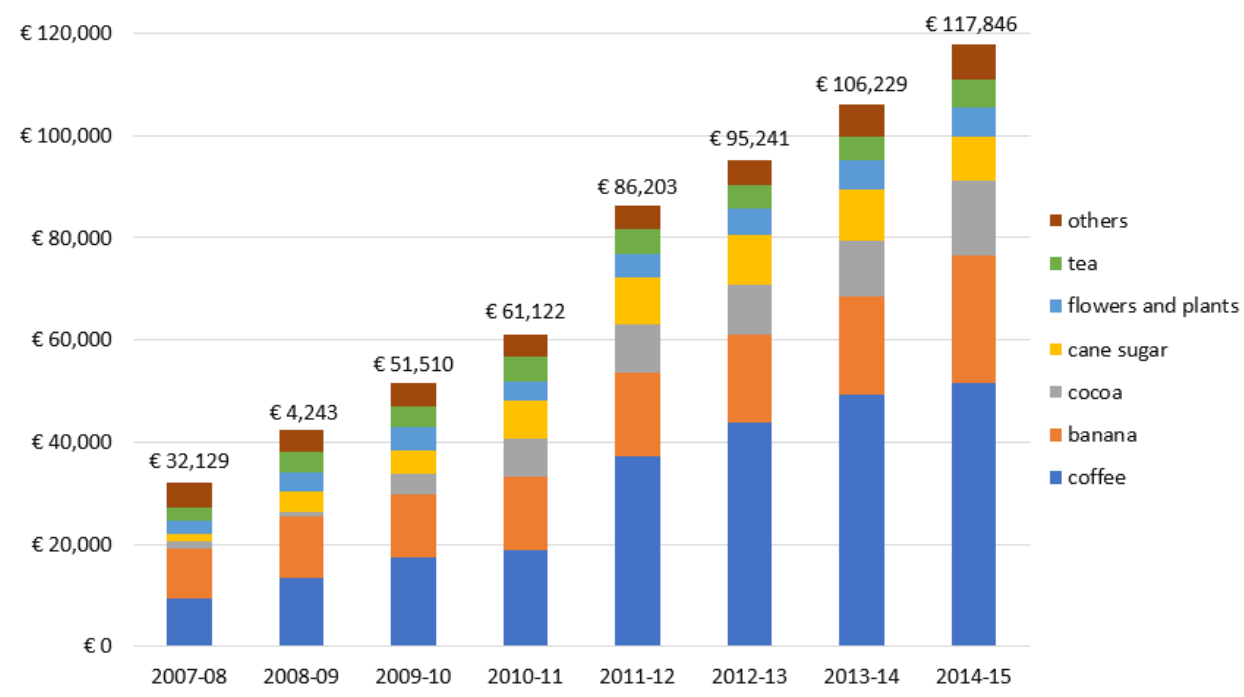

Figure 1 Fair Trade Premium Reported by Producer Organizations (in thousands of Euros)

Source: Fairtrade International Annual Reports from 2007 to 2016 (www.fairtrade.net). "Others" includes items such as fresh fruits, gold, herbs, honey, nuts, oilseeds, rice, seed cotton, spices, sports balls, tea, and vegetables.

While the ultimate goal of the fair trade movement is to support poor farmers by promoting the sales of fair trade certified products, there are ongoing debates on the best means of promotion. One of the biggest issues is mainstreaming, i.e., whether to allow products from major firms that utilize large-scale plantations to be certified as fair trade products. Two organizations at the center of the debate in particular are FLO and FTUSA. The argument between the two sides signified in 2011 when FTUSA announced its plan to allow fair trade certification to large farms that had been excluded by most fair trade organizations, including FLO (Neuman 2011 and Elliott 2012). ${ }^{2}$ In addition, FTUSA revealed its intention to lower the fair trade certification standards for multiingredient products. For example, to be certified as a fair trade product by FLO, a chocolate bar must carry at least 20 percent of fair trade certified raw materials including cocoa, while FTUSA attempted to lower the minimum amount of fair trade certified ingredients to 10 percent. Such

${ }^{2}$ According to the current FLO's standards, major items, such as coffee and cocoa, harvested from large plantations are excluded from fair trade certification. In contrast, FTUSA allows that all products harvested by large farms are eligible to be certified. 
differences in operational philosophies finally led the two organizations to split in 2011 (Neuman 2011, FLO 2017c).

The rationale behind FTUSA's decision, to relax the standards while increasing the total sales, is to make the fair trade model more scalable and accessible. Paul Rice, the CEO of FTUSA, asks "do we want it to be small and pure, or do we want it to be fair trade for all?," asserting that the fair trade market needs to involve more farmers and consumers to bring a greater societal impact (Neuman 2011). Other fair trade organizations including FLO, however, sharply criticized FTUSA of watering down fair trade standards, perhaps motivated by making higher revenue from the certification fees. Critics also fear that the market share of smallholders will be reduced greatly, so the lowered standards only help large companies that mostly source raw materials from large plantations. In light of this, in $\S 5.1$, we aim to examine the positive and negative attributes of mainstreaming (and effects of excluding firms conducting such farming practice) by addressing the question of what is the impact of mainstreaming?

On a related note, we shed light on the resulting social implications by considering the respective welfare of various stakeholders along the value chain of fair trade products. Whereas the goal for the fair trade movement is to contribute "to sustainable development by offering better trading conditions to, and securing the rights of, marginalized producers and workers" (per both FLO and FTUSA), the effectiveness and the social welfare of the two fair trade organizations are not well understood. Hence, to enhance our understanding of social implications and the fairness aspect of the fair trade movement, we pose the final question of fair trade for whom? We address this in $\S 5.2$ by examining the welfare allocation among farmers of varying sizes (e.g., smallholder farmers and large-scale plantations), production firms, and consumers, under the two types of fair trade philosophies (e.g., FLO and FTUSA). With our focus on the welfare allocation perspective, we note that non-monetary considerations of fairness, such as labor conditions and gender equality issues, are beyond the scope of our paper.

The key objective of this study is to address the three questions posed above: (i) how does fair trade work?, (ii) what is the impact of (excluding) mainstreaming?, and (iii) fair trade for whom?; namely, we examine the operations, mainstreaming, and fairness aspects of the fair trade movement. In addition, we shed light on the value chain aspect of fair trade product delivery, and address the implications of two means of fair trade promotion strategies taken by the two certification organizations.

To facilitate the analysis, we develop an analytical model that captures the key features of fair trade value chain that delivers fair trade products to the marketplace. We consider the market of fair trade certified products, which may serve as a substitute for its regular (non-certified) counterpart. 
Further, within the fair trade market, we consider two types of products, i.e., single- and multiingredient products, that are produced independently. A fair trade organization decides the required standards for the fair trade certification, i.e., a (unit) premium to farmers and a minimum fraction of fair trade certified raw materials, with the objective of maximizing the total premium transferred to farmers. While we model the single- and multi-ingredient value chains as operationally independent entities, they are connected through the fair trade certification standards: the premium that applies to the raw materials of both products. Consequently, firms make the entry decision on the fair trade market along with the optimal quantities to sell in each market in order to maximize their own profits.

In $\S 4$, we study the operational aspect of the fair trade market by addressing the optimal decisions of the firms as well as the fair trade organizations. In particular, we first identify the optimal threshold in the firm's fair trade introduction cost, below (above) which suggests the firm (not) to enter the market. Accordingly, we characterize the optimal market equilibrium (e.g., sales quantity, total demand, sales price) along with associate comparative statics. These results are helpful in understanding the market structure and the characteristics of the firms engaging in the fair trade market. We then characterize the fair trade organization's optimal standards, premium and minimum fraction, and their implications with respect to changes in key market parameters.

The issue of mainstreaming is examined in $\$ 5.1$. To clarify the analysis, we specifically model and contrast the two differing philosophies of fair trade organizations: (i) one that prioritizes the protection of smallholders and thus excludes mainstreaming involving plantations, and (ii) the other that prioritizes market expansion and hence allowing large firms sourcing from plantations to engage in the fair trade market. FLO and FTUSA are the respective representative examples of these organizations. We show that, although FTUSA's policy indeed expands the fair trade market in terms of total sales quantity and total premium amount, it often does so at the expense of smallholders' welfare.

In $\S 5.2$, we further explore the fairness and social implications of the fair trade movement. In particular, the welfare allocation among various stakeholders (farmers, firms, and consumers) in the fair trade value chain are identified. We find that FTUSA is favored over FLO by the stakeholders when: the cost of exclusion is high (for both farmers and firms), the cannibalization effect between the fair trade and regular products is relatively small (for firms), and the minimum fraction requirement is stringent (for the farmers supplying to the multi-ingredient market); otherwise, we find that the preferences of fair trade policy typically diverges within the same value chain.

The remainder of this paper proceeds as follows. We briefly summarize the related literature in $\S 2$. We introduce the model in $\S 3$, and we subsequently examine the operations of fair trade marketplace in $\S 4$. In $\S 5$, we address the value of (exclusion of) mainstreaming practice, and examine the fairness and social implications of fair trade. Concluding remarks are provided in $\S 6$. 


\section{Literature Review}

Our study is naturally related to the literature of fair trade movements and products. Early studies such as Davies and Crane (2003), Becchetti and Huybrechts (2008), and Balineau and Dufeu (2010) provide conceptual foundations of the area by investigating the structure of the market as well as the ethical decision processes of the firms. Surveys, case analysis, and field experiments are also employed to examine the role and effectiveness of fair trade products. For example, Pelsmacker et al. (2005) find that the average additional willingness to pay (over regular products) is about $10 \%$, while Castaldo et al. (2008) investigate how consumers' perception towards a company affects their fair trade purchasing decisions. Howard and Jaffee (2013) consider the relationship between firm size and sustainability. Using field experiments, Didier and Lucie (2008) investigate willingness to pay for fair trade and organic products, and Hainmueller et al. (2015) show that the fair trade label is effective in promoting product sales. As pointed out by Moore (2004), although the empirical studies are well-established and useful to understand issues in the fair trade movement, they should be accompanied by theoretical investigations. Aligned with this suggestion, our work provides an analytical modeling foundation to better understand and support the fair trade movement. In addition, we look into latest important issues in fair trade practice including the disagreement between the FLO and FTUSA, impact of mainstreaming, and the resulting social implications.

Fair trade literature is a subset of voluntary standards (or labels) literature, which has been growing rapidly. Among recent studies, Graffin and Ward (2010), Harbaugh et al. (2011), and Fischer and Lyon (2014) investigate how to increase the credibility of certifications when consumers exhibit uncertainty on the certifications. Castka and Corbett (2016) empirically show that credibility of eco-labels (especially to experts and media) can be increased by third-party audits. Heyes and Martin (2016) consider competition on setting labeling standards between non-governmental organizations (NGOs). Murali et al. (2018) compare not only self and external eco-labels, but also mandatory regulations to promote environmentally friendly products. For a review of voluntary standards, we refer readers to Castka and Corbett (2015). Whereas studies in this literature deal with various forms of voluntary label, such as International Organization for Standardization (ISO) standards or eco-labels, it cannot be directly applied to fair trade standards due to the unique standard setup for fair trade products, e.g., a premium. As a result, the motivation of firms and the resulting market outcome may differ from the cases with other certifications; see Raynolds et al. (2007), for example.

Fair trade products are required to contain a certain minimum fraction of fair trade certified raw materials specified by the organization. We note that this feature is similar to the local content requirement (LCR) policy that requires a manufacturer to source a certain fraction of materials from the local suppliers. Munson and Rosenblatt (1997) examines the impact of LCR policy on 
a global manufacturer who makes a sourcing decision between the cost-efficient global supplier and LCR-complying (but expensive) domestic supplier. The paper shows that the LCR policy can yield both positive and negative effects to local industry, and thus illustrates the need for carefully setting the LCR stringency. More recently, Cui and Lu (2018) examines the optimal LCR policy that maximizes the social welfare taking into consideration the technology gap between the local and global suppliers.

Our paper is also related to the topics of fairness among companies in supply chains and socially responsible supply chains. With regard to fairness in supply chains, Cui et al. (2007) consider fairness between a manufacturer and a retailer to be achieved when the fairness in profit difference (i.e., the profit difference between the two firms) is negotiated by the companies. They show that, under a simple wholesale price policy, the required coordination between the two firms can be achieved. As extensions, Loch and Wu (2008), Demirag et al. (2010), and Katok et al. (2012) confirm that the findings in Cui et al. (2007) still remain valid in more general settings.

The notion of socially responsible supply chains was presented in Poist (1989). Whereas most studies in the literature take an empirical approach to examine the issue (see Maloni and Brown (2006) for a comprehensive review), a few studies have provided a theoretical foundation to investigate socially responsible supply chains more recently. For example, Galbreth and Ghosh (2013) consider the effects of consumer awareness on firms' sustainability in a duopoly setting. In addition, Guo et al. (2016), Huang et al. (2016), and Örsdemir et al. (2017) consider how to control the responsibility of firms in upstream supply chains. Similarly, Chen and Lee (2017) examine contract designs to screen the suppliers with various responsibility risk, while Cho et al. (2017) investigate how to prevent child labor in global supply chains. Finally, Agrawal and Lee (2018) examine the use of sourcing policies to influence suppliers' adoption of sustainable farming practices. We note that the "sustainable preferred policy" (and "sustainable required policy") studied in their paper, through which the buyer commits to procuring from the supplier if (and only if) it adopts sustainable practices, is conceptually similar to the fair trade minimum fraction considered in our work.

Finally, our study is related to the literature of product line extensions. Following the seminal works in this field, i.e., Hotelling (1929), Mussa and Rosen (1978), and Moorthy and Png (1992), several studies consider product line design problems. Among recent papers, Lacourbe et al. (2009) investigate a monopolist's optimal product design problems, considering both vertical and horizontal differentiation dimensions; and Ishibashi and Matsushima (2009) show that firms that produce high quality products can be beneficial when low quality products exist in the market. Studies in this literature assume that the cost difference between two products is either given or decided by firms, but in our study, the cost difference is decided by a third party, i.e., a fair trade organization. 


\section{Model}

We consider a two-stage model in which the fair trade organization and the firms sequentially make decisions. Specifically, in the first stage, the fair trade organization decides the standards for fair trade certification. Then, in the second stage, firms in the market simultaneously set their supply decisions for fair trade certified products to maximize their profit. We provide detailed descriptions of each player along with the model settings and assumptions in what follows. The summary of main notation is provided in Appendix A.1.

\subsection{Products}

We consider a fair trade raw material that can be used for making two types of products, i.e., singleingredient and multi-ingredient products. Consider unroasted coffee beans as the raw material, for example. The raw material may be consumed as roasted coffee beans (i.e., single-ingredient products) or as one of the ingredients of composite products such as coffee ice cream (i.e., multiingredient products) along with additional ingredients such as cream, milk, and sugar. These two types of products are sold in their own independent markets. We use subscripts $S$ and $M$ to denote the single- and multi-ingredient markets or products, respectively, and use $J$ to denote the set of the market types; i.e., $J=\{S, M\}$.

\subsection{Fair Trade Organization}

We focus on the market for fair trade certified products. Firms that wish to enter the fair trade market must procure fair trade certified raw materials, which in turn allows such firms to carry fair trade certification labels on their products. Accordingly, the fair trade organization determines the following two standards to certify fair trade products.

Premium. Given the high costs of producing and managing fair trade certified raw materials, the firms are required to not only pay the base raw material price (i.e., regular raw material price) but also make an additional payment to farmers. We call the additional payment the premium to farmers, which is denoted by $\rho>0$. The premium ensures that the farmers (often to a co-op) receive an extra fee in addition to the market price. Co-ops usually use premiums to improve farmers' welfare via various projects in the community such as building hospitals and schools (FTUSA 2017c, FLOCERT 2015). We note that, for certain products, fair trade organizations may impose a price floor (i.e, minimum price) along with the premium to ensure that farmers are paid at least their production costs for the certified raw materials; for example, FLO fixed a minimum price of Arabic natural coffee beans to $\$ 1.35$ per pound in 2011 . This is an effective tool that protects farmers against the stochastic commodity price. However, we do not explicitly model the minimum price, as the time dimension is not considered in this paper. 
Minimum fractions. A product may contain up to $100 \%$ fair trade certified raw materials depending on the product type. In particular, a single-ingredient product, such as coffee beans or bananas, must contain $100 \%$ fair trade certified raw materials in order to be certified as a fair trade product. However, it is generally impossible for a multi-ingredient product to contain $100 \%$ fair trade certified raw materials, due to the limited supply and/or limited variety of fair trade certified raw materials. For example, fair trade certified egg and wheat do not exist (FTUSA 2017d). Hence, a multi-ingredient product can be certified as a fair trade product if the product contains more fair trade certified ingredients than a specified minimum level. We let $\theta_{M}$ be the required minimum fraction of fair trade certified raw materials in a multi-ingredient product where $0<\theta_{M} \leq \bar{\theta}_{M}$, where $\bar{\theta}_{M}$ represents the feasible upper bound of the fair trade raw material usage. For notational convenience, we use $\theta_{S}$ to denote the minimum fraction of fair trade certified raw materials in a single ingredient product, which equals one by definition and is not a decision variable.

Decisions. The fair trade organization decides the (unit) premium $\rho$ and the minimum fraction $\theta_{M}$ in order to maximize the total premium paid to farmers. We let $D_{j}^{F}$ be the demand for fair trade certified products in market $j$. Hence, the total premium for each type of fair trade product is given by $\rho \cdot \theta_{j} \cdot D_{j}^{F}$ for $j \in\{S, M\}$. For the multi-ingredient fair trade products, we assume firms include exactly $\theta_{M}$ fraction of fair trade certified raw materials, since no additional quality differentiation is achieved by adding more certified raw materials. Hence, we formulate the fair trade organization's problem as maximizing total premium from the two markets, $T\left(\rho, \theta_{M}\right)$ :

$$
\max _{\rho, \theta_{M}} T\left(\rho, \theta_{M}\right) \equiv \rho \sum_{j \in J} \theta_{j} \cdot D_{j}^{F} .
$$

Later in $\S 5$, we modify the fair trade organization's problem to reflect the difference in the organizations' operational philosophies.

\subsection{Firms}

Fair trade certified products. We consider firms' decisions to introduce fair trade certified products in a market $j \in\{S, M\}$. We denote the number of firms in market $j$ as $n_{j}$ and the set of firms as $I_{j}$, i.e., $I_{j}=\left\{1,2, \ldots, n_{j}\right\}$. The unit base cost of production for firm $(i, j)$ is denoted by $c_{i, j}>0$. It includes the base price of raw materials (i.e., the price of regular raw materials), as well as the manufacturing and shipping costs, except for the additional payment to farmers $\rho$. Due to the economies of scale in the costs of manufacturing and shipping, we assume that $c_{i, j}$ is firm-specific.

Given the fair trade standards, i.e., the premium $\rho$ and the minimum fraction $\theta_{M}$, firms decide on the quantity of fair trade certified products in each market, denoted by $q_{i, j}$. We use $p_{j}$ to denote the selling price of fair trade certified products in market $j$. Demand for the fair trade certified 
products in market $j$ decreases as the price $p_{j}$ increases. Hence, we consider a demand function of the fair trade certified product $j, D_{j}^{F}\left(p_{j}\right)$, that obeys the following:

$$
D_{j}^{F}\left(p_{j}\right)= \begin{cases}\left(1-\frac{p_{j}}{a_{j}}\right) b_{j} & \text { if } p_{j} \in\left[0, a_{j}\right], \\ 0 & \text { if } p_{j} \in\left(a_{j}, \infty\right),\end{cases}
$$

where $a_{j}>0$ and $b_{j} \geq 0$ for $j \in\{S, M\}$. For a similar demand setting, please see Ishibashi and Matsushima (2009). The above demand specification assumes that a typical customer's willingness to pay follows a uniform distribution ranging between 0 and $a_{j}$, where $a_{j}$ is the maximum willingness to pay from customers. ${ }^{3}$ In addition, the consumer's willingness to pay for fair trade products are largely heterogenous, and thus not all consumers may wish to buy fair trade certified products (see, Prasad et al. 2004 and Hainmueller et al. 2015). This can be due to some consumers' belief that their extra payments do not actually go to "poor farmers," but rather to "rich firms" (Elliott 2012). The maximum demand for the fair trade certified product $j$ is given by $b_{j}$. Although we consider $a_{j}$ and $b_{j}$ as constant in our model, we note that in practice the two may increase as the fair trade standards $\left(\theta_{j} \rho\right)$ increase and thus increase the fair trade demand $\left(D_{j}^{F}\right)$. We have numerically verified that our results and message do not change with such modification of the model. Details are provided in Appendix A.2.

The equilibrium selling price of product $j, p_{j}$, is determined by the total sales quantity of fair trade certified products. ${ }^{4}$ We use $n_{j}^{F}$ to denote the number of firms that make the "entry decision" to sell the fair trade certified products in market $j$, and $I_{j}^{F}$ to denote the set of such firms; i.e., $\left|I_{j}^{F}\right|=n_{j}^{F}$. Note that if $q_{i, j}>0$, then firm $(i, j)$ enters the fair trade market $j$, and thus $i \in I_{j}^{F}$; otherwise if $q_{i, j}=0$, then $i \notin I_{j}^{F}$. Hence, under the assumption that $\sum_{i \in I_{j}^{F}} q_{i, j} \leq b_{j}$, the equilibrium price in market $j, p_{j}$, is given by

$$
p_{j}=a_{j}\left(1-\frac{\sum_{i \in I_{j}^{F}} q_{i, j}}{b_{j}}\right)
$$

due to $D_{j}^{F}\left(p_{j}\right)=\sum_{i \in I_{j}^{F}} q_{i, j}$.

We do not explicitly model the firms' decisions for the regular (non-certified) product market for tractability reasons. However, as the fair trade certified and regular products are substitutes, the demand for the latter and the associated profits are naturally reduced as the former is introduced to the market. Therefore, the firm's profit from selling regular products, denoted by $\pi_{i, j}^{R}\left(D_{j}^{F}\right)$, is

\footnotetext{
${ }^{3}$ As shown in one of the recent field experiments, consumers are indeed willing to pay more for a fair trade products. For example, it finds that the sales of the coffees rose by almost $10 \%$ when they carried a fair trade label as compared to a generic label (Hainmueller et al. 2015).

${ }^{4}$ In order to procure fair trade certified raw materials, firms must make a quantity commitment in advance by (often in long-term) contract. Therefore, we use quantity competition (i.e., Cournot competition) as a suitable representation of the fair trade practice (Raynolds 2009).
} 
a decreasing function in the equilibrium quantity of fair trade certified products in the market, $D_{j}^{F}$. To maintain model tractability, we consider that the profit function takes a linear form, i.e.,

$\pi_{i, j}^{R}\left(D_{j}^{F}\right)=\bar{\pi}_{i, j}^{R}-\gamma_{i, j} D_{j}^{F}$, where $\bar{\pi}_{i, j}^{R}$ denotes firm $i$ 's profits from the regular market in the status quo (i.e., without fair trade certified products), and $\gamma_{i, j}(>0)$ is a profit loss (cannibalization) coefficient that captures the degree of substitutability between the fair trade and regular products.

In Appendix A.3, we provide an alternative derivation of this model that explicitly captures the firms' participation in both regular and fair trade product markets, where demand substitution between the two are captured with standard linear demand functions. In the alternative derivation, we explicitly link the cannibalization coefficient $\gamma_{i, j}$ with the firm's profit margin and market share in the regular market, and the degree of demand substitution between regular and fair trade certified products. While the appendix shows that the linear form of $\pi_{i, j}^{R}(\cdot)$ can arise from a linear demand function, we note that other reasonable functional forms (e.g., convex decreasing $\pi_{i, j}^{R}(\cdot)$ ) also yield similar qualitative findings.

Decisions. Upon observing relevant market parameters, the firm makes the decisions of fair trade market entry as well as the sales quantity. If firm $(i, j)$ enters the fair trade market, then its corresponding per unit margin of the fair trade product is given by $\left(p_{j}-c_{i, j}-\theta_{j} \cdot \rho\right)$. Therefore, the profit-maximizing firm $(i, j)$ 's objective, $\Pi_{i, j}\left(q_{i, j}\right)$, is given by:

$$
\begin{aligned}
\max _{q_{i, j}} \Pi_{i, j}\left(q_{i, j}\right) & \equiv \pi_{i, j}^{R}\left(\sum_{m \in I_{j}^{F}} q_{m, j}\right)+\left(p_{j}-c_{i, j}-\theta_{j} \cdot \rho\right) q_{i, j} \\
& =\bar{\pi}_{i, j}^{R}-\gamma_{i, j} \cdot\left(\sum_{m \in I_{j}^{F}} q_{m, j}\right)+\left\{a_{j}\left(1-\frac{\sum_{m \in I_{j}^{F}} q_{m, j}}{b_{j}}\right)-c_{i, j}-\theta_{j} \cdot \rho\right\} q_{i, j} .
\end{aligned}
$$

Using the model constructed above, we now address the research questions raised in the introduction of the paper.

\section{Operations of Fair Trade}

In this section, we explore the first question of "how does fair trade work?". We address this by sequentially obtaining the optimal decisions of the firms and the fair trade organization. In what follows, we layout the solution of the problem backward and provide relevant insights. All proofs of the main results are provided in Appendix B.

\subsection{Second Stage: Firms' Decisions}

In this stage, given a premium to farmers $\rho$ and a minimum fraction of fair trade certified raw materials in market $j, \theta_{j}$, firms simultaneously make the fair trade market entry and the corresponding sales quantity decisions. 
The following proposition provides the firm's optimal entry decision on whether to carry fair trade certified products or not. For notational convenience, we let $\phi_{i, j}=\left(c_{i, j}+\gamma_{i, j}+\theta_{j} \cdot \rho\right)$ and refer to it as the effective cost of introducing fair trade products.

Proposition 1 (Fair trade market entry). For given fair trade standards of $\left(\rho, \theta_{j}\right)$, it is optimal for the firm $i \in I_{j}$ to enter the fair trade market $j \in J$ if the following holds:

$$
\phi_{i, j}<\frac{a_{j}+\sum_{m \in I_{j}^{F} \backslash\{i\}} \phi_{m, j}}{n_{j}^{F}} .
$$

Proposition 1 highlights that the firm's optimal entry decision can be characterized by $\phi_{i, j}$, the firm's effective cost of introducing fair trade certified products. That is, the firm should enter the fair trade market if the associated cost, which includes the costs of production, cannibalization, and the premium to farmers, is sufficiently low compared with the other firms in the fair trade market. Otherwise, a sufficiently high fair trade cost suggests that it is unprofitable to enter. While in theory this condition could lead to multiple equilibria corresponding to entry of alternative subsets of firms, we note that the equilibrium where firms with the lowest $\phi_{i, j}$ values sequentially enter the fair trade market is the one that maximizes collective welfare (i.e., sum of profits) among firms. We shall focus on this efficient equilibrium in our subsequent analysis. The following lemma characterizes this equilibrium of the fair trade market.

LEMMA 1 (Fair trade market equilibrium). The optimal sales quantity of fair trade certified products by firm $(i, j) \in I_{j}^{F}$ for $j \in\{S, M\}$ is given by

$$
q_{i, j}^{*}=\frac{b_{j}}{\left(n_{j}^{F}+1\right) a_{j}} \cdot\left\{a_{j}-\left(n_{j}^{F}+1\right) \phi_{i, j}+\sum_{m \in I_{j}^{F}} \phi_{m, j}\right\} .
$$

Accordingly, the total sales of the fair trade certified products in market $j$ are

$$
D_{j}^{F, *}=\frac{b_{j}}{\left(n_{j}^{F}+1\right) a_{j}} \cdot\left\{n_{j}^{F} \cdot a_{j}-\sum_{i \in I_{j}^{F}} \phi_{i, j}\right\},
$$

and the selling price of fair trade certified products in market $j$ is

$$
p_{j}^{*}=\frac{1}{\left(n_{j}^{F}+1\right)} \cdot\left\{a_{j}+\sum_{i \in I_{j}^{F}} \phi_{i, j}\right\} .
$$

Based the fair trade market equilibrium, Proposition 2 further illustrates how the firm's optimal sales quantity of fair trade certified products and the corresponding premium paid to firms change as the firm's key parameter values change. 
Proposition 2 (Equilibrium analysis with respect to effective cost of fair trading). An increase in the effective cost of selling the fair trade product, $\phi_{i, j}$, results in a decrease in the optimal fair trade sales quantity of firm $(i, j), q_{i, j}^{*}$, and the optimal aggregate fair trade sales in market $j, D_{j}^{F, *}$, and an increase in the optimal selling price of fair trade certified products in market $j, p_{j}^{*}$, for all $i$ and $j$.

Proposition 2 explores the impact of changes in the effective fair trade cost on the market equilibrium outcome. We find that an increase in the effective fair trade cost results in a reduced fair trade production and total demand, while leading to an increased selling price. This result implies that an increase in the production cost (i.e., the base cost of producing a fair trade product) $c_{i, j}$, degree of cannibalization (i.e., degree of substitution between regular and fair trade products, and the firm's profitability from regular products) $\gamma_{i, j}$, and/or fair trade standards (i.e., minimum fraction and premium) $\theta_{j} \rho$ leads to a decrease in the optimal fair trade sales quantity $q_{i, j}$, the optimal aggregate fair trade sales $D_{j}^{F, *}$, and an increase in the optimal selling price $p_{j}^{*}$ (see Lemma A.1 for details). We note that the increase in $\phi_{i, j}$ may result in a change in the configuration of firms engaging in the fair trade market $I_{j}^{F}$. That is, the firm $(i, j)$ will be less likely to enter the fair trade market as its effective fair trade cost $\phi_{i, j}$ increases, per Proposition 1, assuming the welfare-maximizing equilibrium as discussed above. We next examine how equilibrium is affected by the consumer's demand on the fair trade certified products.

Proposition 3 (Equilibrium analysis with respect to changes in fair trade demand). (a) An increase in the maximum willingness to pay for the fair trade certified product, $a_{j}$, results in a decrease in the optimal fair trade sales quantity, $q_{i, j}^{*}$, if $\phi_{i, j}<\left(\sum_{m \in I_{j}^{F} \backslash\{i\}} \phi_{m, j}\right) / n_{j}^{F}$ holds, and an increase in the optimal aggregate sales, $D_{j}^{F, *}$, for all $i$ and $j$. Furthermore, an increase in $a_{j}$ results in an increase in the optimal selling price, $p_{j}^{*}$, if the set of firms in the fair trade market $j, I_{j}^{F}$, is unchanged.

(b) In addition, an increase in the maximum demand for the fair trade products, $b_{j}$, results in an increase in both the optimal fair trade sales quantity, $q_{i, j}^{*}$, and the optimal aggregate fair trade sales, $D_{j}^{F, *}$, while the optimal selling price, $p_{j}^{*}$, is independent of $b_{j}$ for all $i$ and $j$.

Proposition 3 (a) reveals that although the aggregate demand and the selling price of the fair trade products tend to increase with the maximum willingness to pay $a_{j}$, the individual production quantity at the firm-level can actually decrease with $a_{j}$ for firms with low effective costs for the fair trade product. This is because the firms with cost advantages (i.e., low $\phi$-values) leverage the advantage through selling larger quantities at relatively low selling price. However, such edge diminishes with increasing customers' willingness to pay, as the cost-disadvantaged firms (i.e., high $\phi$-values) also find it profitable to supply larger quantities of fair trade certified products. 
This intensifies competition and results in reduced market shares for the cost-advantaged firms. Note that the above threshold is in line with the optimal fair trade entry condition provided in

Proposition 1 (recall, the firm enters the market if $\phi_{i, j}<\left(a_{j}+\sum_{m \in I_{j}^{F} \backslash\{i\}} \phi_{m, j}\right) / n_{j}^{F}$ holds). From part (b), we find that the optimal selling price is independent of the maximum demand for the fair trade product $b_{j}$, while its optimal production quantity and the aggregate demand increase with $b_{j}$.

\subsection{First Stage: Fair Trade Organization's Decisions}

Now let us consider the fair trade organization's decision on the (unit) premium $\rho$ and the minimum fraction of the fair trade certified raw materials in the multi-ingredient product $\theta_{M}$ to maximize the total premium from both the single- and multi-ingredient markets. Recall that the minimum fraction of fair trade certified raw materials in the single-ingredient product $\theta_{S}$ is always one (i.e., $\left.\theta_{S}=\bar{\theta}_{S}=1\right)$, and the upper bound on the minimum fraction for the multi-ingredient product $\theta_{M}$ is $\bar{\theta}_{M}$. In what follows, we refer to $m_{j}:=\left(a_{j}-\sum_{i \in I_{j}^{F}}\left(c_{i, j}+\gamma_{i, j}\right) / n_{j}^{F}\right)$ as the average base margin of the fair trade market $j$.

Lemma 2. The fair trade organization's optimal decisions on minimum fraction of fair trade certified raw materials and premium to farmers are as follow:

If the average base margin of the single-ingredient market is relatively greater than that of the multi-ingredient market, i.e., $\frac{m_{S}}{\bar{\theta}_{S}}>\frac{m_{M}}{\bar{\theta}_{M}}$, then we have

$$
\theta_{M}^{*}=\frac{m_{M}}{m_{S}} \text { and } \rho^{*}=\frac{m_{S}}{2} .
$$

Otherwise, i.e., $\frac{m_{S}}{\bar{\theta}_{S}} \leq \frac{m_{M}}{\bar{\theta}_{M}}$, we have

$$
\theta_{M}^{*}=\bar{\theta}_{M} \quad \text { and } \rho^{*}=\frac{1}{2} \cdot\left(\sum_{j \in J} m_{j} \cdot \frac{b_{j} n_{j}^{F} \bar{\theta}_{j}}{\left(n_{j}^{F}+1\right) a_{j}}\right) /\left(\sum_{j \in J} \frac{b_{j} n_{j}^{F}\left(\bar{\theta}_{j}\right)^{2}}{\left(n_{j}^{F}+1\right) a_{j}}\right) .
$$

Lemma 2 characterizes the optimal fair trade standards based on the relative average base margins in the two fair trade markets. If the single-ingredient product yields greater margin than the multi-ingredient product, then the first part of the lemma suggests that it is optimal to set $\theta_{M}^{*}=m_{M} / m_{S}$ such that the effective premium of each product, $\theta_{j} \rho$, equals to a constant fraction (one half) of its average base margin; i.e., $\theta_{S} \rho=m_{S} / 2$ and $\theta_{M} \rho=m_{M} / 2$. This allows the effective premiums of the two markets to be optimized independently of each other, and the total premiums of the two markets to be maximized simultaneously. In case the multi-ingredient product yields a greater margin than the single-ingredient product, the above solution becomes infeasible as it would require $\theta_{M}^{*}$ to exceed the maximum value $\bar{\theta}_{M}$. In such a case, the second part of Lemma 2 suggests to set $\theta_{M}^{*}$ to its maximum value $\bar{\theta}_{M}$, allowing the effective premiums to be as close 
as possible to the (unconstrained) optimal values. In this case, the effective premiums of the two markets would depend on the market conditions of each other.

In what follows, we provide the impact of changes in the key parameters to the effective premium.

Proposition 4 (Effective premium analysis). The impact of changes in the effective premium $\theta_{j}^{*} \rho^{*}$ with respect to the key parameters in market $j$ is as follows:

(a) An increase in the production cost $c_{i, j}$ or cannibalization coefficient $\gamma_{i, j}$ results in a decrease in the effective premium, while an increase in the maximum willingness to pay $a_{j}$ results in an increase in the effective premium.

(b) In addition, if the average base margin of the single-ingredient market is relatively greater than that of the multi-ingredient market (i.e., $\frac{m_{S}}{\bar{\theta}_{S}}>\frac{m_{M}}{\bar{\theta}_{M}}$ ), then the effective premium is independent of the maximum fair trade demand $b_{j}$. Otherwise, an increase in the maximum fair trade market for the single-ingredient (multi-ingredient) product $b_{S}\left(b_{M}\right)$ results in a decrease (an increase) in the effective premium.

Proposition 4(a) first shows that the effective premium naturally increases as the margin per unit increases (i.e., either $a_{j}$ increases, or $c_{i, j}$ or $\gamma_{i, j}$ decreases). Proposition 4(b) further identifies the effect of the maximum fair trade demand $b_{j}$ on the effective premium. If it is possible to set effective premiums to simultaneously maximize the total premiums in both types of market (i.e., $\theta_{j}^{*} \rho^{*}=m_{j} / 2$ per Lemma 2$)$, the organization only needs to consider the firms' average margin but not the market size, because such optimal effective premium is charged per unit. Hence, in this case, a change in market size $b_{j}$ has no effect on the optimal effective premium. However, if the total premiums of both markets cannot be simultaneously maximized, the second part of Lemma 2 suggests to set the minimum fraction $\theta_{M}$ as high as possible, along with the premium $\rho$ that maximizes the total premium for the two markets. In this case, the effective premium in the two markets will be dependent on the parameters from both markets. We find that, as the size of the single-ingredient (multi-ingredient) market $b_{S}\left(b_{M}\right)$ increases, the effective premium decreases (increases). This is because, given that the average margin per unit of firms in the single-ingredient market is lower than that in the multi-ingredient market, an increase in $b_{S}\left(b_{M}\right)$ causes the average profit of firms from the two markets to decrease (increase), and thus decreases (increases) the effective premium. We next examine the impact of changes in the effective premium to consumers and firm.

Proposition 5 (Equilibrium analysis with respect to the effective premium). An increase in the effective premium $\theta_{j}^{*} \rho^{*}$ results in a decrease in market demand $D_{j}^{F, *}$. Furthermore, an increase in the effective premium $\theta_{j}^{*} \rho^{*}$ results in an increase in the firm's profit $\Pi_{i, j}^{*}$ if and only if $\gamma_{i, j}>q_{i, j}^{*}\left\{\frac{2 a_{j}}{b_{j}\left(n_{j}^{F}-1\right)}\right\}$. 
Proposition 5 illustrates how the fair trade organization's decision affects other stakeholders. It shows that the market demand will shrink as the effective premium increases. This is because the firms naturally increase the price of fair trade products by supplying less collectively, as the fair trade standards become more stringent. However, we find that this does not always hurt the firms' profit, since firms with large cannibalization factor could actually benefit from a smaller total fair trade demand. That is, the firms' with large $\gamma_{i, j}$ can benefit more from the regular market as the fair trade demand decreases. While this result holds for general values of $\gamma_{i, j}$, we note that $\gamma_{i, j}$ in practice may be correlated with the firm's size, as larger incumbent firms may have more to lose if a niche fair trade segment grows in size. In such a case, Proposition 5 would suggest that larger firms are more likely to benefit from more stringent certification standards as the effective premium increases.

\subsection{Cross Market Interaction}

In the previous subsection, we examined the fair trade organization's optimal decision and how changes in the key parameters in each type of market (single- or multi-ingredient) affect the effective premium and the resulting market equilibrium. We now examine how the two markets interact with each other.

Interestingly, we find that the effective premium in each type of market depends not only on the market parameters of its own, but also on the parameters of the other market. Specifically, although the two markets are operationally independent, the fair trade standards provide an important link through which the two markets could interact.

COROLlary 1 (Cross-market interaction). The change of the optimal value of the effective premium of market $j, \theta_{j}^{*} \rho^{*}$, which depends on the key parameters in the other market, market $-j$, is as follows:

(a) If $\frac{m_{S}}{\bar{\theta}_{S}}>\frac{m_{M}}{\bar{\theta}_{M}}$, then any change in $c_{-i,-j}, \gamma_{-i,-j}, a_{-j}$, or $b_{-j}$ does not affect $\theta_{j}^{*} \rho^{*}$.

(b) If $\frac{m_{S}}{\bar{\theta}_{S}} \leq \frac{m_{M}}{\bar{\theta}_{M}}$, an increase in $c_{-i,-j}$ or $\gamma_{-i,-j}$ results in a decrease in $\theta_{j}^{*} \rho^{*}$, while an increase in $a_{-j}$ results in an increase in $\theta_{j}^{*} \rho^{*}$. In addition, an increase in $b_{-j}$ results in an increase in $\theta_{j}^{*} \rho^{*}$ if and only if $\frac{m_{-j}}{\bar{\theta}_{-j}} \geq \frac{m_{j}}{\bar{\theta}_{j}}$.

Corollary 1 follows from Lemma 2 and is also closely related to Proposition 4. Under the condition in part (a), the optimal effective premiums in the single- and multi-ingredient markets are given by $\theta_{S}^{*} \rho^{*}=m_{S} / 2$ and $\theta_{M}^{*} \rho^{*}=m_{M} / 2$, respectively. In this case, parameter changes in one market (say $-j$ ) affects the other $(j)$ through the organization's choice in premium value since $\rho^{*}$ is commonly applied to both markets. However, the fair trade organization can contain such impact by adjusting $\theta_{M}^{*}$ accordingly, and thus maintains the effective premium value $\theta_{j}^{*} \rho^{*}$ unchanged. We find that the cross market interaction becomes prominent under the condition in part (b), the case in which the 
average base margin of the multi-ingredient market is relatively greater than that of the singleingredient market, $\theta_{M}^{*}$ is determined by the binding constraint $\bar{\theta}_{M}$ (per Lemma 2). Hence, the effect on effective premium $\theta_{-j}^{*} \rho^{*}$ carries over to market $j$, and thus the parameter changes in one type of market affects the equilibrium of the other market as well.

Combining Corollary 1 with Proposition 5, we find that a decrease in production cost, a decrease in cannibalization effect, or an increase in willingness to pay in one market results in increases in the effective premium in the other market when $\frac{m_{S}}{\bar{\theta}_{S}} \leq \frac{m_{M}}{\bar{\theta}_{M}}$. This decreases total equilibrium demand of fair trade products and reduces a firm's profit in the other market if and only if the firm's cannibalization factor is relatively small (e.g., when the firm has relatively small margin and market share for regular products). This result also implies that the effectiveness of investments for cost innovation could depend on the fair trade standards. Although each type of market is operationally independent, the two markets interact through the effective premium when the margin of the multi-ingredient market is relatively greater than that of the single-ingredient market. In such a case, investing in cost reduction in one type of market could negatively affect the other market by increasing the effective premium. Therefore, firms that participate in both markets must be aware of such cross market interaction when making the investment decisions of cost innovation.

\section{Fairness and Social Implications of Fair Trade}

We have examined the fair trade market equilibrium by obtaining the optimal decisions of the firms and the fair trade organization in the previous section. In this section, we examine the fairness and its social implications of the fair trade movement. In particular, we consider two differing philosophies of fair trade organizations: one that wishes to preserve the original spirit of the fair trade movement by protecting the marginalized smallholders, i.e., a mission-driven model; the other that wishes to reform the traditional business setting by strategically expanding the fair trade market, i.e., a market-driven model. The representative examples of the two models in practice are FLO and FTUSA, respectively.

Our focus in this section is to examine if and how the fair trade movement (as well as mainstreaming) benefits the farmers under the two fair trade practices, and thereby address the questions of "what is the impact of (excluding) mainstreaming?" in $\S 5.1$, followed by "fair trade for whom?" in $\S 5.2$.

\subsection{Fair Trade Movements: Mission-driven vs. Market-driven}

As mentioned, one of the most debated issues in the emerging fair trade market is mainstreaming, i.e., whether to allow products from large farms with plantations to be certified as fair trade products (Neuman 2011). The proponents of mainstreaming, most notably FTUSA, argue that the scale economies and efficiency of large plantations could make the industry and producers better 
off. Large plantations certainly allow stability and scalability in fair trade sourcing, which helps increase accessibility to mass consumers. In contrast, the opponents of mainstreaming, such as FLO, claim that such practice will result in a disproportionate welfare distribution, likely only benefiting the large firms. Whereas the large firms can thrive by utilizing the cost-effective products of large-scale plantations, such firms may also industrialize the fair trade market using intensive control and traditional management practices that exploit the workers. This could go against the original mission of the fair trade movement.

To examine the implications of the two differing fair trade philosophies, we specifically model the organizations' decisions as follows. We first assume that, under FLO's certification policy, raw materials from large plantations are not eligible to be fair trade certified (i.e., excluded). We denote the set of firms that procure from such plantations in the status quo by $I_{j}^{P, F L O}$. Hence, if firm $(i, j)$ 's procurement source is excluded from fair trade certification due to the use of large plantations, then the firm can choose to either: (i) engage in the regular product market only or (ii) enter the fair trade market by procuring the raw materials from alternative smallholder farmers at a unit cost of $c_{i, j}+\alpha_{i, j}$; that is, the fair trade base cost of the firm $(i, j) \in I_{j}^{P, F L O}$ will be increased by $\alpha_{i, j}$ under FLO's certification policy. We assume that it is more costly to procure from individual smallholders than from (large) plantations, i.e., $\alpha_{i, j}>0$ for $(i, j) \in I_{j}^{P, F L O}$, due to economies of scale for the latter. On the other hand, under FTUSA's policy in which plantations are allowed, any firm can engage in the fair trade market with no additional cost, i.e., $I_{j}^{P, F T U S A}=\emptyset$. While we do not impose such an assumption in the model, it is often the case that $\alpha_{i, j}$ is correlated with the firm's size. That is, larger firms are more likely to be enjoying the cost efficiency by procuring large amount of raw materials from large plantations in the status quo, and would incur more significant cost increases to source their supplies from smallholders.

Second, the standards on the minimum fraction of the fair trade raw materials for the two organizations may differ. As a mission-driven organization, FLO wants to ensure multi-ingredient products contain fair trade raw materials as much as possible (FLO 2017a). ${ }^{5}$ Accordingly, we consider FLO's minimum fraction in market $M$ is set to the upper bound $\bar{\theta}_{M}$. In contrast, the market-driven FTUSA operates under a more relaxed basis with the goal of expanding the fair trade market (FTUSA 2017e). Hence, we allow the minimum fraction in the multi-ingredient market to be the organization's decision variable under the FTUSA regime. Indeed, we observe that FTUSA

\footnotetext{
${ }^{5}$ The standards of the minimum fair trade raw materials contents in multi-ingredient products by FLO are as follows: "For a food composite product to carry the FAIRTRADE Mark, at least 20 percent of the content must be Fairtrade certified. If a Fairtrade certified ingredient is available, it must be used, regardless of what percentage it makes up in the final product." See FLO (2017a) for details.
} 
generally offers lower fair trade quality stringency in practice; it offers varying levels of certification and aims to lower the minimum fraction standards. ${ }^{6}$

In what follows, we discuss the market equilibrium under FLO's certification policy. Given $\theta_{M}^{F L O}=$ $\bar{\theta}_{M}$, FLO decides $\rho^{F L O}$ to maximize the total premium to farmers. Incorporating the requirement of excluding plantations, we first characterize the firm's fair trade market entry decisions. For notational convenience, we modify the effective cost of introducing fair trade products under the FLO policy to $\phi_{i, j}^{F L O}=c_{i, j}+\gamma_{i, j}+\theta_{j}^{F L O} \rho^{F L O}+\mathbf{1}_{\left\{(i, j) \in I_{j}^{P, F L O}\right\}} \alpha_{i, j}$; that is, as firm $(i, j)$ 's plantation is excluded from fair trade, then the additional cost $\alpha_{i, j}$ is incurred if the firm still wishes to enter the fair trade market. Although the effective fair trade cost $\phi_{i, j}^{F L O}\left(I_{j}^{P, F L O}\right)$ is a function of exclusion set $I_{j}^{P, F L O}$, we simply express the above as $\phi_{i, j}^{F L O}$ for notational convenience.

Corollary 2 (Fair trade market entry under FLO). For a given certification policy of $F L O,\left(\rho^{F L O}, \theta_{j}^{F L O}\right)$, it is optimal for the firm $i \in I_{j}^{F L O}$ to enter the fair trade market $j \in\{S, M\}$ if the following holds:

$$
\phi_{i, j}^{F L O}<\frac{a_{j}+\sum_{m \in I_{j}^{F L O} \backslash\{i\}} \phi_{m, j}^{F L O}}{n_{j}^{F L O}} .
$$

We note that the above entry condition is identical to that provided in Proposition 1 where the effective fair trade cost is adjusted by the additional cost $\alpha_{i, j}$ under FLO's plantation exclusion policy.

Next, we discuss the model for FTUSA's policy. Following the practice of the current fair trade market, we assume that FTUSA adopts FLO's premium standard, $\rho^{F L O}$. Although FTUSA can deviate from FLO's premium level, it is well-documented that FTUSA acknowledges the importance of honoring the global premium standard, and sets the level following the FLO-CERT certification standards which are adopted by the majority of the certification organizations (FLO 2017b, FTUSA 2017d). Hence, given $\rho^{F T U S A}=\rho^{F L O}$, FTUSA determines $\theta_{M}^{F T U S A}$ to maximize the total premium to farmers. Recall also that FTUSA allows the use of plantations. Thus, firm $(i, j)$ 's effective cost of introducing fair trade products under the FTUSA policy is given by $\phi_{i, j}^{F T U S A}=$ $c_{i, j}+\gamma_{i, j}+\theta_{j}^{F T U S A} \rho^{F L O}$.

Under FTUSA's certification policy, the firms' fair trade market entry equilibrium follows directly from Proposition 1. Comparing the entry conditions under the two policies, we find that firms procuring from large plantations are less likely to enter the fair trade market under FLO compared with the case under FTUSA, due to the additional cost. Therefore, the exclusion of plantations

${ }^{6}$ Unlike FLO, FTUSA does not stipulate all available fair trade ingredients to be used for the product as long as " $100 \%$ of particular ingredients are fair trade certified." In addition, even if a product fails to contain a minimum required fraction level of a fair trade certified ingredient, it still allows the product to carry a "Fair Trade Certified ${ }^{T M}$ " statement but without the "fair trade certification logo." See FTUSA (2017e). 
results in a reduced number of firms participating in the fair trade market (i.e., $I_{j}^{F L O} \subseteq I_{j}^{F T U S A}$ ). We note that direct competition between the two organizations is not considered in this paper. This, again, follows from the current fair trade market practice; FTUSA is the most dominant certification in the U.S., whereas FLO is the most popular certification outside the U.S., predominantly in Europe and Asia.

The following result examines the optimal decision by each fair trade certification granting organization. As before, we modify the average base margin of the fair trade market as $m_{j}^{F L O}:=\left(a_{j}-\sum_{i \in I_{j}^{F L O}}\left(c_{i, j}+\gamma_{i, j}+\mathbf{1}_{\left\{(i, j) \in I_{j}^{P, F L O}\right\}} \alpha_{i, j}\right) / n_{j}^{F L O}\right)$ under FLO and $m_{j}^{F T U S A}:=$ $\left(a_{j}-\sum_{i \in I_{j}^{F T U S A}}\left(c_{i, j}+\gamma_{i, j}\right) / n_{j}^{F T U S A}\right)$ under FTUSA.

COROllary 3. The optimal fair trade standards of the two organizations are as follows:

(i) FLO's fair trade standards are $\theta_{S}^{F L O}=\bar{\theta}_{S}=1, \theta_{M}^{F L O}=\bar{\theta}_{M}$ and

$$
\rho^{F L O, *}=\frac{1}{2} \cdot\left(\sum_{j \in J} m_{j}^{F L O} \cdot \frac{b_{j} n_{j}^{F L O} \bar{\theta}_{j}}{\left(n_{j}^{F L O}+1\right) a_{j}}\right) /\left(\sum_{j \in J} \frac{b_{j} n_{j}^{F L O}\left(\bar{\theta}_{j}\right)^{2}}{\left(n_{j}^{F L O}+1\right) a_{j}}\right) .
$$

(ii) FTUSA's fair trade standards are $\theta_{S}^{F L O}=\bar{\theta}_{S}=1, \rho^{F T U S A}=\rho^{F L O, *}$ and

$$
\theta_{M}^{F T U S A, *}=\min \left\{\bar{\theta}_{M}, \frac{m_{M}^{F T U S A}}{2 \rho^{F L O, *}}\right\}
$$

Given that FLO sets the minimum fraction to its upper bound, Corollary 3(i) follows directly from the second part of Lemma 2. From Corollary 3(ii), one can verify that the effective premiums to single-ingredient products by both organizations are identical, since $\theta_{S}^{F L O}=\theta_{S}^{F T U S A}=1$ and that FTUSA adopts the FLO's premium. In addition, the effective premium to multi-ingredient products by FLO is greater than that by FTUSA, i.e., $\bar{\theta}_{M} \rho^{F L O, *} \geq \theta_{M}^{F T U S A, *} \rho^{F T U S A}$. Hence, this shows that FLO's policy induces greater overall effective premium to farmers compared with FTUSA's policy.

We next provide further analysis on the impact of excluding plantations by comparing the equilibrium outcomes under the two certification policies.

Proposition 6. (i) Total sales of fair trade certified products under FTUSA is always greater than that under FLO, while the selling price of fair trade certified products under FTUSA is always less than that under FLO. That is, $D_{j}^{F T U S A} \geq D_{j}^{F L O}$ and $p_{j}^{F T U S A} \leq p_{j}^{F L O}$.

(ii) Suppose firm $(i, j)$ sells fair trade certified products under both FTUSA and FLO. Then, the fair trade sales quantity of firm $(i, j)$ under the FLO policy is greater than that under the FTUSA policy (i.e., $q_{i, j}^{F L O} \geq q_{i, j}^{F T U S A}$ ) if and only if

$$
\left(\phi_{i, j}^{F L O}-\phi_{i, j}^{F T U S A}\right) \leq \frac{a_{j}}{b_{j}} \cdot\left(D_{j}^{F T U S A}-D_{j}^{F L O}\right)
$$


Proposition 6(i) shows that the exclusion of plantations may result in a decreased total premium to farmers (i.e., $D_{j} \theta_{j} \rho_{j}$ ). That is, the exclusion always makes the total premium to farmers in the single-ingredient market decrease ( since $D_{S}^{F T U S A} \geq D_{S}^{F L O}, \theta_{S}^{F L O}=\theta_{S}^{F T U S A}$, and $\rho^{F L O}=\rho^{F T U S A}$ ) and it may also decrease the total premium in the multi-ingredient market (since $D_{M}^{F T U S A} \geq D_{M}^{F L O}$ while $\theta_{M}^{F T U S A} \leq \theta_{M}^{F L O}$ ). This implies that FLO's anti-mainstreaming policy, despite the fact that it induces greater per unit effective premium to farmers (per Corollary 3), may not be necessarily beneficial to farmers in aggregate (as well as to firms). This is because the exclusion of plantations adds extra cost of procurement to the large firms, which results in a reduced number of firms engaging in the fair trade market, and thus leads to a decreased overall total premium paid to the farmers.

Proposition 6(ii) reveals the implications of excluding plantations on individual firms' sales. Although the number of firms in the fair trade market decreases under FLO compared with FTUSA, the firms that remain engaged in the fair trade market actually sell more fair trade products if (2) is satisfied. This implies that the remaining firms in the market can benefit from the exclusion of plantations due to reduced competition in the fair trade market. However, for the firms that do not satisfy condition (2), we find that the fair trade sales can also decrease. Note that condition (2) compares a firm's additional costs to participate in the FLO-certified market over the case of FTUSA, $\left(\phi_{i, j}^{F L O}-\phi_{i, j}^{F T U S A}\right)$, against the difference in market demand under the two policies, $\left(D_{j}^{F T U S A}-D_{j}^{F L O}\right)$. When a firm's additional cost under the FLO regime lies in a moderately large range relative to (the rest of) the market, it sells less under FLO than under FTUSA; and in the case its additional cost is sufficiently large, the firm exits the fair trade market under FLO. If the firms' additional sourcing costs $\alpha_{i, j}$ are positively correlated with firm size, this result suggests that larger firms may tend to participate less in fair trade under FLO than under FTUSA. However, since the firm's objective is to maximize its own profit, we should compare profits under FLO and FTUSA. This is explored in $§ 5.2$.

All in all, Proposition 6 illustrates the arguments for and against mainstreaming. Whereas FTUSA's model benefits the farmers in its entirety by increasing the scale of the fair trade market, it often does so at the expense of smallholders' surplus, since a large proportion of the total premium goes to plantations. In contrast, marginalized smallholders are more likely to be protected under FLO's certification policy. This result calls for a careful investigation on the impact of fair trade to individual parties involved in the market.

In the following section, we explore how the difference between philosophies affects different stakeholders (i.e., farmers, firms and customers), i.e., "fair trade for whom?" 


\subsection{Social Implications of Fair Trade}

We now explore social implications of the fair trade movement under the respective policies of the two fair trade organizations. In particular, we aim to provide understanding of the welfare allocation among the stakeholders involved in the value chain, and to address the fairness of the fair trade movement.

We consider three entities in the value chain, namely, farmers, firms, and consumers. The welfare measure for each stakeholder is defined as follows: (i) total premium to farmers (i.e., $\left.\left(\theta_{j} \rho\right) \sum q_{i, j}\right)$ from the fair trade market; (ii) firm's profit (i.e., $\Pi_{i, j}$ ) obtained from both regular and fair trade markets; (iii) consumer surplus (i.e., $\left.\left(a_{j}-p_{j}\right) D_{j}^{F} / 2\right)$ that captures the welfare derived from additional valuation of consuming fair trade products.

We summarize the welfare implication of each stakeholder in the fair trade market by comparing the preference between the two fair trade certification policies as follows.

Proposition 7. Consider given sets of firms $I_{j}$ for $j \in\{S, M\}$, and the corresponding respective sets of firms in the fair trade market under FLO and FTUSA, $I_{j}^{F L O}$ and $I_{j}^{F T U S A}$ for $j \in\{S, M\}$. The welfare implications to each stakeholder are as follows:

(i) Farmers: Smallholders, in aggregate, prefer FLO's policy if

$$
\sum_{i \in I_{j}^{F L O}} \frac{\left(\phi_{i, j}^{F L O}-\phi_{i, j}^{F T U S A}\right)}{n_{j}^{F L O}} \leq \frac{a_{j}}{b_{j}} \cdot\left(D_{j}^{F T U S A}-D_{j}^{F L O}\right) .
$$

Plantation farmers always prefer FTUSA's policy.

(ii) Firms: Firm $(i, j)$ prefers FLO's policy if and only if

$$
\frac{\left(\phi_{i, j}^{F L O}-\phi_{i, j}^{F T U S A}\right)}{\left(1+\zeta_{i, j}\right)} \leq \frac{a_{j}}{b_{j}} \cdot\left(D_{j}^{F T U S A}-D_{j}^{F L O}\right),
$$

where $\zeta_{i, j}:=\gamma_{i, j} /\left\{\gamma_{i, j}+\left(a_{j} / b_{j}\right)\left(q_{i, j}^{F L O}+q_{i, j}^{F T U S A}\right)\right\}$.

(iii) Consumers: Consumers always prefer FTUSA's policy.

We note that the conditions under which smallholder farmers and firms prefer FLO's policy, i.e., (3) and (4), respectively, are similar to condition (2) in Proposition 6. From Proposition 6, we note that when condition (2) holds for individual firms (i.e., the additional costs under FLO are small relative to the market size difference under the two policies), such firms would supply larger quantities of fair trade products under FLO certification. When the similar condition (3) holds for the market on average, Proposition 7 suggests that smallholder farmers are better off under the FLO policy, since they are better compensated and still supply a relatively large amount in aggregate (recall that the equilibrium market supply is still always smaller under FLO).

Comparing Propositions 6 and 7, we also note that some firms may prefer FLO over FTUSA (if (4) holds), despite selling less (not satisfying (2)) and at smaller margins under FLO. This is 
due to the fact that FLO reduces the total sales in the entire fair trade market, which mitigates the cannibalization effect on the regular market. Naturally, this happens for firms with larger cannibalization factors (large $\gamma_{i, j}$, e.g., firms that focus more on selling regular than fair trade products), which imply larger values of $\zeta_{i, j}$. If the firms' cannibalization factors $\gamma_{i, j}$ are positively correlated with firm size in the market, then this result further suggests that larger incumbent firms may prefer FLO while firms focusing mostly in the fair trade market (or small entrants) may prefer FTUSA.

Finally, as expected, consumer surplus in the fair trade market is always larger under FTUSA since mainstreaming enhances the overall size (and reduces the price) of the fair trade market. However, we note that this is solely based on the consumer surplus perspective, and does not take into account individual consumers' preference which may depend their own perception of respective fair trade brand and business philosophy.

Note that Proposition 7 evaluates the total surplus of all smallholder farmers in aggregate. As the preferences of individual farmers depend heavily on the firms they supply, we further analyze the individual farmer's surplus in the following by refining Proposition 7(i).

Corollary 4. Consider the setting in Proposition 7. Further, suppose smallholder farmer $(i, j)$ supplies only to firm $(i, j)$. Then, the welfare implications to individual farmer $(i, j)$ are as follows:

(i) Single-ingredient products: The smallholder farmer $(i, S)$ prefers FLO's policy if and only if

$$
\left(\phi_{i, S}^{F L O}-\phi_{i, S}^{F T U S A}\right) \leq \frac{a_{S}}{b_{S}} \cdot\left(D_{S}^{F T U S A}-D_{S}^{F L O}\right) .
$$

(ii) Multi-ingredient products: If $m_{M}^{F T U S A}<2 \rho^{F L O}$ (i.e., $\theta_{M}^{F T U S A}<\bar{\theta}_{M}^{F L O}$ ), then the smallholder farmer $(i, M)$ prefers FLO if and only if

$$
\left(\phi_{i, M}^{F L O}-\phi_{i, M}^{F T U S A}\right)-\left(\frac{\bar{\theta}_{M}}{\theta_{M}^{F T U S A}}-1\right)\left(\frac{a_{M}}{b_{M}}\right) q_{i, M}^{F L O} \leq \frac{a_{M}}{b_{M}} \cdot\left(D_{M}^{F T U S A}-D_{M}^{F L O}\right) .
$$

Otherwise, if $m_{M}^{F T U S A} \geq 2 \rho^{F L O}$ (i.e., $\theta_{M}^{F T U S A}=\bar{\theta}_{M}^{F L O}$ ), the smallholder farmer $(i, M)$ prefers $F L O$ 's policy if and only if

$$
\left(\phi_{i, M}^{F L O}-\phi_{i, M}^{F T U S A}\right) \leq \frac{a_{M}}{b_{M}} \cdot\left(D_{M}^{F T U S A}-D_{M}^{F L O}\right) .
$$

Altogether, we summarize each stakeholder's preference between the two fair trade certification policies for individual value chain of fair trade product $(i, j)$; i.e., smallholder farmer $(i, j)$ supplies the raw material to firm $(i, j)$ who produces the fair trade product, which is then consumed by the end consumers in fair trade market $j \in\{S, M\}$.

Proposition 8. The preferences of stakeholders in value chain $(i, j)$ are given in Figure 2. 


\begin{tabular}{|c|c|c|c|c|c|}
\hline & (4) \& (5) & \multicolumn{2}{|c|}{ (4) \& ᄀ(5) } & $\neg(4) \& \neg(5)$ & \\
\hline \multirow{4}{*}{$\begin{array}{l}\text { Single- } \\
\text { ingredient } \\
\text { market }\end{array}$} & Smallholders & \multicolumn{2}{|c|}{ Smallholders } & Smallholders & \\
\hline & Firms & \multicolumn{2}{|c|}{ Firms } & Firms & \\
\hline & Consumers & \multicolumn{2}{|c|}{ Consumers } & Consumers & \multirow{2}{*}{$\begin{array}{l}\square \text { Prefers FTUSA } \\
\square \text { Prefers FLO }\end{array}$} \\
\hline & (4) \& (6) & (4) \& $\neg(6)$ & $\neg(4) \&(6)$ & $\neg(4) \& \neg(6)$ & \\
\hline \multirow{3}{*}{$\begin{array}{l}\text { Multi- } \\
\text { ingredient } \\
\text { market }\end{array}$} & Smallholders & Smallholders & Smallholders & Smallholders & \\
\hline & Firms & Firms & Firms & Firms & \\
\hline & Consumers & Consumers & Consumers & Consumers & \\
\hline
\end{tabular}

Figure 2 Who prefers each fair trade certification policy?

The above suggests that the preferences of stakeholders within the same value chain over the certification policy are not always aligned. Since consumers always gain higher surplus under FTUSA, whether a value chain exhibits divergence in preferences depends on the producers (farmers and firm). In the single-ingredient market, farmers and the firm in the same value chain would both prefer FLO if (4) (the cannibalization factor is relatively large) and (5) (firm's additional procurement cost under FLO is relatively small) hold. In this case, Propositions 6 and 7 suggest that both the fair trade supply quantity and the firm's profit are higher under FLO. On the other hand, if only (4) holds but not (5), which represents the case in which the cannibalization factor is sufficiently large such that the firm prefers FLO despite smaller sales quantity, then the preferences of the two types of producers diverge. This is because the farmers supplying to such firms obtain smaller surpluses with a smaller supply quantity. Note that this tends to be the case for large firms if both the cannabilization factor and the additional procurement cost are positively correlated with firm size. Furthermore, if both (4) and (5) do not hold, i.e., it is substantially more expensive to procure under FLO and the firms benefit little from reduced cannibalization, both the farmers and the firm prefer FTUSA due to the higher resulting sales quantity and profit.

For multi-ingredient products, Proposition 8 suggests a different pattern. In particular, whether the preferences within a value chain are aligned or not depends on two conditions, (4) and (6). From Corollary 4 (when $\theta_{M}^{F T U S A}<\bar{\theta}_{M}^{F L O}$ ), farmers supplying to the multi-ingredient market would benefit more under FLO if (6) holds, which is equivalent to $\theta_{M}^{F L O} q_{i, M}^{F L O} \geq \theta_{M}^{F T U S A} q_{i, M}^{F T U S A}$. Since $\theta_{M}^{F L O} \geq \theta_{M}^{F T U S A}$, it is possible that farmers prefer FLO when the firm produces a smaller quantity of certified products $\left(q_{i, M}^{F L O} \leq q_{i, M}^{F T U S A}\right)$ but procures a higher proportion of ingredients through fair trade. Note that neither (4) nor (6) is implied by the other. In the case of where both hold (i.e., additional procurement cost under FLO is relatively small, cannibalization factor is relatively large, and FTUSA's minimum fraction requirement is relatively lenient), both types of producers prefer FLO while consumers prefer FTUSA. If only (4) holds but not (6) (i.e., cannabalization factor is large but FTUSA's minimum fraction mandate is stringent), the firm prefers FLO while the 
farmers and consumers prefer FTUSA. However, if the opposite holds (i.e., only (6) holds but not (4)), then the preferences are reversed - the firm and consumers both prefer FTUSA but farmers prefer FLO. Finally, if neither conditions hold (i.e., cannabalization factor is small and FTUSA's requirement is stringent), then it follows that all parties prefer FTUSA.

All in all, we find that FTUSA is favored over FLO by the stakeholders in value chain when: the cost of mainstreaming exclusion (i.e., additional procurement cost of fair trade raw materials) is high (for both types of producers), the cannablization effect between fair trade and regular products is small (for the firm), and its minimum fraction requirement is stringent (for farmers supplying to the multi-ingredient market). When these conditions do not hold simultaneously, a divergence of preferences within the same value chain would arise. This suggests that effective and equitable implementation of fair trade certification policy often requires coordination mechanisms to carefully align stakeholders' interests along the value chain.

To complement the above findings, we further examine the welfare allocation effects of the FLO and FTUSA certification policies with a numerical example consisting of four firms. Figure 6 illustrates the general (most representative) trend of how farmers' premium and firms' profits are affected under the two fair trade policies We assume the two larger firms (firms $(1, M)$ and $(2, M)$ ) procure from plantations in the status quo. Under the FLO regime where plantations are excluded, they have an option to enter the fair trade market by procuring from alternative smallholder farmers with additional unit costs of $\alpha_{1, M}$ and $\alpha_{2, M}$. In contrast, the smaller firms in the example (firms $(3, M)$ and $(4, M))$ do not incur such costs, i.e., $\alpha_{3, M}=\alpha_{4, M}=0$.

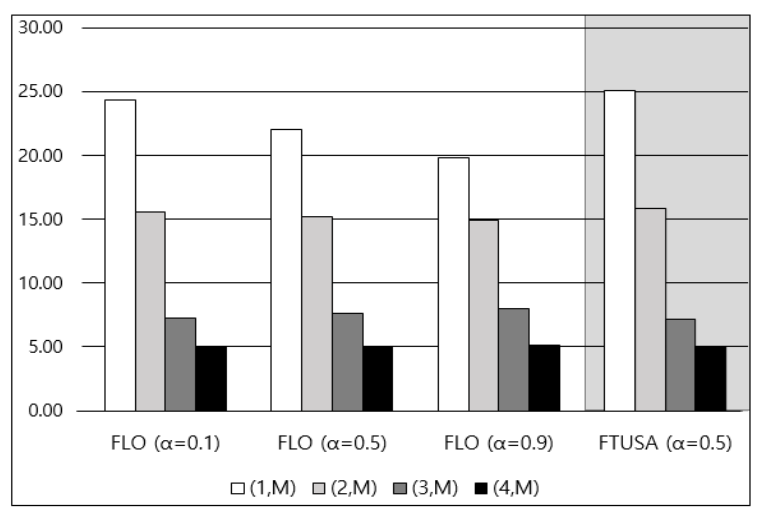

(a) Firm's profit

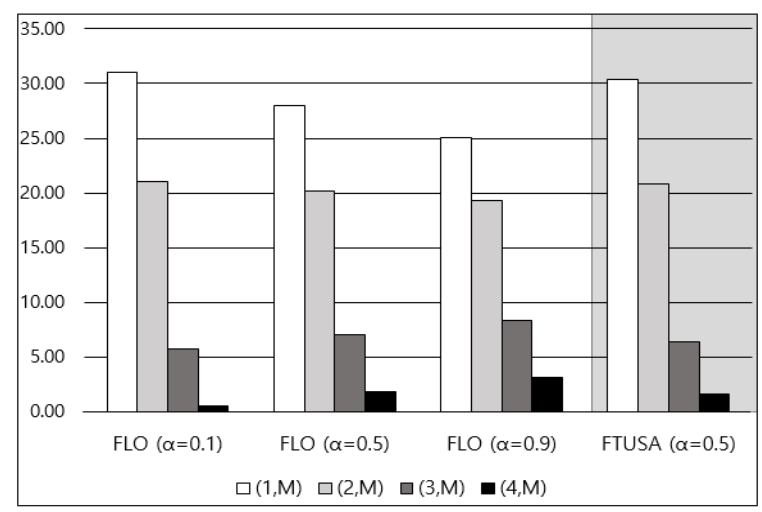

(b) Farmer premium

Figure 3 Firm's Profit and Farmer Premium with Changes in $\alpha_{i, M}$

The figure is based on a market with four firms. Under FLO's policy, we chose three levels of $\alpha=\{0.1,0.5,0.9\}$ where individual firm's additional unit cost due to the exclusion of plantation farms is set by $\alpha_{1, M}:=\alpha, \alpha_{2, M}:=\frac{\alpha}{2}$, and $\alpha_{3, M}=\alpha_{4, M}=0$. (Other parameter values are set as $a_{S}=25, b_{S}=25, a_{M}=20, b_{M}=25, \bar{\theta}_{M}=0.9, c_{S, 1}=c_{M, 1}=$ $\left.1, c_{S, 2}=c_{M, 2}=3, c_{S, 3}=c_{M, 3}=5, c_{S, 4}=c_{M, 4}=6, \gamma_{S, 1}=\gamma_{M, 1}=2, \gamma_{S, 2}=\gamma_{M, 2}=1, \gamma_{S, 3}=\gamma_{M, 3}=0.5, \gamma_{S, 4}=\gamma_{M, 4}=0.\right)$ For FTUSA, we set $\alpha=0.5$. 
Comparing the FLO and FTUSA policies, we first find that both measures, farmers' premium and firms' profits, are greater for larger firms under FTUSA compared to the case under FLO. In contrast, for smaller firms, both measures are smaller under FTUSA than under FLO. Hence, as anticipated, we observe that FTUSA typically favors the larger firms and their associated suppliers. This is in line with FTUSA's philosophy of expanding the fair trade market, which, in turn, benefits the other involved stakeholders in the value chain. Second, we find that the large firms and their associated farmers both do worse as $\alpha$ increases. That is, as the cost of exclusion of mainstreaming practices increases, larger firms are penalized more severely whereas smaller firms benefit. This confirms FLO's philosophy of protecting the smallholders. Furthermore, FLO's policy is effective in directing substantial farmers' premium associated with larger firms from plantation farmers to smallholders directly, through excluding the use of plantations. We note that we only report the comparisons for the multi-ingredient market in Figure 6 since the qualitative trends for the singleingredient market are similar. Counterpart figures for the single-ingredient market are provided in Appendix A.4. We only report one case for FTUSA as the effect of changes in $\alpha$ is negligible under FTUSA in equilibrium.

We now explore the impact of value chain structures, by studying how firms' profits and farmers' premium change as more firms source from large plantations in the status quo. In particular, we consider a varying number of firms to procure from plantations across different scenarios. A representative result from a numerical study is summarized in Figure 7. We set three scenarios under FLO: in the status quo, firms which procure from plantations are: 1) only firm $(1, M) ; 2)$ both firms $(1, M)$ and $(2, M) ; 3)$ all the firms except for firm $(4, M)$. To isolate the effect of the type of farmers (smallholders vs. plantations), we consider the firms' base procurement costs to

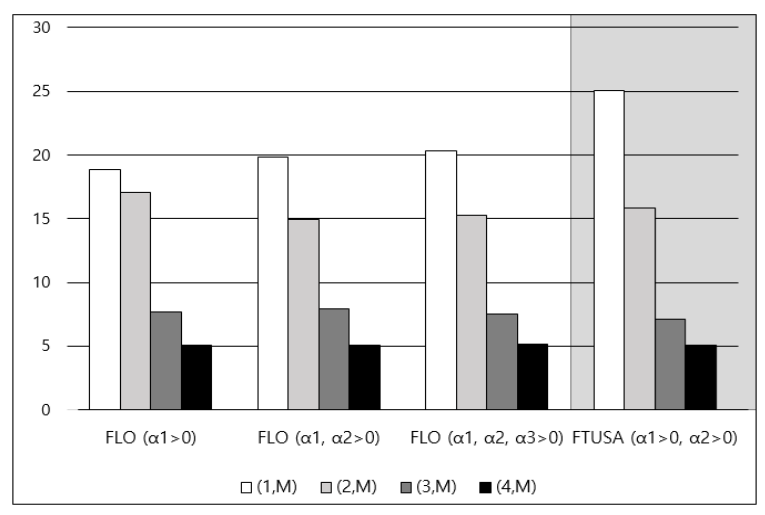

(a) Firm's profit

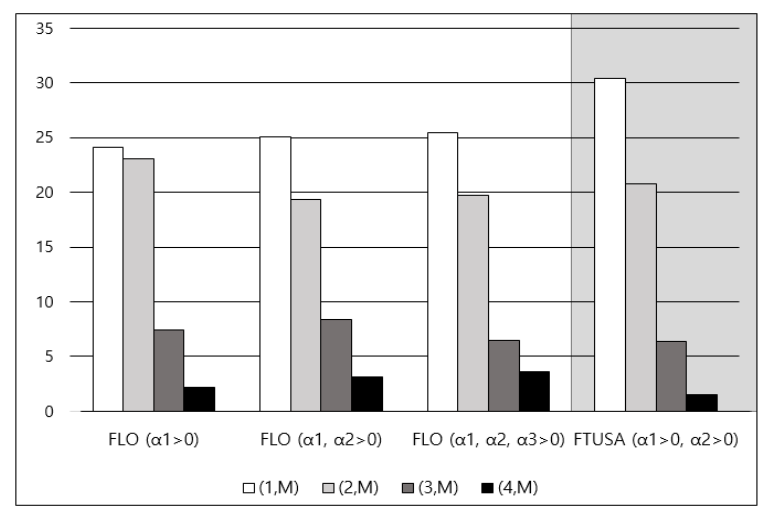

(b) Farmer premium

Figure 4 Firm's Profit and Farmer Premium with Changes in $I_{M}^{P, F L O}$

We set $\alpha=0.9$ and chose three scenarios under FLO: 1) $\left.\alpha_{1, M}=\alpha, \alpha_{2, M}=\alpha_{3, M}=\alpha_{4, M}=0 ; 2\right) \alpha_{1, M}=\alpha, \alpha_{2, M}=\frac{\alpha}{2}$, $\left.\alpha_{3, M}=\alpha_{4, M}=0 ; 3\right) \alpha_{1, M}=\alpha, \alpha_{2, M}=\frac{\alpha}{2}, \alpha_{3, M}=\frac{\alpha}{4}, \alpha_{4, M}=0$. Other parameter values are the same as those in Figure 6. 
be the same across scenarios regardless of their associated farmers' type. We observe that a firm's profit and its farmer premium increase as more competing firms procure from large plantations. This is because 1) higher number of farmers who are assigned as plantations increases the average base margin in the fair trade market, and then it lowers fair trade standards (per Corollary 3); and 2) higher cost of a competitor, due to its plantation being excluded by FLO, should be beneficial to another firm. Hence, a firm's profit and its associated farmer premium would increase as a larger fraction of competitors source from plantations. In contrast, when a firm switches its supplier from smallholders to a plantation (without changing procurement costs), both the focal firm's profit and farmer premium will decrease.

Finally, we note that it is important to recognize that the farmers employed by large plantations can also possibly be considered as marginalized workers. However, since they practically act as an integrated channel (i.e., the individual farmers are part of the large plantation, often owned by the firm), it is difficult to parse out whether the premiums are effectively transferred to such workers or not. In fact, the inability to transparently track the surplus transfer between farmers and the firm is one of the main criticisms of against mainstreaming. While we acknowledge this as a shortcoming of our model, we leave further examination on this issue as a topic for future study.

\section{Conclusion}

We conclude this study by summarizing a number of useful insights to better understand and support the fair trade movement.

First, to increase the total welfare of stakeholders in the fair trade value chain, we find that the certification granting organizations should focus on expanding the fair trade demand base (i.e., increasing the market size) rather than desiring the consumers pay more for the products. Although an increase in the maximum willingness to pay for fair trade certified products helps increase the total sales, it may decrease the market share of cost-advantaged firms while increasing the selling price (as shown in Proposition 3). Hence, expanding the market size would be a more promising direction to every stakeholder in the value chain: firms and the fair trade organization enjoy higher sales quantities and consumers enjoy lower prices.

Second, from the perspective of FTUSA, it must be cautious about excessively lowering the fair trade standards to expand the market. As FTUSA steadily relaxes the standards of its fair trade products, the disparity level in fair trade quality between FTUSA and FLO may become consideraly large. This, in turn, can affect the fair trade demand-the FTUSA's certification may not be as attractive as the one with FLO's, i.e., $a_{j}$ and $b_{j}$ decrease (per Proposition 3 ), resulting in a decrease in profits and total premium. Aggressively stretching the market, in the long run, may weaken consumers' support for FTUSA-certified products. 
Third, from the perspective of FLO, it is critical to expand the scope of fair trade partners without sacrificing the fair trade standards. After the split of FTUSA from FLO in 2011, FLO launched a new initiative in 2014, Fairtrade Sourcing Programs (FSP), which offers lower certification standards for a limited number of products. ${ }^{7}$ This hints that, FLO may be considering to increase the volume at the expense of quality, following the footsteps of FTUSA. Alternatively, we recommend that FLO invest on initiatives that help reduce the certification costs without sacrificing the standards, as the certification cost difference, i.e., $\left(\phi_{i, j}^{F L O}-\phi_{i, j}^{F T U S A}\right)$, plays a key role in our discussion in $§ 5.2$. Collaborating with firms (especially the large ones) to identify practices and programs that reduce the burden of fair trade certification, such as streamlining the distribution system or supporting the communities to organize large-scale co-ops, can be promising possibilities to maintain the core mission of the fair trade movement.

Fourth, from the producers' (firms' and farmers') perspectives, our findings confirm the intuition that the less stringent FTUSA certification policy allows larger firms and their associated farmers to obtain greater surpluses from fair trade, while FLO is effective in protecting the smaller firms (and farmers') interests. In practice, large firms often have the market power to promote their favored standards (e.g., Starbuck's C.A.F.E. program). Our results in Section 5.2 suggest that, although large firms tend to perform better in the fair trade market under FTUSA, those who focus more on regular products may prefer FLO, since doing so limits the fair trade products' cannibalization on the regular market. In addition, for smaller firms with low cannibalization factors (e.g., firms selling most products in the fair trade market) may prefer FTUSA, although the firms's mission would be more aligned with FLO, since the smaller firms could reduce costs in their main market (i.e., fair trade market) under FTUSA.

In conclusion, we identify a couple of directions for extending the scope of our current model. First, our model assumes that FLO and FTUSA adopt the same level of premium while only their standards on minimum fraction of raw materials can vary. Although this assumption is in line with current practice, it is plausible that the organization could deviate from the conventional standard norm; for example, lowering the premium amount for either or both the single- and multi-ingredient products in addition to the option of choosing its own minimum fraction of raw materials. Doing so could offer more flexibility in the design of certification policy, although one must take into consideration the resulting changes in consumer behavior and perception. Second, our model does not consider direct competition between the two certification granting organizations. Instead, we

${ }^{7}$ After FTUSA's new policy on the multi-ingredient products, which lowers the standards, became effective in August of 2013, FLO started FSP in January of 2014 (FTUSA 2017e, Fairtrade Foundation 2017). Under FSP, multiingredient products containing one of three ingredients, i.e., cocoa, sugar, and cotton, can put the FLO logo (a slightly differently designed logo compared with the original one) on the products even though the minimum fraction of fair trade certified ingredients is less than its original standards, i.e., 20 percent (FLO 2017d). 
develop insights based on the individual cases in which either type of organization is the sole certification provider in the marketplace, and draw further policy implications by comparing the two cases. While our model certainly provides a starting point, developing a model that explicitly captures the certification competition can be another fruitful direction for future research.

\section{References}

Agrawal, V., D. Lee. 2018. The effect of sourcing policies on suppliers' sustainable practices. Production and Operations Management Forthcoming.

Balineau, G., I. Dufeu. 2010. Are fair trade goods credence goods? A new proposal, with French illustrations. Journal of Business Ethics 92 331-345.

Becchetti, L., B. Huybrechts. 2008. The dynamics of fair trade as a mixed-form market. Journal of Business Ethics 81 733-750.

Castaldo, S., F. Perrini, N. Misani, A. Tencati. 2008. The missing link between corporate social responsibility and consumer trust: The case of fair trade products. Journal of Business Ethics 84 1-15.

Castka, P., C.J. Corbett. 2015. Management systems standards: Diffusion, impact and governance of ISO 9000, ISO 14000, and Other Management Systems Standards. Foundations and Trends in Technology, Information and Operations Management 7 (3-4): 161-379.

Castka, P., C.J. Corbett. 2016. Governance of eco-labels: Expert opinion and media coverage. Journal of Business Ethics 135(2): 309-326.

Chen, L., H.L. Lee. 2017. Sourcing under supplier responsibility risk: The effects of certification, audit, and contingency payment. Management Science 63(9): 2795-2812.

Cho, S., X. Fang, S. Tayur, Y. Xu. 2017. Combating child labor: Incentives and information disclosure in global supply chains. Working paper, Carnegie Mellon University, Pittsburgh, PA.

Cui, S., L.X. Lu. 2018. Optimizing Local Content Requirements under Technology Gaps. Manufacturing and Service Operations Management, forthcoming.

Cui, T.H., J.S. Raju, Z.J. Zhang. 2007. Fairness and channel coordination. Management Science 53(8) 1303-1314.

Davies, I.A., A. Crane. 2003. Ethical decision making in fair trade companies. Journal of Business Ethics $4579-92$.

Demirag, O.C., Y. Chen, J. Li. 2010. Channel coordination under fairness concerns and nonlinear demand. European Journal of Operational Research 207 1321-1326.

Didier, T., S. Lucie. 2008. Measuring consumers willingness to pay for organic and fair trade products. International Journal of Consumer Studies 32 479-490

Elliott, K. 2012. Is my fair trade coffee really fair? Trends and challenges in fair trade certification. Report, Center for Global Development, Washington, D.C. 
Fairtrade Foundation. 2017. Fairtrade Sourcing Programs. Accessed July 1, 2017, http://www.fairtrade.org.uk/For-Business/Ways-of-working-with-Fairtrade/Fairtrade-SourcingPrograms

Fischer, C., T.P. Lyon. 2014. Competing Environmental Labels. Journal of Economics and Management Strategy 23(3) 692-716

Fairtrade Labelling Organizations International (FLO). 2016. Monitoring the scope and benefits of fairtrade 2016. Accessed May 25, 2017, https://monitoringreport2016.fairtrade.net/en/

Fairtrade Labelling Organizations International (FLO). 2017a. Composite Products. Accessed June 25, 2017, http://www.fairtrade.net/composite-products.html

Fairtrade Labelling Organizations International (FLO). 2017b. Minimum Price and Premium Information. Accessed June 7, 2017, https://www.fairtrade.net/standards/price-and-premium-info.html

Fairtrade Labelling Organizations International (FLO). 2017c. Q\&A on Fairtrade International and Fair Trade USA. Accessed May 31, 2017, https://www.fairtrade.net/about-fairtrade/fairtrade-in-theusa/on-flo-and-fair-trade-usa.html

Fairtrade Labelling Organizations International (FLO). 2017d. Q\&A on the Fairtrade Sourcing Progams. Accessed July 1, 2017, https://www.fairtrade.net/about-fairtrade/fairtrade-sourcing-programs/fspfaq.html

Fairtrade Labelling Organizations International Certification (FLOCERT). 2015. Composite Products. Accessed October 6, 2015, http://www.flocert.net/fairtrade-services/fairtradecertification/compliance-criteria/

Fair Trade USA (FTUSA). 2015. Almanac. Accessed June 7, 2017, http://fairtradeusa.org/resources/factsfigures

Fair Trade USA (FTUSA). 2016. Fifty-Nine Percent of Americans Now Aware of Fair Trade Certified Products. Accessed June 7, 2017, https://fairtradeusa.org/press-room/press_release/fifty-nine-percentamericans-now-aware-fair-trade-certified-products

Fair Trade USA (FTUSA). 2017a. Agriculture Program Assurance Manual. Accessed November 26, 2017, https://www.fairtradecertified.org/business/standards/agricultural-production-standard

Fair Trade USA (FTUSA). 2017b. Frequently Asked Questions: What is fair trade? Accessed June 25, 2017, http://fairtradeusa.org/what-is-fair-trade/faq

Fair Trade USA (FTUSA). 2017c. Fair Trade Standards. Accessed June 25, 2017, http://fairtradeusa.org/certification/standards

Fair Trade USA (FTUSA). 2017d. Price and Premium Database. Accessed June 25, 2017, http://fairtradeusa.org/certification/pricing-database

Fair Trade USA (FTUSA). 2017e. Product Certification: Multiple Ingredients Product Policy. Accessed June 25, 2017, http://fairtradeusa.org/certification/producers/ingredients 
Galbreth, M., B. Ghosh. 2013. Competition and sustainability: The impact of consumer awareness. Decision Sciences 44(1): 127-159.

Graffin, S.D., A.J. Ward. 2010. Certifications and reputation: Determining the standard of desirability amidst uncertainty. Organization Science 21(2): 331-346.

Guo, R., H.L. Lee, R. Swinney. 2016. Responsible sourcing in supply chains. Management Science 62(9): 2722-2744.

Hainmueller, J., M.J. Hiscox, S. Sequeira. 2015. Consumer demand for fair trade: Evidence from a multi-store field Experiment. Review of Economics and Statistics 97(2): 242-256.

Harbaugh, R., J.W. Maxwell, B. Roussillon. 2011. Label confusion: The Groucho effect of uncertain standards Management Science 57(9): 1512-1527.

Heyes, A., S. Martin. 2016. Social labeling by competing NGOs: A model with multiple issues and entry. Management Science Forthcoming.

Hotelling, H. 1929. Stability in competition. The Economic Journal 39 41-57.

Howard, P.H., D. Jaffee. 2013. Tensions between firm size and sustainability goals: Fair trade coffee in the United States. Sustainability 5 72-89.

Huang, L., J. Song, R. Swinney. 2016. Managing social responsibility in multitier supply chains. Working Paper, Duke University, Durham, NC.

Ishibashi, I., N. Matsushima. 2009. The existence of low-end firms may help high-end firms. Marketing Science 28(1): 136-147.

Katok E., T. Olsen, V. Pavlov. 2012. Wholesale pricing under mild and privately known concerns for fairness. Production and Operations Management 23(2): 285-302.

Lacourbe, P., C.H. Loch, S. Kavadias. 2009. Product positioning in a two-dimensional market space. Production and Operations Management 18(3): 315-332.

Loch, C.H., Y. Wu. 2008. Social preferences and supply chain performance: An experimental study. Management Science 54(11): 1835-1849.

Maloni, M., M.E. Brown. 2006. Corporate social responsibility in the supply chain: An application in the food industry. Journal of Business Ethics 68(1): 35-52.

Moore, G. 2004. The fair trade movement: Parameters, issues and future research. Journal of Business Ethics 53 73-86.

Moorthy, K.S., I.P.L. Png. 1992. Market segmentation, cannibalization, and the timing of product introductions. Management Science 38(3): 345-359.

Munson, C.L., Rosenblatt, M.J. 1997. The impact of local content rules on global sourcing decisions. Production and Operations Management 6(3) 277-190. 
Murali, K., M.K. Lim, N.C. Petruzzi. 2018. The effects of ecolabels and environmental regulations on green product development. Manufacturing and Service Operations Management, forthcoming.

Mussa M., S. Rosen. 1978. Monopoly and product quality. Journal of Economic Theory 18 301-317.

Neuman, W. 2011. A question of fairness. The New York Times (November 23).

Örsdemir, A., Hu, B., Deshpande, V. 2017. Ensuring Corporate Social and Environmental Responsibility through Vertical Integration and Horizontal Sourcing Working paper, University of California at Riverside, CA.

Pelsmacker, P.D., L. Driesen, G. Rayp. 2005. Do consumers care about ethics? Willingness to pay for fairtrade coffee. The Journal of Consumer Affairs 39(2): 363-385.

Poist, R.F. 1989. Evolution of conceptual approaches to the design of logistics systems: A sequel. Transportation Journal 28(3): 35-39.

Prasad, M., H. Kimeldorf, R. Meyer, I. Robinson. 2004. Consumers of the World Unite: A Market-based Response to Sweatshops. Labor Studies Journal 29(3): 57-80.

Raynolds, L.T., D. Murray, A. Heller. 2007. Regulating sustainability in the coffee sector: A comparative analysis of third-party environmental and social certification initiatives. Agriculture and Human Values 24 147-163.

Raynolds, L.T. 2009. Mainstreaming fair trade coffee: From partnership to traceability. World Development 37(6): 1083-1093.

United States Department of Agriculture (USDA). 2015. Coffee: World markets and trade. Report, Foreign Agricultural Service, United States Department of Agriculture, Washington, D.C. 


\section{Appendix}

\section{Appendix A. Supplementary Information}

\section{A.1. Main Notation}

In this appendix, we summarize the main notation of this study.

Table 1 Main notation

\begin{tabular}{cl}
\hline Notation & Definition \\
\hline$J$ & set of market types, $J=\{S, M\}$ \\
$I_{j}$ & set of firms in market $j, I_{j}=\left\{1,2, \ldots, n_{j}\right\}$ \\
$I_{j}^{F}$ & set of firms which sell fair trade in market $j, I_{j}=\left\{1,2, \ldots, n_{j}^{F}\right\}$ \\
\hline$\rho$ & premium to farmers \\
$\theta_{j}$ & required minimum fraction of fair trade certified raw materials in product $j\left(\theta_{S}=1\right.$ by definition) \\
$\bar{\theta}_{j}$ & upper bound of $\theta_{j}\left(\bar{\theta}_{S}=1\right.$ by definition) \\
$T$ & total premium from both single- and multi-ingredient markets \\
\hline$p_{j}$ & selling price of fair trade certified products in market $j$. \\
$a_{j}$ & maximum willingness to pay from customers \\
$b_{j}$ & maximum demand for the fair trade certified product $j$ \\
$D_{j}^{F}$ & demand for fair trade certified products in market $j$ \\
$n_{j}\left(n_{j}^{F}\right)$ & number of firms in (fair trade) market $j$ \\
\hline$\pi_{i, j}^{R}\left(\bar{\pi}_{i, j}^{R}\right)$ & firm (i,j)'s profit from selling regular products (when there is no fair trade market) \\
$\Pi_{i, j}$ & firm (i,j)'s total profit from both regular and fair trade products \\
$q_{i, j}$ & quantity of fair trade certified products by firm $i$ in market $j$ \\
$c_{i, j}$ & unit base cost of production for firm $(i, j)$ \\
$\gamma_{i, j}$ & a profit loss (cannibalization) coefficient for firm $(i, j)$ \\
$\alpha_{i, j}$ & additional cost to sell fair trade products under FLO for firm $(i, j)$ \\
\hline &
\end{tabular}

\section{A.2. Fair Trade Standards and its Market Demand}

In this appendix, we re-examine our main results when the fair trade market demand size is affected by fair trade standards. This is because the fair trade market demand factors, i.e., both the customer's willingness to pay $a_{j}$ and the maximum market size $b_{j}$, can grow as the fair trade standards $\theta_{j} \rho$ increase, which is not reflected in our main model. Hence, we consider a modified market demand as follows:

$$
D_{j}^{F}\left(p_{j}\right)= \begin{cases}\left(1-\frac{p_{j}}{a_{j}}\right) b_{j} & \text { if } p_{j} \in\left[0, a_{j}\right] \\ 0 & \text { if } p_{j} \in\left(a_{j}, \infty\right)\end{cases}
$$

where

$$
a_{j}=\alpha_{0}+\alpha_{1} \cdot\left(\theta_{j} \rho\right)^{\delta_{j}^{a}} \quad \text { and } \quad b_{j}=\beta_{0}+\beta_{1} \cdot\left(\theta_{j} \rho\right)^{\delta_{j}^{b}}
$$

Verifying the findings in Section 4. We first examine whether the findings in Section 4 change under the modified market demand function described above. We find that as the effective premium $\left(\theta_{j} \rho\right)$ increases, the total demand $D_{j}^{F}$ (as well as the sales quantity $q_{i, j}^{F}$ ) can either increase or decrease, where its respective conditions are given as follows: 
(i) $\frac{\partial D_{j}^{F}}{\partial\left(\theta_{j} \rho\right)}>0$ and (ii) $\frac{\partial q_{i, j}^{F}}{\partial\left(\theta_{j} \rho\right)}>0$ hold if and only

$$
\delta_{j}^{a}\left\{\beta_{1} a_{j}\left(\theta_{j} \rho\right)^{\delta_{j}^{b}-1}-\alpha_{1} b_{j}\left(\theta_{j} \rho\right)^{\delta_{j}^{a}-1}\right\}\left\{\alpha_{1}\left(\theta_{j} \rho\right)^{\delta_{j}^{a}}-\left(\theta_{j} \rho\right)+\Delta\right\}+a_{j} b_{j}\left\{\alpha_{1} \delta_{j}^{a}\left(\theta_{j} \rho\right)^{\delta_{j}^{a}-1}-1\right\}>0
$$

holds, where $\Delta=\alpha_{0}-\frac{\sum\left(c_{i, j}+\gamma_{i, j}\right)}{n_{j}^{F}}$ for (i) and $\Delta=\alpha_{0}-\left(n_{j}^{F}+1\right)\left(c_{i, j}+\gamma_{i, j}\right)+\sum\left(c_{i, j}+\gamma_{i, j}\right)$ for (ii).

We make a couple of observations on this condition. First, if the condition for $\partial D_{j}^{F} / \partial\left(\theta_{j} \rho\right)>0$ holds, then it follows that the fair trade organization's optimal decision is to set $\left(\theta_{j} \rho\right)^{*}$ as high as possible; i.e., the problem becomes unbounded. Furthermore, we find that this condition holds for sufficiently high values of $\delta_{j}$ (where $\delta_{j}^{a}<\delta_{j}^{b}$ ), such that the net benefit of increase in the fair trade standard is always positive. That is, the sales grows faster than the cost as the fair trade standard increases, and therefore, the organization finds it optimal to simply push the standard as high as possible. Clearly, this is unrealistic, and thus we must restrict our attention to the case in which $D_{j}^{F}$ decreases as $\left(\theta_{j} \rho\right)$ increases.

Second, given that $\partial D_{j}^{F} / \partial\left(\theta_{j} \rho\right)<0$ holds, as in reality, we find that the model becomes intractable with the inclusion of the positive effect of fair trade standard on the market demand. Since carrying out further analysis was difficult, we have pursued this avenue through numerical exploration. Under the modified demand function, we find that all the major findings do not change under most ranges of parameters. The typical trends of the total demand $D_{j}^{F}$ (and the sales quantity $q_{i, j}^{F}$ ) with respect to the effective premium $\theta_{j} \rho$ are illustrated in Figure 1 below.

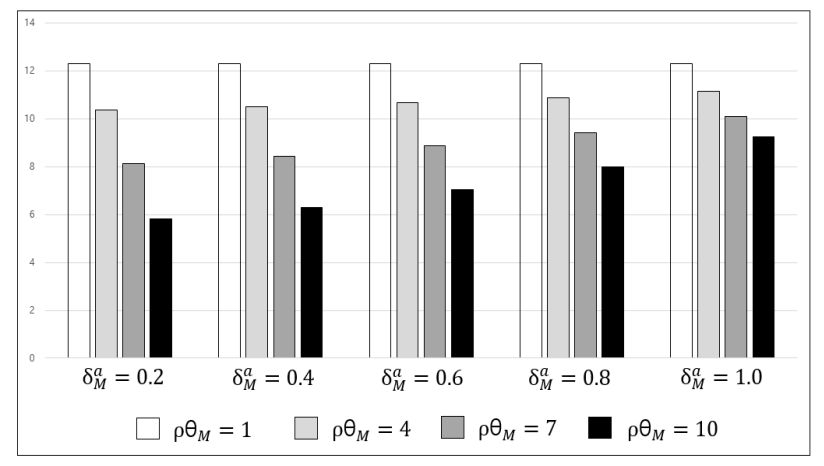

(a) Market Demand and Effective Premium with Various $\delta_{M}^{a}$

Figure 5 Changes in the multi-ingredient market demand $D_{M}^{F}$ and firms' sales quantity $q_{i, M}^{F}$ with respect to the effective premium. We consider the case of four firms in the market. The specific parameter values are set as $\alpha_{0}=\beta_{0}=20, \alpha_{1}=\beta_{1}=1, \delta_{i}^{a}=\delta_{i}^{b}=0.4 ; n_{i}=4, c_{i, 1}=1, c_{i, 2}=3, c_{i, 3}=5, c_{i, 4}=6, \gamma_{i, 1}=2, \gamma_{i, 2}=1, \gamma_{i, 3}=0.5, \gamma_{i, 4}=0$ where $i \in\{S, M\}$.

Verifying the findings in Section 5. Under the modified demand function and the assumption of $\partial D_{j}^{F} / \partial\left(\theta_{j} \rho\right)<0$, we examine the findings made in Section 5. We find that all results qualitatively hold as before, with the exception of Corollary 3 in which the closed-form solution is not easy to 
find. Not surprisingly, the modified demand function favors the FLO due to the positive impact of $\left(\theta_{j} \rho\right)$ on $a_{j}$ and $b_{j}$ increases. This holds especially when the impact of the effective premium on the ratio of the market size to the willingness to pay is negligible, i.e., $\left(b_{j}^{F L O} / a_{j}^{F L O}\right) \approx\left(b_{j}^{F T U S A} / a_{j}^{F T U S A}\right)$. We note that, while the inclusion of $\left(\theta_{j} \rho\right)$ on $a_{j}$ and $b_{j}$ makes FLO more favorable in general (thus, the specific conditions in Figure 2 in the main manuscript changes), the main trends remain the same as before.

\section{A.3. Model with Regular and Fair Trade Markets}

In this appendix, we formulate an alternative model that explicitly captures firms' participation in both the markets for fair trade and regular (non-certified) products. Our derivations below show that this alternative model is equivalent to the main model considered in the paper.

Consider market $j \in\{S, M\}$. Let the selling prices for regular and fair trade products in market $i$ be $u_{j}$ and $p_{j}$, respectively and let the total demand for regular (non-fair trade certified) products under the status quo be $\bar{D}_{j}$. We assume that the substitution between regular and fair trade products take a linear form, i.e., the demand for regular products becomes $D_{j}=\bar{D}_{j}-\beta_{j} \sum_{i \in L_{j}} q_{l, j}$ when the fair trade supply equals $\sum_{i \in L_{j}} q_{l, j}$. As the regular market is well established and fair trade accounts for a small proportion of total volume, we consider the market share of firm $(i, j)$ for regular products to be exogenously given by $\mu_{i, j}$ (where $\sum_{i \in I_{j}} \mu_{i, j}=1$ ). Then, firm $(i, j)$ 's problem becomes:

$$
\max _{q_{i, j}} \pi_{i, j}\left(q_{i, j}\right) \equiv\left(u_{j}-c_{i, j}\right) \cdot D_{j} \cdot \mu_{i, j}+\left\{p_{j}+a_{j}\left(1-\frac{\sum_{m \in I_{j}^{F}} q_{m, j}}{b_{j}}\right)-c_{i, j}-\theta_{j} \cdot \rho\right\} q_{i, j} .
$$

In the above, the first and second terms constitute the profits from the regular and fair trade markets, respectively. Then, we can further express:

$$
\begin{aligned}
\pi_{i, j}\left(q_{i, j}\right)= & \left(u_{j}-c_{i, j}\right) \cdot\left(\bar{D}_{j}-\beta_{j} \sum_{l \in L_{j}} q_{l, j}\right) \cdot \mu_{i, j}+\left[a_{j}\left\{\left(\frac{p_{j}}{a_{j}}+1\right)-\frac{\sum_{m \in I_{j}^{F}} q_{m, j}}{b_{j}}\right\}-c_{i, j}-\theta_{j} \cdot \rho\right] q_{i, j} \\
= & \left(u_{j}-c_{i, j}\right) \cdot\left(\bar{D}_{j}-\beta_{j} \sum_{l \in L_{j}} q_{l, j}\right) \cdot \mu_{i, j}+\left[a_{j}\left(\frac{p_{j}}{a_{j}}+1\right)\left\{1-\frac{\sum_{m \in I_{j}^{F}} q_{m, j}}{b_{j}} /\left(\frac{p_{j}}{a_{j}}+1\right)\right\}\right. \\
& \left.-c_{i, j}-\theta_{j} \cdot \rho\right] q_{i, j} \\
= & \bar{\pi}_{i, j}^{R}-\gamma_{i, j} \sum_{l \in L_{j}} q_{l, j}+\left\{a_{j}^{\prime}\left(1-\frac{\sum_{m \in I_{j}^{F}} q_{m, j}}{b_{j}^{\prime}}\right)-c_{i, j}-\theta_{j} \cdot \rho\right\} q_{i, j},
\end{aligned}
$$

where we performed the following substitution in the last equality:

$$
\bar{\pi}_{i, j}^{R} \equiv\left(u_{j}-c_{i, j}\right) \cdot \bar{D}_{j} \cdot \mu_{i, j}
$$




$$
\begin{aligned}
\gamma_{i, j} & \equiv\left(u_{j}-c_{i, j}\right) \cdot \beta_{j} \cdot \mu_{i, j} \\
a_{j}^{\prime} & \equiv a_{j}\left(\frac{p_{j}}{a_{j}}+1\right) \\
b_{j}^{\prime} & \equiv b_{j} \cdot a_{j}\left(\frac{p_{j}}{a_{j}}+1\right) .
\end{aligned}
$$

Finally, dropping ' in $a_{j}^{\prime}$ and $b_{j}^{\prime}$ yields our original formulation. Thus, our original formulation is equivalent to this alternative model that captures both the regular and fair trade markets. This equivalence further suggests that the cannibalization factor $\gamma_{i, j}$ depends on three factors: the profit margin for the regular product $\left(u_{j}-c_{i, j}\right)$, the degree of demand substitution between regular and fair trade products $\left(\beta_{j}\right)$, and the firm's regular product market share $\left(\mu_{i, j}\right)$.

\section{A.4. Figures in the Single-ingredient Market}

In the manuscript, we provide the changes on firms' profits and farmers premium in the multiingredient case. This appendix shows the counterpart figures for the single-ingredient market.

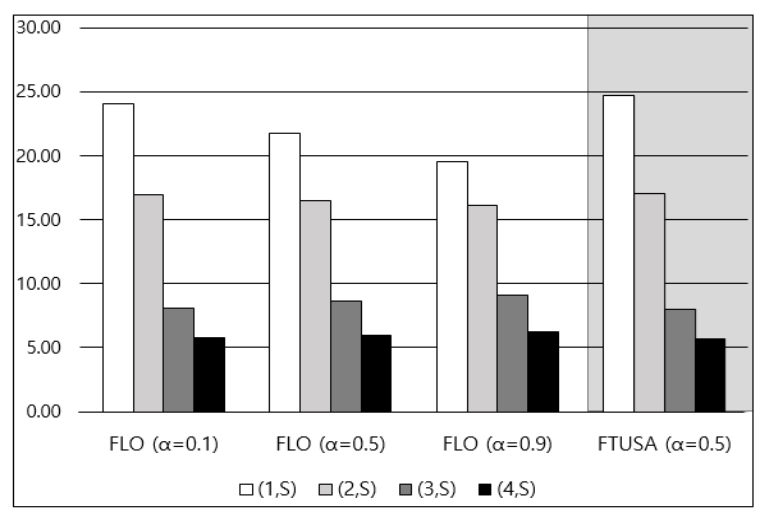

(a) Firm's profit

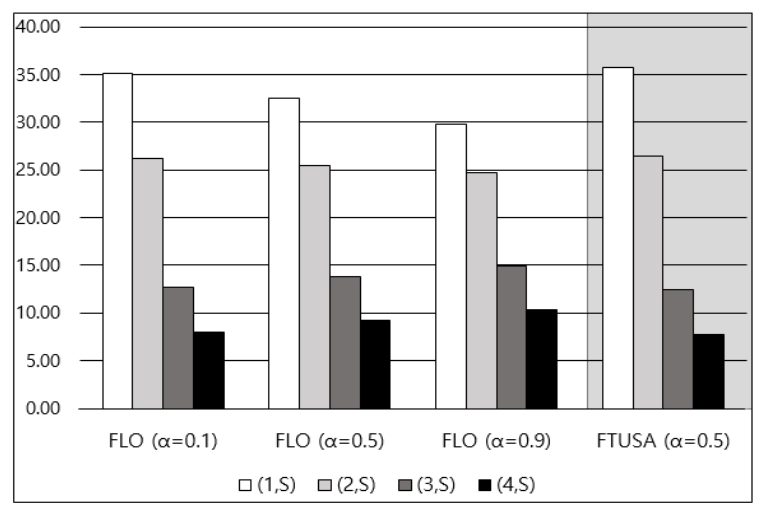

(b) Farmer premium

Figure 6 Farmer Premium and Firm's Profit with Changes in $\alpha_{i, S}$

We set $\alpha_{1, S}:=\alpha, \alpha_{2, S}:=\frac{\alpha}{2}$, and $\alpha_{3, S}=\alpha_{4, S}=0$. Other parameter values are the same as those in Figure 3 in the manuscript. 


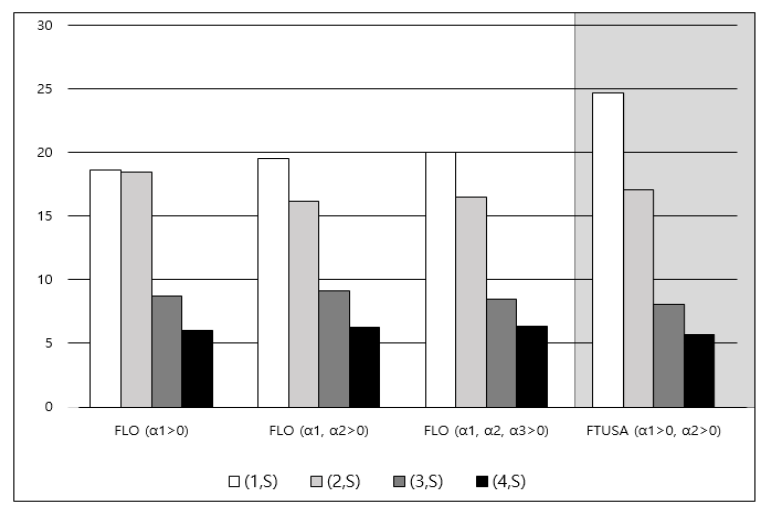

(a) Firm's profit

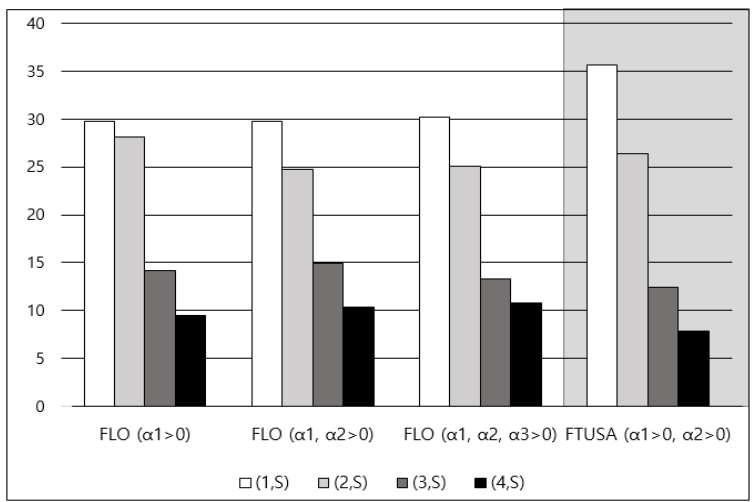

(b) Farmer premium

Figure 7 Firm's Profit and Farmer Premium with Changes in $I_{S}^{P, F L O}$

We set $\alpha=0.9$ and chose three scenarios under FLO: 1) $\left.\alpha_{1, S}=\alpha, \alpha_{2, S}=\alpha_{3, S}=\alpha_{4, S}=0 ; 2\right) \alpha_{1, S}=\alpha, \alpha_{2, S}=\frac{\alpha}{2}$, $\left.\alpha_{3, S}=\alpha_{4, S}=0 ; 3\right) \alpha_{1, S}=\alpha, \alpha_{2, S}=\frac{\alpha}{2}, \alpha_{3, S}=\frac{\alpha}{4}, \alpha_{4, S}=0$. Other parameter values are the same as those in Figure 3 in the manuscript.

\section{Appendix B. Proofs of Lemmas, Propositions, and Corollaries}

Proofs of Proposition 1 and Lemma 1. In stage 2, a fair trade standard of $\left(\rho, \theta_{j}\right)$ is given. Let us suppose that firm $(i, j)$ is not selling fair trade products to market $j$ and the number of firms which sell the fair trade products is $\left(n_{j}^{F}-1\right)$. Firm $(i, j)$ will enter the fair trade market if it is more profitable. In what follows, we compare firm $(i, j)$ 's profits in two cases, i.e., with and without entering the fair trade market, to find the fair trade market entry decision.

Case 1. We first consider the case in which firm $(i, j)$ sells fair trade certified products. In this case, the number of firms which sell the fair trade certified products in market $j$ becomes $n_{j}^{F}$, i.e., $\left|I_{j}^{F}\right|=n_{j}^{F}$. Then, the profit of firm $(i, j)$ is

$$
\Pi_{i, j}\left(q_{i, j}\right)=\left\{a_{j}\left(1-\frac{\sum_{m \in I_{j}^{F}} q_{m, j}}{b_{j}}\right)-c_{i, j}-\theta_{j} \cdot \rho\right\} q_{i, j}+\bar{\pi}_{i, j}^{R}-\gamma_{i, j} \cdot\left(\sum_{m \in I_{j}^{F}} q_{m, j}\right) .
$$

Hence, the first derivative of $\Pi_{i, j}\left(q_{i, j}\right)$ with respect to $q_{i, j}$ is

$$
\frac{\partial \Pi_{i, j}\left(q_{i, j}\right)}{\partial q_{i, j}}=\left\{a_{j}\left(1-\frac{\sum_{m \in I_{j}^{F}} q_{m, j}}{b_{j}}\right)-c_{i, j}-\theta_{j} \cdot \rho\right\}-\left(\frac{a_{j}}{b_{j}}\right) q_{i, j}-\gamma_{i, j} .
$$

Then, $q_{i, j}$ which satisfies the first order conditions of all the firms is, using a notation of $\phi_{i, j}=$ $\left(c_{i, j}+\gamma_{i, j}+\theta_{j} \cdot \rho\right)$

$$
\begin{aligned}
q_{i, j}^{*} & =\frac{b_{j}}{\left(n_{j}^{F}+1\right) a_{j}} \cdot\left\{\left(a_{j}-\theta_{j} \cdot \rho\right)-\left(n_{j}^{F}+1\right)\left(c_{i, j}+\gamma_{i, j}\right)+\sum_{m \in I_{j}^{F}}\left(c_{m, j}+\gamma_{m, j}\right)\right\} . \\
& =\frac{b_{j}}{\left(n_{j}^{F}+1\right) a_{j}} \cdot\left\{a_{j}-\left(n_{j}^{F}+1\right) \phi_{i, j}+\sum_{m \in I_{j}^{F}} \phi_{m, j}\right\}
\end{aligned}
$$


Then, given $q_{i, j}^{*}>0$, from (9), supply of the fair trade certified products is

$$
D_{j}^{F, *}=\sum_{m \in I_{j}^{F}} q_{m, j}^{*}=\frac{b_{j}}{\left(n_{j}^{F}+1\right) a_{j}} \cdot\left\{n_{j}^{F} \cdot a_{j}-\sum_{i \in I_{j}^{F}} \phi_{i, j}\right\} .
$$

Then, from (10), the resulting selling price of fair trade certified products in market $j$ is

$$
p_{j}^{*}=a_{j}\left(1-\frac{D_{j}^{F, *}}{b_{j}}\right)=\frac{1}{\left(n_{j}^{F}+1\right)} \cdot\left\{a_{j}+\sum_{i \in I_{j}^{F}} \phi_{i, j}\right\} .
$$

Hence, profit of firm $(i, j)$ is

$$
\Pi_{i, j}\left(q_{i, j}^{*}\right)=\left(p_{j}^{*}-c_{i, j}-\theta_{j} \cdot \rho\right) q_{i, j}^{*}+\bar{\pi}_{i, j}^{R}-\gamma_{i, j} \cdot D_{j}^{F, *}
$$

where $q_{i, j}^{*}, D_{j}^{F, *}$, and $p_{j}^{*}$ are given in (9), (10), and (11), respectively.

Case 2. We next consider the case in which firm $(i, j)$ does not sell the fair trade certified products; thus $q_{i, j}=0$ and $\left|I_{j}^{F}\right|=n_{j}^{F}-1$. Hence, the profit of firm $i$ in market $j$ is

$$
\begin{aligned}
\Pi_{i, j}\left(q_{i, j}=0\right) & =\bar{\pi}_{i, j}^{R}-\gamma_{i, j} \cdot\left(\sum_{m \in I_{j}^{F} \backslash\{i\}} q_{m, j}\right) \\
& =\bar{\pi}_{i, j}^{R}-\gamma_{i, j} \cdot\left[\left(\frac{b_{j}}{n_{j}^{F} a_{j}}\right) \cdot\left\{\left(n_{j}^{F}-1\right) \cdot a_{j}-\sum_{m \in I_{j}^{F} \backslash\{i\}} \phi_{i, j}\right\} \cdot\right]
\end{aligned}
$$

From Cases 1 and 2, the profit difference with and without selling the fair trade products, i.e., (12)- (13), is

$$
\begin{aligned}
\Pi_{i, j}\left(q_{i, j}^{*}\right)-\Pi_{i, j}\left(q_{i, j}=0\right) & =\left(p_{j}^{*}-c_{i, j}-\theta_{j} \cdot \rho\right) \cdot q_{i, j}^{*}-\gamma_{i, j} \cdot \frac{q_{i, j}^{*}}{n_{j}^{F}} \\
& =\left(p_{j}^{*}-c_{i, j}-\theta_{j} \cdot \rho-\gamma_{i, j} / n_{j}^{F}\right) \cdot q_{i, j}^{*} \\
& =\left\{q_{i, j}^{*}+\frac{b_{j} \gamma_{i, j}\left(n_{j}^{F}+1\right)}{\left(n_{j}^{F}+1\right) a_{j}}\left(1-\frac{1}{n_{j}^{F}}\right)\right\} q_{i, j}^{*},
\end{aligned}
$$

since

$$
\begin{aligned}
& {\left[\frac{b_{j}}{\left(n_{j}^{F}+1\right) a_{j}} \cdot\left\{n_{j}^{F} \cdot a_{j}-\sum_{i \in I_{j}^{F}} \phi_{i, j}\right\}\right]-\left[\left(\frac{b_{j}}{n_{j}^{F} a_{j}}\right) \cdot\left\{\left(n_{j}^{F}-1\right) \cdot a_{j}-\sum_{m \in I_{j}^{F} \backslash\{i\}} \phi_{i, j}\right\}\right]} \\
& =\left[\frac{b_{j}}{n_{j}^{F}\left(n_{j}^{F}+1\right) a_{j}} \cdot\left\{a_{j}-\left(n_{j}^{F}+1\right) \phi_{i, j}+\sum_{m \in I_{j}^{F}} \phi_{m, j}\right\}\right]=\frac{q_{i, j}^{*}}{n_{j}^{F}} \text { and }
\end{aligned}
$$




$$
\begin{aligned}
\left(p_{j}^{*}-c_{i, j}-\theta_{j} \cdot \rho-\gamma_{i, j} / n_{j}^{F}\right) & =\frac{b_{j}}{\left(n_{j}^{F}+1\right) a_{j}} \cdot\left\{a_{j}-\left(n_{j}^{F}+1\right) \phi_{i, j}+\sum_{m \in I_{j}^{F}} \phi_{m, j}+\gamma_{i, j}\left(n_{j}^{F}+1\right)\left(1-\frac{1}{n_{j}^{F}}\right)\right\} \\
& =q_{i, j}^{*}+\frac{b_{j} \gamma_{i, j}\left(n_{j}^{F}+1\right)}{\left(n_{j}^{F}+1\right) a_{j}}\left(1-\frac{1}{n_{j}^{F}}\right) .
\end{aligned}
$$

Therefore, firm $(i, j)$ sells the fair trade products if and only if $q_{i, j}^{*}>0$. In other words, firm $(i, j)$ enters the fair trade market $j \in J$ if $\phi_{i, j}<\frac{a_{j}+\sum_{m \in I_{j}^{F} \backslash\{i\}} \phi_{m, j}}{n_{j}^{F}}$ since $q_{i, j}^{*}=\frac{b_{j}}{\left(n_{j}^{F}+1\right) a_{j}}$. $\left\{a_{j}-\left(n_{j}^{F}+1\right) \phi_{i, j}+\sum_{m \in I_{j}^{F}} \phi_{m, j}\right\}=\frac{b_{j}}{\left(n_{j}^{F}+1\right) a_{j}} \cdot\left\{a_{j}-n_{j}^{F} \phi_{i, j}+\sum_{m \in I_{j}^{F} \backslash\{i\}} \phi_{m, j}\right\}$, thus Proposition 1 is proved. Then, Lemma 1 is also proved from (9), (10), and (11).

Proof of Proposition 2. An increase of the effective cost of fair trade cost, $\phi_{i, j}$, may change a set of firms which sell in the fair trade market. In what follows, we proceed the proof by examining two cases: 1) an increase of $\phi_{i, j}$ does not change the set of firms; 2) an increase of $\phi_{i, j}$ changes the set of firms. (Note that we use Lemma A.1. to prove the first case of this proof, and which is provided in the below of this proof.)

Case 1. Suppose that an increase of $\phi_{i, j}$ does not change a set of firms which sell fair trade products. That is, for a fixed set of $I_{j}^{F}$, from Lemma A.1 (please see below), $\frac{\partial q_{i, j}^{*}}{\partial \phi_{i, j}}<0, \frac{\partial D_{j}^{F, *}}{\partial \phi_{i, j}}<0$, and $\frac{\partial p_{j}^{*}}{\partial \phi_{i, j}}>0$ for all $i, j$.

Case 2. Suppose that due to an increase of $\phi_{i, j}$, firm $(i, j)$ does not sell fair trade products, i.e., $(i, j) \notin I_{j}^{F}$. That is, from Proposition $1, \phi_{i, j}>\frac{a_{j}+\sum_{m \in I_{j}^{F} \backslash\{i\}} \phi_{m, j}}{n_{j}^{F}}$ and $q_{i, j}=0$. In addition, since the total sales of the fair trade products in market $j$ are decreased (i.e., $\sum_{m \in I_{j}^{F}} q_{m, j}-\sum_{m \in I_{j}^{F} \backslash\{i\}} q_{m, j}=$ $\left.\frac{b_{j}}{a_{j} n_{j}^{F}\left(1+n_{j}^{F}\right)}\left\{a_{j}+\sum_{m \in I_{j}^{F} \backslash\{i\}} \phi_{m, j}-n_{j}^{F} \phi_{i, j}\right\}<0\right)$, the selling price increases. Hence, $\frac{\partial q_{i, j}^{*}}{\partial \phi_{i, j}}<0, \frac{\partial D_{j}^{F, *}}{\partial \phi_{i, j}}<$ 0 , and $\frac{\partial p_{j}^{*}}{\partial \phi_{i, j}}>0$ for all $i, j$.

Therefore, by Cases 1 and $2, \frac{\partial q_{i, j}^{*}}{\partial \phi_{i, j}}<0, \frac{\partial D_{j}^{F, *}}{\partial \phi_{i, j}}<0$, and $\frac{\partial p_{j}^{*}}{\partial \phi_{i, j}}>0$ for all $i, j$.

Lemma A.1. Given a fixed set of fair trade market $I_{j}^{F}$, the comparative statics of the optimal fair trade sales quantity of firm $(i, j), q_{i, j}^{*}$, the optimal aggregate fair trade sales in market $j, D_{j}^{F, *}$, and the selling price of fair trade certified products in market $j, p_{j}^{*}$, with respect to parameters $c_{i, j}, \gamma_{i, j}, \theta_{j}$, and $\rho$ are as follows: i) $\frac{\partial q_{i, j}^{*}}{\partial c_{i, j}}<0, \frac{\partial q_{i, j}^{*}}{\partial \gamma_{i, j}}<0, \frac{\partial q_{i, j}^{*}}{\partial \theta_{j}}<0$, and $\frac{\partial q_{i, j}^{*}}{\partial \rho}<0$ for all $i, j$; ii) $\frac{\partial D_{j}^{F, *}}{\partial c_{i, j}}<$ $0, \frac{\partial D_{j}^{F, *}}{\partial \gamma_{i, j}}<0, \frac{\partial D_{j}^{F, *}}{\partial \theta_{j}}<0$, and $\frac{\partial D_{j}^{F, *}}{\partial \rho}<0$ for all $i, j$; iii) $\frac{\partial p_{j}^{*}}{\partial c_{i, j}}>0, \frac{\partial p_{j}^{*}}{\partial \gamma_{i, j}}>0, \frac{\partial p_{j}^{*}}{\partial \theta_{j}}>0$, and $\frac{\partial p_{j}^{*}}{\partial \rho}>0$ for all $i, j$.

Proof of Lemma A.1. We prove this lemma by finding the first derivatives of our interests (i.e., $q_{i, j}^{*}, D_{j}^{F, *}$, and $\left.p_{j}^{*}\right)$ with respect to parameters $c_{i, j}, \gamma_{i, j}, \theta_{j}$, and $\rho$.

i) Comparative statics on $q_{i, j}^{*}$ with respect to parameters $c_{i, j}, \gamma_{i, j}, \theta_{j}$, and $\rho$ :

$$
\frac{\partial q_{i, j}^{*}}{\partial c_{i, j}}=\frac{\partial q_{i, j}^{*}}{\partial \gamma_{i, j}}=-\frac{b_{j}}{\left(n_{j}^{F}+1\right) a_{j}} n_{j}^{F}<0, \quad \frac{\partial q_{i, j}^{*}}{\partial \theta_{j}}=-\frac{b_{j}}{\left(n_{j}^{F}+1\right) a_{j}} \rho<0, \quad \frac{\partial q_{i, j}^{*}}{\partial \rho}=-\frac{b_{j}}{\left(n_{j}^{F}+1\right) a_{j}} \theta_{j}<0 .
$$


ii) Comparative statics on $D_{j}^{F, *}$ with respect to parameters $c_{i, j}, \gamma_{i, j}, \theta_{j}$, and $\rho$ :

$$
\begin{aligned}
\frac{\partial D_{j}^{F, *}}{\partial c_{i, j}} & =\frac{\partial D_{j}^{F, *}}{\partial \gamma_{i, j}}=-\frac{b_{j}}{\left(n_{j}^{F}+1\right) a_{j}}<0, \quad \frac{\partial D_{j}^{F, *}}{\partial \theta_{j}}=-\frac{b_{j}}{\left(n_{j}^{F}+1\right) a_{j}} \cdot n_{j}^{F} \cdot \rho<0, \\
\frac{\partial D_{j}^{F, *}}{\partial \rho} & =-\frac{b_{j}}{\left(n_{j}^{F}+1\right) a_{j}} \cdot n_{j}^{F} \cdot \theta_{j}<0 .
\end{aligned}
$$

iii) Comparative statics on $p_{j}^{*}$ with respect to parameters $c_{i, j}, \gamma_{i, j}, \theta_{j}$, and $\rho$ :

$$
\frac{\partial p_{j}^{*}}{\partial c_{i, j}}=\frac{\partial p_{j}^{*}}{\partial \gamma_{i, j}}=\frac{1}{\left(n_{j}^{F}+1\right)}>0, \quad \frac{\partial p_{j}^{*}}{\partial \theta_{j}}=\frac{1}{\left(n_{j}^{F}+1\right)} \cdot\left(n_{j}^{F} \cdot \rho\right)>0, \frac{\partial p_{j}^{*}}{\partial \rho}=\frac{1}{\left(n_{j}^{F}+1\right)} \cdot\left(n_{j}^{F} \cdot \theta_{j}\right)>0
$$

Proof of Proposition 3. An increase of the maximum demand for the fair trade products, $b_{j}$ does not change the set of firms in the fair trade market (see, Proposition 1). However, an increase of the maximum willingness to pay, $a_{j}$, may change a set of firms which sell in the fair trade market. In what follows, we proceed the proof by examining two cases: 1) an increase of $a_{j}$ does not change the set of firms; 2) an increase of $a_{j}$ changes the set of firms. (Note that we use Lemma A.2 and Lemma A.3 to show this proof, which are provided in the below of this proof.)

Case 1. Suppose that an increase of $a_{j}$ does not change a set of firms which sell fair trade products. That is, for a fixed set of $I_{j}^{F}$, from Lemma A.2 (please see below), $\frac{\partial q_{i, j}^{*}}{\partial a_{j}}<0$, if and only if $\phi_{i, j}>$ $\left(\sum_{m \in I_{j}^{F} \backslash\{i\}} \phi_{m, j}\right) / n_{j}^{F}, \frac{\partial D_{j}^{F, *}}{\partial a_{j}}>0, \frac{\partial p_{j}^{*}}{\partial a_{j}}>0, \frac{\partial q_{i, j}^{*}}{\partial b_{j}}>0 \frac{\partial D_{j}^{F, *}}{\partial b_{j}}>0$, and $\frac{\partial p_{j}^{*}}{\partial b_{j}}=0$, for all $i, j$.

Case 2. Suppose that due to an increase of $a_{j}$, another firm now enters the fair trade market. Then, from Lemma A.3 (please see below), if $\phi_{i, j}>\left(\sum_{m \in I_{j}^{F} \backslash\{i\}} \phi_{m, j}\right) / n_{j}^{F}$, then $q_{i, j}^{*}$ decreases; $D_{j}^{F, *}$ increases; and $p_{j}^{*}$ does not always increase. Note that in Case 2, we do not investigate changes of $q_{i, j}^{*}, D_{j}^{F, *}$, and $p_{j}^{*}$ with respect to $b_{j}$ since the change of $b_{j}$ does not change the set of firms in the fair trade market (see, Proposition 1).

From Cases 1 and 2, therefore, $\frac{\partial q_{i, j}^{*}}{\partial a_{j}}<0$, if $\phi_{i, j}>\left(\sum_{m \in I_{j}^{F} \backslash\{i\}} \phi_{m, j}\right) / n_{j}^{F}, \frac{\partial D_{j}^{F, *}}{\partial a_{j}}>0, \frac{\partial q_{i, j}^{*}}{\partial b_{j}}>0$, $\frac{\partial D_{j}^{F, *}}{\partial b_{j}}>0$, and $\frac{\partial p_{j}^{*}}{\partial b_{j}}=0$, for all $i, j$. In addition, $\frac{\partial p_{j}^{*}}{\partial a_{j}}>0$ if $I_{j}^{F}$ does not change due to the change of $a_{j}$ for all $i, j .$.

Lemma A.2. Given a fixed set of fair trade market $I_{j}^{F}$, the comparative statics of the optimal fair trade sales quantity of firm $(i, j), q_{i, j}^{*}$, the optimal aggregate fair trade sales in market $j, D_{j}^{F, *}$, and the selling price of fair trade certified products in market $j, p_{j}^{*}$, with respect to parameters $a_{j}$ and $b_{j}$ are as follows: i) $\frac{\partial q_{i, j}^{*}}{\partial a_{j}}<0$ if and only if $\phi_{i, j}<\left(\sum_{m \in I_{j}^{F} \backslash\{i\}} \phi_{m, j}\right) / n_{j}^{F}, \frac{\partial D_{j}^{F, *}}{\partial a_{j}}>0$, and $\frac{\partial p_{j}^{*}}{\partial a_{j}}>0$ for all $i, j$; ii) $\frac{\partial q_{i, j}^{*}}{\partial b_{j}}>0, \frac{\partial D_{j}^{F, *}}{\partial b_{j}}>0$, and $\frac{\partial p_{j}^{*}}{\partial a_{j}}=0$ for all $i, j$.

Proof of Lemma A.2. We prove this proposition by finding the first derivatives of our interests 
(i.e., $q_{i, j}^{*}, D_{j}^{F, *}$, and $p_{j}^{*}$ ) with respect to parameters $a_{j}$ and $b_{j}$.

i) Comparative statics on $q_{i, j}^{*}, D_{j}^{F, *}$, and $p_{j}^{*}$ with respect to parameters $a_{j}$ :

$$
\begin{aligned}
\frac{\partial q_{i, j}^{*}}{\partial a_{j}} & =\frac{b_{j}}{\left(n_{j}^{F}+1\right) a_{j}^{2}} \cdot\left\{\left(n_{j}^{F}+1\right) \phi_{i, j}-\sum_{m \in I_{j}^{F}} \phi_{m, j}\right\}, \frac{\partial D_{j}^{F, *}}{\partial a_{j}}=\frac{b_{j}}{\left(n_{j}^{F}+1\right) a_{j}^{2}} \cdot\left(\sum_{m \in I_{j}^{F}} \phi_{m, j}\right)>0, \text { and } \\
\frac{\partial p_{j}^{*}}{\partial a_{j}} & =\frac{1}{\left(n_{j}^{F}+1\right)}>0 .
\end{aligned}
$$

Note that $\frac{\partial q_{i, j}^{*}}{\partial a_{j}}<0$ if and only if $\phi_{i, j}<\left(\sum_{m \in I_{j}^{F} \backslash\{i\}} \phi_{m, j}\right) / n_{j}^{F}$.

ii) Comparative statics on $q_{i, j}^{*}, D_{j}^{F, *}$, and $p_{j}^{*}$ with respect to parameters $b_{j}$ :

$$
\begin{gathered}
\frac{\partial q_{i, j}^{*}}{\partial b_{j}}=\frac{1}{\left(n_{j}^{F}+1\right) a_{j}} \cdot\left\{a_{j}-\left(n_{j}^{F}+1\right) \phi_{i, j}+\sum_{m \in I_{j}^{F}} \phi_{m, j}\right\}>0, \\
\frac{\partial D_{j}^{F, *}}{\partial b_{j}}=\frac{1}{\left(n_{j}^{F}+1\right) a_{j}} \cdot\left\{n_{j}^{F} \cdot a_{j}-\sum_{i \in I_{j}^{F}} \phi_{i, j}\right\}>0, \text { and } \frac{\partial p_{j}^{*}}{\partial b_{j}}=0 .
\end{gathered}
$$

Lemma A.3. Suppose an increase of the maximum willingness to pay increases the number of firms in the fair trade market $j$ from $n_{j}$ to $\left(n_{j}+1\right)$. Then, i) the optimal fair trade sales quantity by firm $(i, j)$ decreases if $\phi_{i, j}<\left(\sum_{m \in I_{j}^{F} \backslash\{i\}} \phi_{m, j}\right) / n_{j}^{F}$; ii) the optimal aggregate fair trade sales in market $j$ increases; and iii) the selling price of fair trade certified products in market $j$ does not always increase.

Proof of Lemma A.3. To show this lemma, we assume that when the maximum willingness to pay is $a_{j}$, firm $(i, j)$ sells products to the fair trade market $j$ and $\left|I_{j}^{F}\right|=n_{j}^{F}$ and firm $(k, j)$ does not enter the fair trade market $j$ (i.e., $q_{k, j}^{*}=0$ ). Then, when the maximum willingness to pay is increased from $a_{j}$ to $a_{j}^{\prime}$, firm $(k, j)$ now enters the fair trade market $j$ (i.e., $q_{k, j}^{*,}>0$ ) and $\left|I_{j}^{F{ }^{\prime}}\right|=\left(n_{j}^{F}+1\right)$. Under this setting, we investigate how the change of the fair trade set affects the changes on $q_{i, j}^{*}, D_{j}^{F, *}$, and $p_{j}^{*}$.

i) Changes on the optimal sales quantity of fair trade certified products by firm $(i, j)$ in market $j$ (Note that $q_{i, j}^{*}$ and $q_{i, j}^{*, '}$ denote the optimal sales quantity of fair trade certified products by firm $(i, j)$ in market $j$ under $I_{j}^{F}$ and $I_{j}^{F,}$, respectively.)

From Lemma 1,

$q_{i, j}^{*,}-q_{i, j}^{*}=\frac{b_{j}}{\left(n_{j}^{F}+2\right) a_{j}^{\prime}} \cdot\left\{a_{j}^{\prime}-\left(n_{j}^{F}+2\right) \phi_{i, j}+\sum_{m \in I_{j}^{F,}} \phi_{m, j}\right\}-\frac{b_{j}}{\left(n_{j}^{F}+1\right) a_{j}} \cdot\left\{a_{j}-\left(n_{j}^{F}+1\right) \phi_{i, j}+\sum_{m \in I_{j}^{F}} \phi_{m, j}\right\}$. 
In this case, we assume that $\phi_{i, j}<\left(\sum_{m \in I_{j}^{F} \backslash\{i\}} \phi_{m, j}\right) / n_{j}^{F}$, thus an increase of the maximum willingness to pay decreases the optimal sales quantity by firm $(i, j)$ under $I_{j}^{F}$, see Lemma A.2.i). Hence, since $a_{j}<a_{j}^{\prime}$,

$$
\frac{b_{j}}{\left(n_{j}^{F}+1\right) a_{j}} \cdot\left\{a_{j}-\left(n_{j}^{F}+1\right) \phi_{i, j}+\sum_{m \in I_{j}^{F}} \phi_{m, j}\right\}>\frac{b_{j}}{\left(n_{j}^{F}+1\right) a_{j}^{\prime}} \cdot\left\{a_{j}^{\prime}-\left(n_{j}^{F}+1\right) \phi_{i, j}+\sum_{m \in I_{j}^{F}} \phi_{m, j}\right\} .
$$

Then,

$$
\begin{aligned}
q_{i, j}^{*,}-q_{i, j}^{*} & <\frac{b_{j}}{\left(n_{j}^{F}+2\right) a_{j}^{\prime}} \cdot\left\{a_{j}^{\prime}-\left(n_{j}^{F}+2\right) \phi_{i, j}+\sum_{m \in I_{j}^{F,}} \phi_{m, j}\right\}-\frac{b_{j}}{\left(n_{j}^{F}+1\right) a_{j}^{\prime}} \cdot\left\{a_{j}^{\prime}-\left(n_{j}^{F}+1\right) \phi_{i, j}+\sum_{m \in I_{j}^{F}} \phi_{m, j}\right\} \\
& =-\frac{b_{j}}{\left(n_{j}^{F}+1\right)\left(n_{j}^{F}+2\right) a_{j}^{\prime}} \cdot\left\{a_{j}^{\prime}-\left(n_{j}^{F}+2\right) \phi_{k, j}+\sum_{m \in I_{j}^{F,}} \phi_{m, j}\right\}=-\frac{q_{i, j}^{*, \prime}}{\left(n_{j}^{F}+1\right)}<0 .
\end{aligned}
$$

Therefore, if $\phi_{i, j}<\left(\sum_{m \in I_{j}^{F} \backslash\{i\}} \phi_{m, j}\right) / n_{j}^{F}$ and an increase of the maximum willingness to pay changes the set of firms in the fair trade market $j$, then an increase of the maximum willingness to pay decreases the optimal sales quantity by firm $(i, j)$.

ii) Changes on the total sales of fair trade certified products in market $j$ (Note that $D_{j}^{F, *}$ and $D_{j}^{F, *,}$ denote the total sales of fair trade certified products in market $j$ under $I_{j}^{F}$ and $I_{j}^{F,}$, respectively.) From Lemma 1 and Lemma A.2. (i.e., $\frac{\partial D_{j}^{F, *}}{\partial a_{j}}>0$ ),

$$
\begin{aligned}
D_{j}^{F, *,}-D_{j}^{F, *} & =\frac{b_{j}}{\left(n_{j}^{F}+2\right) a_{j}^{\prime}} \cdot\left\{\left(n_{j}^{F}+1\right) \cdot a_{j}^{\prime}-\sum_{m \in I_{j}^{F,}} \phi_{m, j}\right\}-\frac{b_{j}}{\left(n_{j}^{F}+1\right) a_{j}} \cdot\left\{n_{j}^{F} \cdot a_{j}-\sum_{m \in I_{j}^{F}} \phi_{m, j}\right\} \\
& \geq \frac{b_{j}}{\left(n_{j}^{F}+2\right) a_{j}} \cdot\left\{\left(n_{j}^{F}+1\right) \cdot a_{j}-\sum_{m \in I_{j}^{F, '}} \phi_{m, j}\right\}-\frac{b_{j}}{\left(n_{j}^{F}+1\right) a_{j}} \cdot\left\{n_{j}^{F} \cdot a_{j}-\sum_{m \in I_{j}^{F}} \phi_{m, j}\right\} \\
& =\frac{b_{j}}{\left(n_{j}^{F}+1\right)\left(n_{j}^{F}+2\right) a_{j}} \cdot\left\{a_{j}-\left(n_{j}^{F}+2\right) \phi_{k, j}+\sum_{m \in I_{j}^{F,}} \phi_{m, j}\right\} .
\end{aligned}
$$

Then, since $q_{k, j}^{*,}=\frac{b_{j}}{\left(n_{j}^{F}+2\right) a_{j}^{\prime}} \cdot\left\{a_{j}^{\prime}-\left(n_{j}^{F}+2\right) \phi_{k, j}+\sum_{m \in I_{j}^{F,}} \phi_{m, j}\right\}$ (from Lemma 1),

$$
D_{j}^{F, *,}-D_{j}^{F, *}=\frac{a_{j}^{\prime}}{a_{j}\left(n_{j}^{F}+1\right)} q_{k, j}^{*, '}>0
$$

Therefore, if an increase of the maximum willingness to pay changes the set of firms in the fair trade market $j$, then an increase of the maximum willingness to pay increases the optimal aggregate 
demand.

iii) Changes on the selling price of fair trade certified products in market $j$ (Note that $p_{j}^{*}$ and $p_{j}^{*}$, denote the selling price of fair trade certified products in market $j$ under $I_{j}^{F}$ and $I_{j}^{F,}$, respectively.) From Lemma 1,

$$
\begin{aligned}
p_{j}^{*,}-p_{j}^{*} & =\frac{1}{\left(n_{j}^{F}+2\right)} \cdot\left\{a_{j}^{\prime}+\sum_{m \in I_{j}^{F,}} \phi_{m, j}\right\}-\frac{1}{\left(n_{j}^{F}+1\right)} \cdot\left\{a_{j}+\sum_{m \in I_{j}^{F}} \phi_{m, j}\right\} \\
& =\frac{1}{\left(n_{j}^{F}+1\right)\left(n_{j}^{F}+2\right)} \cdot\left\{\left(n_{j}^{F}+1\right) a_{j}^{\prime}-\left(n_{j}^{F}+2\right) a_{j}+\left(n_{j}^{F}+2\right) \phi_{k, j}-\sum_{m \in I_{j}^{F,}} \phi_{m, j}\right\} .
\end{aligned}
$$

Then, since $q_{k, j}^{*,}=\frac{b_{j}}{\left(n_{j}^{F}+2\right) a_{j}} \cdot\left\{a_{j}^{\prime}-\left(n_{j}^{F}+2\right) \phi_{k, j}+\sum_{m \in I_{j}^{F},} \phi_{m, j}\right\}$ (from Lemma 1),

$$
\begin{aligned}
p_{j}^{*, '}-p_{j}^{*} & =\frac{1}{\left(n_{j}^{F}+1\right)\left(n_{j}^{F}+2\right)} \cdot\left\{\left(n_{j}^{F}+1\right) a_{j}^{\prime}-\left(n_{j}^{F}+2\right) a_{j}+a_{j}^{\prime}-\frac{\left(n_{j}^{F}+2\right) a_{j}^{\prime}}{b_{j}} q_{k, j}^{\prime}\right\} \\
& =\frac{1}{\left(n_{j}^{F}+1\right)} \cdot\left\{\left(a_{j}^{\prime}-a_{j}\right)-\left(\frac{a_{j}^{\prime}}{b_{j}}\right) q_{k, j}^{\prime}\right\} .
\end{aligned}
$$

Hence, $p_{j}^{*,}-p_{j}^{*}$ is positive if and only if $q_{k, j}^{\prime}<\frac{\left(a_{j}^{\prime}-a_{j}\right)}{a_{j}^{\prime}} b_{j}$. Therefore, if an increase of the maximum willingness to pay changes the set of firms in the fair trade market $j$, then an increase of the maximum willingness to pay does not always increase the optimal selling price.

Proof of Lemma 2. Let us find a fair trade organization's decisions: $\rho$ and $\theta_{M}$ to maximize total premium, $T\left(\rho, \theta_{M}\right)$ (recall that $\left.\theta_{S}=1\right)$ :

$$
T\left(\rho, \theta_{M}\right)=\rho\left(D_{S}^{F, *}+\theta_{M} \cdot D_{M}^{F, *}\right),
$$

where, from Lemma 1,

$$
\begin{aligned}
& D_{S}^{F, *}=\frac{b_{S}}{\left(n_{S}^{F}+1\right) a_{S}} \cdot\left\{n_{S}^{F} a_{S}-\sum_{i \in I_{S}^{F}} \phi_{i, j}\right\}=\frac{b_{S}}{\left(n_{S}^{F}+1\right) a_{S}} \cdot\left\{n_{S}^{F} \cdot\left(a_{S}-\rho\right)-\sum_{i \in I_{S}^{F}}\left(c_{S, j}+\gamma_{S, j}\right)\right\} \text { and } \\
& D_{M}^{F, *}=\frac{b_{M}}{\left(n_{M}^{F}+1\right) a_{M}} \cdot\left\{n_{M}^{F} a_{M}-\sum_{i \in I_{M}^{F}} \phi_{i, j}\right\}=\frac{b_{M}}{\left(n_{M}^{F}+1\right) a_{M}} \cdot\left\{n_{M}^{F} \cdot\left(a_{M}-\theta_{M} \cdot \rho\right)-\sum_{i \in I_{M}^{F}}\left(c_{M, j}+\gamma_{M, j}\right)\right\} .
\end{aligned}
$$

Then, the first derivatives of $T$ with respect to $\theta_{M}$ and $\rho$ are the following:

$$
\frac{\partial T}{\partial \theta_{M}}=\rho \cdot \frac{b_{M}}{\left(n_{M}^{F}+1\right) a_{M}} \cdot\left\{n_{M}^{F} a_{M}-\sum_{i \in I_{M}^{F}}\left(c_{M, j}+\gamma_{M, j}\right)-2 \theta_{M} \cdot \rho \cdot n_{M}^{F}\right\} \text { and }
$$




$$
\begin{aligned}
\frac{\partial T}{\partial \rho}= & \frac{b_{S}}{\left(n_{S}^{F}+1\right) a_{S}} \cdot\left\{n_{S}^{F} a_{S}-\sum_{i \in I_{S}^{F}}\left(c_{S, j}+\gamma_{S, j}\right)-2 \rho \cdot n_{S}^{F}\right\} \\
& +\frac{\theta_{M} b_{M}}{\left(n_{M}^{F}+1\right) a_{M}} \cdot\left\{n_{M}^{F} a_{M}-\sum_{i \in I_{M}^{F}}\left(c_{M, j}+\gamma_{M, j}\right)-2 \theta_{M} \cdot \rho \cdot n_{M}^{F}\right\} .
\end{aligned}
$$

Hence, without any constraints on $\theta_{M}$, the following $\rho$ and $\theta_{M}$ satisfies the above first order conditions:

$$
\begin{aligned}
\rho & =\frac{n_{S}^{F} a_{S}-\sum_{i \in I_{S}^{F}}\left(c_{S, j}+\gamma_{S, j}\right)}{2 n_{S}^{F}}=\frac{m_{S}}{2} \text { and } \\
\theta_{M} & =\frac{\left\{n_{M}^{F} a_{M}-\sum_{i \in I_{M}^{F}}\left(c_{M, j}+\gamma_{M, j}\right)\right\} / n_{M}^{F}}{\left\{n_{S}^{F} a_{S}-\sum_{i \in I_{S}^{F}}\left(c_{S, j}+\gamma_{S, j}\right)\right\} / n_{S}^{F}}=\frac{m_{M}}{m_{S}} .
\end{aligned}
$$

where $m_{S}:=a_{S}-\sum_{i \in I_{S}^{F}}\left(c_{S, j}+\gamma_{S, j}\right) / n_{M}^{F}$ and $m_{M}:=a_{M}-\sum_{i \in I_{M}^{F}}\left(c_{M, j}+\gamma_{M, j}\right) / n_{M}^{F}$. In the following, we consider two cases: 1) the unconstrained solution of $\theta_{M}$ is less than the maximum value of $\theta_{M}$, i.e., $\bar{\theta}_{M}$; and 2) the unconstrained solution of $\theta_{M}$ is greater than $\bar{\theta}_{M}$.

Case 1. $\frac{m_{M}}{m_{S}}<\bar{\theta}_{M}$ (i.e., the unconstrained solution of $\theta_{M}<\bar{\theta}_{M}$ )

In this case, the unconstrained solution becomes the optimal solution. Hence, from (16) and (17), the optimal solution is the following:

$$
\theta_{M}^{*}=\frac{m_{M}}{m_{S}} \text { and } \rho^{*}=\frac{m_{S}}{2} .
$$

Case 2. $\frac{m_{M}}{m_{S}} \geq \bar{\theta}_{M}$ (i.e., the unconstrained solution of $\theta_{M} \geq \bar{\theta}_{M}$ )

In this case, given $\theta_{M}=\bar{\theta}_{M}$, from (15),

$$
\rho=\frac{1}{2} \cdot\left(\sum_{j \in J} m_{j} \cdot \frac{b_{j} n_{j}^{F} \bar{\theta}_{j}}{\left(n_{j}^{F}+1\right) a_{j}}\right) /\left(\sum_{j \in J} \frac{b_{j} n_{j}^{F}\left(\bar{\theta}_{j}\right)^{2}}{\left(n_{j}^{F}+1\right) a_{j}}\right) .
$$

In addition, if $0<\theta_{M} \leq \bar{\theta}_{M}$ and $\frac{m_{M}}{m_{S}} \geq \bar{\theta}_{M}$, then we can show that $T$ increases as $\theta_{M}$ increases, i.e., $\frac{\partial T\left(\rho\left(\theta_{M}\right), \theta_{M}\right)}{\partial \theta_{M}}>0$. Hence, when $0<\theta_{M} \leq \bar{\theta}_{M}$ and $\frac{m_{M}}{m_{S}} \geq \bar{\theta}_{M}$, the optimal $\theta_{M}$ is $\bar{\theta}_{M}$ (i.e., $\theta_{M}^{*}=\bar{\theta}_{M}$ ) and the optimal $\rho$ is $\rho^{*}=\frac{1}{2} \cdot\left(\sum_{j \in J} m_{j} \cdot \frac{b_{j} n_{j}^{F} \bar{\theta}_{j}}{\left(n_{j}^{F}+1\right) a_{j}}\right)^{m_{S}} /\left(\sum_{j \in J} \frac{b_{j} n_{j}^{F}\left(\bar{\theta}_{j}\right)^{2}}{\left(n_{j}^{F}+1\right) a_{j}}\right)$.

Proof of Proposition 4. There exist two types of optimal effective premiums $\theta_{j}^{*} \rho^{*}$ (see Lemma 2). Hence, we consider the two cases as the following.

Case 1. $\theta_{M}^{*}<\bar{\theta}_{M}$ (i.e., $\frac{m_{M}}{m_{S}}<\bar{\theta}_{M}$ ).

In this case, from Lemma 2, the optimal effective premium is the following:

$$
\theta_{j}^{*} \rho^{*}=\frac{a_{j}-\sum_{i \in I_{j}^{F}}\left(c_{i, j}+\gamma_{i, j}\right) / n_{j}^{F}}{2} .
$$


Hence, the comparative statics on $\theta_{j}^{*} \rho^{*}$ with respect to parameters $c_{i, j}, \gamma_{i, j}, a_{j}$, and $b_{j}$ are the following:

$$
\frac{\partial \theta_{j}^{*} \rho^{*}}{\partial c_{i, j}}=-\frac{1}{2 n_{j}^{F}}<0, \frac{\partial \theta_{j}^{*} \rho^{*}}{\partial \gamma_{i, j}}=-\frac{1}{2 n_{j}^{F}}<0, \frac{\partial \theta_{j}^{*} \rho^{*}}{\partial a_{j}}=\frac{1}{2}>0, \text { and } \frac{\partial \theta_{j}^{*} \rho^{*}}{\partial b_{j}}=0 .
$$

Case 2. $\theta_{M}^{*} \geq \bar{\theta}_{M}$ (i.e., $\frac{m_{M}}{m_{S}} \geq \bar{\theta}_{M}$ ).

In this case, from Lemma 2, the optimal effective premium is the following:

$$
\theta_{j}^{*} \rho^{*}=\bar{\theta}_{j} \frac{\sum_{j \in J}\left[\frac{b_{j} \bar{\theta}_{j} n_{j}^{F}}{\left(n_{j}^{F}+1\right) a_{j}} \cdot\left\{a_{j}-\sum_{i \in I_{j}^{F}}\left(c_{i, j}+\gamma_{i, j}\right) / n_{j}^{F}\right\}\right]}{\left\{2 \cdot \sum_{j \in J} \frac{b_{j}\left(\bar{\theta}_{j}\right)^{2} n_{j}^{F}}{\left(n_{j}^{F}+1\right) a_{j}}\right\}} .
$$

Hence, the comparative statics on $\theta_{j}^{*} \rho^{*}$ with respect to parameters $c_{i, j}, \gamma_{i, j}, a_{j}$, and $b_{j}$ are the following:

$$
\begin{aligned}
\frac{\partial \theta_{j}^{*} \rho^{*}}{\partial c_{i, j}}= & \frac{\partial \theta_{j}^{*} \rho^{*}}{\partial \gamma_{i, j}}=-\bar{\theta}_{j} \frac{\left\{\frac{b_{j} \bar{\theta}_{j}}{\left(n_{j}^{F}+1\right) a_{j}}\right\}}{\left\{2 \cdot \sum_{j \in J} \frac{b_{j}\left(\bar{\theta}_{j}\right)^{2} n_{j}^{F}}{\left(n_{j}^{F}+1\right) a_{j}}\right\}}<0, \\
\frac{\partial \theta_{j}^{*} \rho^{*}}{\partial a_{S}}= & \left.\frac{a_{M} b_{S}\left(1+n_{M}^{F}\right)^{2}\left(1+n_{S}^{F}\right) n_{S}^{F} n_{M}^{F}}{2\left\{a_{M} b_{S}\left(1+n_{M}^{F}\right) n_{S}^{F}+a_{S} b_{M}\left(1+n_{S}^{F}\right) n_{M}^{F}\left(\bar{\theta}_{M}\right)^{2}\right\}^{2}}\right\} \\
& \cdot\left[\left\{\frac{a_{M} b_{S} n_{S}^{F}}{n_{M}^{F}\left(1+n_{S}^{F}\right)}\right\}+\left\{\frac{b_{M}\left(\bar{\theta}_{M}\right)^{2} \sum_{i \in I_{S}^{F}}\left(c_{i, S}+\gamma_{i, S}\right)}{n_{S}^{F}\left(1+n_{M}^{F}\right)}\right\}+\left\{\frac{b_{S} \bar{\theta}_{M} m_{M}}{\left(1+n_{M}^{F}\right)}\right\}\right]>0, \\
\frac{\partial \theta_{j}^{*} \rho^{*}}{\partial a_{M}}= & \left.\frac{a_{S} b_{M} \bar{\theta}_{M}\left(1+n_{S}^{F}\right)^{2}\left(1+n_{M}^{F}\right) n_{S}^{F} n_{M}^{F}}{2\left\{a_{M} b_{S}\left(1+n_{M}^{F}\right) n_{S}^{F}+a_{S} b_{M}\left(1+n_{S}^{F}\right) n_{M}^{F}\left(\bar{\theta}_{M}\right)^{2}\right\}^{2}}\right\} \\
& \cdot\left[\left\{\frac{a_{S} b_{M} n_{M}^{F}\left(\bar{\theta}_{M}\right)^{2}}{n_{S}^{F}\left(1+n_{M}^{F}\right)}\right\}+\left\{\frac{b_{S} \sum_{i \in I_{M}^{F}}\left(c_{i, M}+\gamma_{i, M}\right)}{n_{M}^{F}\left(1+n_{S}^{F}\right)}\right\}+\left\{\frac{b_{S} \bar{\theta}_{M} m_{S}}{\left(1+n_{S}^{F}\right)}\right\}\right]>0, \\
\frac{\partial \theta_{j}^{*} \rho^{*}}{\partial b_{S}}= & -\frac{a_{S} a_{M} b_{M} \bar{\theta}_{M}\left(1+n_{S}^{F}\right)\left(1+n_{M}^{F}\right) n_{S}^{F} n_{M}^{F}}{2\left\{a_{M} b_{S}\left(1+n_{M}^{F}\right) n_{S}^{F}+a_{S} b_{M}\left(1+n_{S}^{F}\right) n_{M}^{F}\left(\bar{\theta}_{M}\right)^{2}\right\}^{2}}\left(m_{M}-m_{S} \bar{\theta}_{M}\right)<0, \text { and } \\
\frac{\partial \theta_{j}^{*} \rho^{*}}{\partial b_{M}}= & \frac{a_{S} a_{M} b_{S} \bar{\theta}_{M}\left(1+n_{S}^{F}\right)\left(1+n_{M}^{F}\right) n_{S}^{F} n_{M}^{F}}{2\left\{a_{M} b_{S}\left(1+n_{M}^{F}\right) n_{S}^{F}+a_{S} b_{M}\left(1+n_{S}^{F}\right) n_{M}^{F}\left(\bar{\theta}_{M}\right)^{2}\right\}^{2}} \cdot\left(m_{M}-m_{S} \bar{\theta}_{M}\right)>0 . \quad
\end{aligned}
$$

Proof of Proposition 5. In this proposition, we show how the market demand $D_{j}^{F, *}$ and the profit $\Pi_{i, j}^{*}$ change as the optimal effective premium $\theta_{j}^{*} \rho^{*}$ changes.

i) The market demand in an equilibrium decreases as the optimal effective premium increases since, from Lemma 1,

$$
\frac{\partial D_{j}^{F, *}}{\partial \theta_{j}^{*} \rho^{*}}=-\left(\frac{b_{j}}{a_{j}}\right) \cdot\left\{\frac{n_{j}^{F}}{\left(n_{j}^{F}+1\right)}\right\}<0 .
$$


ii) The profit of firm $(i, j)$ in an equilibrium increases as the optimal effective premium increases if and only if $\gamma_{i, j}>q_{i, j}^{*}\left\{\frac{2 a_{j}}{b_{j}\left(n_{j}^{F}-1\right)}\right\}$ since

$$
\begin{aligned}
\frac{\partial \Pi_{j}^{F, *}}{\partial \theta_{j}^{*} \rho^{*}} & =\gamma_{i, j} \cdot\left\{\frac{b_{j}}{\left(n_{j}^{F}+1\right) a_{j}}\right\}\left(n_{j}^{F}-1\right)-\left\{\frac{b_{j}}{\left(n_{j}^{F}+1\right)^{2} a_{j}}\right\} \cdot 2 \cdot\left\{a_{j}-\left(n_{j}^{F}+1\right) \phi_{i, j}+\sum_{m \in I_{j}^{F}} \phi_{m, j}\right\} \\
& =\gamma_{i, j} \cdot\left\{\frac{b_{j}}{\left(n_{j}^{F}+1\right) a_{j}}\right\}\left(n_{j}^{F}-1\right)-q_{i, j}^{*} \cdot\left\{\frac{2}{\left(n_{j}^{F}+1\right)}\right\} .
\end{aligned}
$$

Hence, $\frac{\partial \Pi_{j}^{F, *}}{\partial \theta_{j}^{*} \rho^{*}}>0$ if and only if $\gamma_{i, j}>q_{i, j}^{*}\left\{\frac{2 a_{j}}{b_{j}\left(n_{j}^{F}-1\right)}\right\}$. Note that the profit of firm $(i, j)$ is

$$
\begin{aligned}
\Pi_{i, j}^{*}= & \bar{\pi}_{i, j}^{R}-\gamma_{i, j} \cdot D_{j}^{F, *}+\left(p_{j}^{*}-c_{i, j}-\theta_{j}^{*} \cdot \rho^{*}\right) q_{i, j}^{*} \\
= & \bar{\pi}_{i, j}^{R}-\gamma_{i, j} \cdot \frac{b_{j}}{\left(n_{j}^{F}+1\right) a_{j}} \cdot\left\{\left(n_{j}^{F}-1\right) a_{j}+\left(n_{j}^{F}+1\right) \phi_{i, j}-2 \sum_{m \in I_{j}^{F}} \phi_{m, j}\right\} \\
& +\frac{b_{j}}{\left(n_{j}^{F}+1\right)^{2} a_{j}} \cdot\left\{a_{j}-\left(n_{j}^{F}+1\right) \phi_{i, j}+\sum_{m \in I_{j}^{F}} \phi_{m, j}\right\}^{2} .
\end{aligned}
$$

This is because, from Lemma 1,

$$
\begin{aligned}
\left(p_{j}^{*}-c_{i, j}-\theta_{j}^{*} \cdot \rho^{*}\right) q_{i, j}^{*}= & \frac{1}{\left(n_{j}^{F}+1\right)} \cdot\left\{a_{j}+\sum_{i \in I_{j}^{F}} \phi_{i, j}-\left(n_{j}^{F}+1\right) c_{i, j}-\left(n_{j}^{F}+1\right) \theta_{j}^{*} \cdot \rho^{*}\right\} q_{i, j}^{*} \\
= & \frac{1}{\left(n_{j}^{F}+1\right)} \cdot\left\{a_{j}-\left(n_{j}^{F}+1\right) \phi_{i, j}+\sum_{m \in I_{j}^{F}} \phi_{m, j}+\left(n_{j}^{F}+1\right) \gamma_{i, j}\right\} q_{i, j}^{*} \\
= & \frac{b_{j}}{\left(n_{j}^{F}+1\right)^{2} a_{j}} \cdot\left\{a_{j}-\left(n_{j}^{F}+1\right) \phi_{i, j}+\sum_{m \in I_{j}^{F}} \phi_{m, j}\right\}^{2} \\
& +\gamma_{i, j} \cdot \frac{b_{j}}{\left(n_{j}^{F}+1\right) a_{j}} \cdot\left\{a_{j}-\left(n_{j}^{F}+1\right) \phi_{i, j}+\sum_{m \in I_{j}^{F}} \phi_{m, j}\right\},
\end{aligned}
$$

and

$$
\begin{aligned}
& -\gamma_{i, j} \cdot D_{j}^{F, *}+\gamma_{i, j} \cdot \frac{b_{j}}{\left(n_{j}^{F}+1\right) a_{j}} \cdot\left\{a_{j}-\left(n_{j}^{F}+1\right) \phi_{i, j}+\sum_{m \in I_{j}^{F}} \phi_{m, j}\right\} \\
& =-\gamma_{i, j} \cdot \frac{b_{j}}{\left(n_{j}^{F}+1\right) a_{j}} \cdot\left\{n_{j}^{F} \cdot a_{j}-\sum_{i \in I_{j}^{F}} \phi_{i, j}\right\}+\gamma_{i, j} \cdot \frac{b_{j}}{\left(n_{j}^{F}+1\right) a_{j}} \cdot\left\{a_{j}-\left(n_{j}^{F}+1\right) \phi_{i, j}+\sum_{m \in I_{j}^{F}} \phi_{m, j}\right\}
\end{aligned}
$$




$$
=-\gamma_{i, j} \cdot \frac{b_{j}}{\left(n_{j}^{F}+1\right) a_{j}} \cdot\left\{\left(n_{j}^{F}-1\right) a_{j}+\left(n_{j}^{F}+1\right) \phi_{i, j}-2 \sum_{m \in I_{j}^{F}} \phi_{m, j}\right\}=-\gamma_{i, j}\left(D_{j}^{F, *}-q_{i, j}^{*}\right) .
$$

Proof of Corollary 1. In this corollary, we explore the impact of changes in the effective premium of market $j, \theta_{j}^{*} \rho^{*}$, with respect to key parameters in the other market, market $-j$. Recall that $m_{j}=\left(a_{j}-\sum_{i \in I_{j}^{F}}\left(c_{i, j}+\gamma_{i, j}\right) / n_{j}^{F}\right)$.

(a) Suppose that $\frac{m_{S}}{\bar{\theta}_{S}}>\frac{m_{M}}{\bar{\theta}_{M}}$. Then, from Lemma 2, the optimal effective premium is

$$
\theta_{j}^{*} \rho^{*}=\frac{m_{j}}{2}
$$

Hence, any change in $c_{-i,-j}, \gamma_{-i,-j}, a_{-j}$, or $b_{-j}$ does not affect $\theta_{j}^{*} \rho^{*}$.

(b) Suppose that $\frac{m_{S}}{\bar{\theta}_{S}} \leq \frac{m_{M}}{\bar{\theta}_{M}}$. Then, from Lemma 2, the optimal effective premium is

$$
\theta_{j}^{*} \rho^{*}=\bar{\theta}_{j} \frac{\sum_{j \in J}\left[\frac{b_{j} \bar{\theta}_{j} n_{j}^{F}}{\left(n_{j}^{F}+1\right) a_{j}} \cdot\left\{a_{j}-\sum_{i \in I_{j}^{F}}\left(c_{i, j}+\gamma_{i, j}\right) / n_{j}^{F}\right\}\right]}{\left\{2 \cdot \sum_{j \in J} \frac{b_{j}\left(\bar{\theta}_{j}\right)^{2} n_{j}^{F}}{\left(n_{j}^{F}+1\right) a_{j}}\right\}} .
$$

Hence, the effective premium increases in one market decreases as the cost factors in the other market (i.e., $c_{-i,-j}$ and $\gamma_{-i,-j}$ ) increase because

$$
\frac{\partial \theta_{j}^{*} \rho^{*}}{\partial c_{-i,-j}}=\frac{\partial \theta_{j}^{*} \rho^{*}}{\partial \gamma_{-i,-j}}=-\bar{\theta}_{j} \frac{\left\{\frac{b_{-j} \bar{\theta}_{-j}}{\left(n_{-j}^{F}+1\right) a_{-j}}\right\}}{\left\{2 \cdot \sum_{j \in J} \frac{b_{j}\left(\bar{\theta}_{j}\right)^{2} n_{j}^{F}}{\left(n_{j}^{F}+1\right) a_{j}}\right\}}<0 .
$$

In addition, the effective premium increases in one market increases as the maximum willingness to pay in the other market increases. Moreover, as the market size in one market increases, the effective premium in the other market increases if and only if the focal market's margin is relatively greater than the other. That is,

$$
\begin{array}{r}
\frac{\partial \theta_{j}^{*} \rho^{*}}{\partial a_{-j}}>0 \text { and } \\
\frac{\partial \theta_{j}^{*} \rho^{*}}{\partial b_{-j}}>0 \text { if and only if }\left(\frac{m_{-j}}{\bar{\theta}_{-j}}\right)>\left(\frac{m_{j}}{\bar{\theta}_{j}}\right)
\end{array}
$$

because, from Case 2 in the proof of Proposition $4, \frac{\partial \theta_{j}^{*} \rho^{*}}{\partial a_{S}}>0, \frac{\partial \theta_{j}^{*} \rho^{*}}{\partial a_{M}}>0, \frac{\partial \theta_{j}^{*} \rho^{*}}{\partial b_{S}}>0$ if and only if $m_{S} \bar{\theta}_{M}>m_{M}$, and $\frac{\partial \theta_{j}^{*} \rho^{*}}{\partial b_{M}}>0$ if and only if $m_{M}>m_{S} \bar{\theta}_{M}$.

Proof of Corollary 2. We can prove Corollary 2 by following the same logic exhibited in the proof of Proposition 1. Therefore, we omit the details of the proof of Corollary 2. 
Proof of Corollary 3. We can prove Corollary 3 by following the same logic exhibited in the proof of Lemma 2. Therefore, we omit the details of the proof of Corollary 3.

Proof of Proposition 6. In this proposition, for notational convenience, we let

$$
D_{j}^{D i f f}=\left(\frac{b_{j}}{a_{j}}\right)\left[\frac{a_{j}\left(n_{j}^{F T U S A}-n_{j}^{F L O}\right)}{\left(n_{j}^{F L O}+1\right)\left(n_{j}^{F T U S A}+1\right)}+\left\{\frac{\sum_{i \in I_{j}^{F L O}} \phi_{i, j}^{F L O}}{\left(n_{j}^{F L O}+1\right)}-\frac{\sum_{i \in I_{j}^{F T U S A}} \phi_{i, j}^{F T U S A}}{\left(n_{j}^{F T U S A}+1\right)}\right\}\right] .
$$

To prove this proposition, we first show the condition in which $q_{i, j}^{F L O} \geq q_{i, j}^{F T U S A}$ (in Case 1 , see below). Then, we show that $D_{j}^{F T U S A} \geq D_{j}^{F L O}$ and $p_{j}^{F T U S A} \leq p_{j}^{F L O}$ (in Case 2, see below).

Case 1. Condition in which $q_{i, j}^{F L O} \geq q_{i, j}^{F T U S A}$

From Lemma 1, we can show that the optimal sales quantities of fair trade products by firm $(i, j)$ under FLO and FTUSA are the following:

$$
\begin{aligned}
q_{i, j}^{F L O} & =\frac{b_{j}}{\left(n_{j}^{F L O}+1\right) a_{j}} \cdot\left\{a_{j}-\left(n_{j}^{F L O}+1\right) \phi_{i, j}^{F L O}+\sum_{m \in I_{j}^{F L O}} \phi_{m, j}^{F L O}\right\} \text { and } \\
q_{i, j}^{F T U S A} & =\frac{b_{j}}{\left(n_{j}^{F T U S A}+1\right) a_{j}} \cdot\left\{a_{j}-\left(n_{j}^{F T U S A}+1\right) \phi_{i, j}^{F T U S A}+\sum_{m \in I_{j}^{F T U S A}} \phi_{m, j}^{F T U S A}\right\} .
\end{aligned}
$$

Then, the difference between $q_{i, j}^{F L O}$ and $q_{i, j}^{F T U S A}$ is

$$
\begin{aligned}
& q_{i, j}^{F L O}-q_{i, j}^{F T U S A} \\
& =\frac{b_{j}}{a_{j}\left(n_{j}^{F L O}+1\right)\left(n_{j}^{F T U S A}+1\right)} \cdot\left\{a_{j}\left(n_{j}^{F T U S A}-n_{j}^{F L O}\right)\right\}-\left(\frac{b_{j}}{a_{j}}\right) \cdot\left(\phi_{i, j}^{F L O}-\phi_{i, j}^{F T U S A}\right) \\
& +\left(\frac{b_{j}}{a_{j}}\right) \cdot\left\{\frac{\sum_{m \in I_{j}^{F L O}}^{F L, j}}{\left(n_{j}^{F L O}+1\right)}-\frac{\sum_{m \in I_{j}^{F T U S A}} \phi_{m, j}^{F T U S A}}{\left(n_{j}^{F T U S A}+1\right)}\right\} \\
& =D_{j}^{D i f f}-\left(\frac{b_{j}}{a_{j}}\right)\left(\phi_{i, j}^{F L O}-\phi_{i, j}^{F T U S A}\right) .
\end{aligned}
$$

Hence,

$$
q_{i, j}^{F L O} \geq q_{i, j}^{F T U S A} \quad \text { if and only if }\left(\frac{b_{j}}{a_{j}}\right)\left(\phi_{i, j}^{F L O}-\phi_{i, j}^{F T U S A}\right) \leq D_{j}^{D i f f}
$$

Case 2. Proof of $D_{j}^{F T U S A}>D_{j}^{F L O}$

From Lemma 1, we can show that the total sales of fair trade products in market $j$ under FLO and FTUSA are the following:

$$
\begin{aligned}
D_{j}^{F T U S A} & =\frac{b_{j}}{\left(n_{j}^{F T U S A}+1\right) a_{j}} \cdot\left\{n_{j}^{F T U S A} \cdot a_{j}-\sum_{i \in I_{j}^{F T U S A}} \phi_{i, j}^{F T U S A}\right\} \text { and } \\
D_{j}^{F L O} & =\frac{b_{j}}{\left(n_{j}^{F L O}+1\right) a_{j}} \cdot\left\{n_{j}^{F L O} \cdot a_{j}-\sum_{i \in I_{j}^{F L O}} \phi_{i, j}^{F L O}\right\} .
\end{aligned}
$$


Then, the difference between $D_{j}^{F T U S A}$ and $D_{j}^{F L O}$ is

$$
\begin{aligned}
D_{j}^{F T U S A}-D_{j}^{F L O}= & \frac{b_{j}}{a_{j}\left(n_{j}^{F L O}+1\right)\left(n_{j}^{F T U S A}+1\right)} \cdot\left\{a_{j}\left(n_{j}^{F T U S A}-n_{j}^{F L O}\right)\right\} \\
& +\left(\frac{b_{j}}{a_{j}}\right) \cdot\left\{\frac{\sum_{m \in I_{j}^{F L O}} \phi_{m, j}^{F L O}}{\left(n_{j}^{F L O}+1\right)}-\frac{\sum_{m \in I_{j}^{F T U S A}} \phi_{m, j}^{F T S A}}{\left(n_{j}^{F T U S A}+1\right)}\right\}=D_{j}^{\text {Diff }} .
\end{aligned}
$$

Hence, $D_{i, j}^{F T U S A} \geq D_{i, j}^{F L O}$ if and only if $D_{j}^{D i f f} \geq 0$.

Now, let us suppose that $D_{j}^{D i f f}<0$. Then, $D_{i, j}^{F T U S A}<D_{i, j}^{F L O}$, and at least one firm's selling quantity under FLO is greater than that under FTUSA, i.e., $(i, j), q_{i, j}^{F L O}>q_{i, j}^{F T U S A}$. From Case 1 , we know that $q_{i, j}^{F L O}>q_{i, j}^{F T U S A}$ if and only if $\left(\frac{b_{j}}{a_{j}}\right)\left(\phi_{i, j}^{F L O}-\phi_{i, j}^{F T U S A}\right)<D_{j}^{D i f f}$. However, if $D_{j}^{D i f f}<0$, then the condition, $\left(\frac{b_{j}}{a_{j}}\right)\left(\phi_{i, j}^{F L O}-\phi_{i, j}^{F T U S A}\right)<D_{j}^{D i f f}$, is impossible to hold because $\left(\phi_{i, j}^{F L O}-\phi_{i, j}^{F T U S A}\right)>0$ for all $i, j$. Hence, $D_{j}^{D i f f}$ is always non-negative. Therefore, $D_{j}^{F T U S A}$ is always greater than or equal to $D_{j}^{F L O}$, and thus $p_{j}^{F T U S A}$ is always less than or equal to $p_{j}^{F L O}$.

Note that from Cases 1 and 2, we show that $q_{i, j}^{F L O} \geq q_{i, j}^{F T U S A}$ if and only if $\left(\phi_{i, j}^{F L O}-\phi_{i, j}^{F T U S A}\right) \leq$ $\frac{a_{j}}{b_{j}} \cdot\left(D_{j}^{F T U S A}-D_{j}^{F L O}\right)$ because $D_{j}^{D i f f}=\left(D_{i, j}^{F T U S A}-D_{i, j}^{F L O}\right)$.

Proof of Proposition 7. In this proposition, for notational convenience, we let

$$
D_{j}^{D i f f}=\left(\frac{b_{j}}{a_{j}}\right)\left[\frac{a_{j}\left(n_{j}^{F T U S A}-n_{j}^{F L O}\right)}{\left(n_{j}^{F L O}+1\right)\left(n_{j}^{F T U S A}+1\right)}+\left\{\frac{\sum_{i \in I_{j}^{F L O}} \phi_{i, j}^{F L O}}{\left(n_{j}^{F L O}+1\right)}-\frac{\sum_{i \in I_{j}^{F T U S A}} \phi_{i, j}^{F T U S A}}{\left(n_{j}^{F T U S A}+1\right)}\right\}\right] .
$$

(i) In this part, we investigate preference of aggregate smallholder farmers by comparing the total premium under FLO and FTUSA. The total premium to smallholder farmers under FLO is $\theta_{j}^{F L O} \rho^{F L O} D_{j}^{F L O}$ because plantations are prohibited under FLO. In contrast, under FTUSA, the total premium to smallholder farmers is $\theta_{j}^{F T U S A} \rho^{F L O} D_{j}^{F T U S A, s m a l l}$ where $D_{j}^{F T U S A, \text { small }}$ denotes the total sales of fair trade certified products by sourcing from smallholder farmers under FTUSA. Note that $\sum_{i \in I_{j}^{F L O}} q_{i, j}^{F T U S A}$ is greater than $D_{j}^{F T U S A, \text { small }}$ because not all firms in $I_{j}^{F L O}$ will procure from smallholder farmers when they are certified under FTUSA.

In what follows, we find a condition in which $D_{j}^{F L O}>\sum_{i \in I_{j}^{F L O}} q_{i, j}^{F T U S A}$. Under the condition, smallholder farmers prefer FLO since $\theta_{j}^{F L O}>\theta_{j}^{F T U S A}$. From Lemma $1, D_{j}^{F L O}$ and $\sum_{i \in I_{j}^{F L O}} q_{i, j}^{F T U S A}$ are the following:

$$
\begin{aligned}
D_{j}^{F L O} & =\frac{b_{j}}{\left(n_{j}^{F L O}+1\right) a_{j}} \cdot\left\{n_{j}^{F L O} \cdot a_{j}-\sum_{i \in I_{j}^{F L O}} \phi_{i, j}^{F L O}\right\} \text { and } \\
\sum_{i \in I_{j}^{F L O}} q_{i, j}^{F T U S A} & =\frac{b_{j}}{\left(n_{j}^{F T U S A}+1\right) a_{j}} \cdot\left\{n_{j}^{F L O} \cdot a_{j}-\left(n_{j}^{F T U S A}+1\right) \sum_{i \in I_{j}^{F L O}} \phi_{i, j}^{F T U S A}+n_{j}^{F L O} \sum_{i \in I_{j}^{F T U S A}} \phi_{i, j}^{F T U S A}\right\} .
\end{aligned}
$$


Then, the difference between $D_{j}^{F L O}$ and $\sum_{i \in I_{j}^{F L O}} q_{i, j}^{F T U S A}$ is

$$
\begin{aligned}
& D_{j}^{F L O}-\sum_{i \in I_{j}^{F L O}} q_{i, j}^{F T U S A} \\
& =\frac{b_{j}}{a_{j}\left(n_{j}^{F L O}+1\right)\left(n_{j}^{F T U S A}+1\right)} \cdot\left\{a_{j} n_{j}^{F L O}\left(n_{j}^{F T U S A}-n_{j}^{F L O}\right)\right\}-\left(\frac{b_{j}}{a_{j}}\right)\left\{\frac{\sum_{i \in I_{j}^{F L O} \phi_{i, j}^{F L O}}}{\left(n_{j}^{F L O}+1\right)}\right\} \\
& +\left(\frac{b_{j}}{a_{j}}\right) \sum_{i \in I_{j}^{F L O}} \phi_{i, j}^{F T U S A}-\left(\frac{b_{j}}{a_{j}}\right)\left\{\frac{n_{j}^{F L O} \sum_{i \in I_{j}^{F T U S A}} \phi_{i, j}^{F T U S A}}{\left(n_{j}^{F T U S A}+1\right)}\right\} \\
& =n_{j}^{F L O} \cdot\left[D_{j}^{D i f f}-\left(\frac{b_{j}}{a_{j}}\right)\left\{\frac{\sum_{i \in I_{j}^{F L O}} \phi_{i, j}^{F L O}}{\left(n_{j}^{F L O}+1\right)}\right\}-\left(\frac{b_{j}}{a_{j}}\right)\left\{\frac{\sum_{i \in I_{j}^{F L O}} \phi_{i, j}^{F L O}}{n_{j}^{F L O}\left(n_{j}^{F L O}+1\right)}\right\}+\left(\frac{b_{j}}{a_{j}}\right)\left\{\frac{\sum_{i \in I_{j}^{F L O} \phi_{i, j}^{F U S A}}}{n_{j}^{F L O}}\right\}\right] \\
& =n_{j}^{F L O} \cdot\left[D_{j}^{D i f f}-\left(\frac{b_{j}}{a_{j}}\right)\left\{\frac{\sum_{i \in I_{j}^{F L O}}\left(\phi_{i, j}^{F L O}-\phi_{i, j}^{F T U S A}\right)}{n_{j}^{F L O}}\right\}\right]
\end{aligned}
$$

Hence,

$$
D_{j}^{F L O} \geq \sum_{i \in I_{j}^{F L O}} q_{i, j}^{F T U S A} \quad \text { if and only if } \sum_{i \in I_{j}^{F L O}}\left(\phi_{i, j}^{F L O}-\phi_{i, j}^{F T U S A}\right) / n_{j}^{F L O} \leq\left(\frac{a_{j}}{b_{j}}\right) D_{j}^{D i f f} .
$$

Since $\theta_{j}^{F L O} \rho^{F L O}>\theta_{j}^{F T U S A} \rho^{F T U S A}$, the total premium to small farmers under FLO is greater than that under FTUSA if $\sum_{i \in I_{j}^{F L O}}\left(\phi_{i, j}^{F L O}-\phi_{i, j}^{F T U S A}\right) / n_{j}^{F L O} \leq\left(\frac{b_{j}}{a_{j}}\right) D_{j}^{D i f f}$. (Recall that $D_{j}^{D i f f}=$ $D_{j}^{F T U S A}-D_{j}^{F L O}$ from the proof of Case 2 of Proposition 6.) Note that the selling quantity of plantation farmers under FLO is always zero. Hence, the plantation farmers always prefer FTUSA. (ii) In this part, we explore preference of firm $(i, j)$ by comparing its profits under FLO and FTUSA. In what follows, we investigate three cases: 1) the firm does not enter the fair trade market under both FLO and FTUSA; 2) the firm only enters the fair trade market under FTUSA; 3) the firm enters the fair trade market under either FLO or FTUSA.

Case 1. Not entering the fair trade market under both FLO and FTUSA (i.e., $\phi_{i, j}^{F L O} \geq$ $\frac{a_{j}+\sum_{m \in\left(I_{j}^{F L O} \backslash\{i\}\right)} \phi_{m, j}^{F L O}}{n_{j}^{F L O}}$ and $\phi_{i, j}^{F T U S A} \geq \frac{a_{j}+\sum_{m \in\left(I_{j}^{F T U S A} \backslash\{i\}\right)} \phi_{m, j}^{F T U A}}{n_{j}^{F T U S A}}$, from Proposition 1)

In this case, since firm $(i, j)$ does not sell fair trade products under both FLO and FTUSA, both $q_{i, j}^{F L O}$ and $q_{i, j}^{F T U S A}$ are zero. Then, from $\S 3.3$, the profits of firm $(i, j)$ under FLO and FTUSA are the following:

$$
\Pi_{i, j}^{F L O}=\bar{\pi}_{i, j}^{R}-\gamma_{i, j} \cdot D_{j}^{F L O} \text { and } \Pi_{i, j}^{F T U S A}=\bar{\pi}_{i, j}^{R}-\gamma_{i, j} \cdot D_{j}^{F T U S A}
$$

Then, the difference between $\Pi_{i, j}^{F L O}$ and $\Pi_{i, j}^{F T U S A}$ is

$$
\Pi_{i, j}^{F L O}-\Pi_{i, j}^{F T U S A}=\gamma_{i, j} \cdot\left(D_{j}^{F T U S A}-D_{j}^{F L O}\right)>0,
$$

because $D_{j}^{F T U S A} \geq D_{j}^{F L O}$, see Proposition 6 .

Case 2. Entering the fair trade market only under FTUSA (i.e., $\phi_{i, j}^{F L O} \geq \frac{a_{j}+\sum_{m \in\left(I_{j}^{F L O} \backslash\{i\}\right)} \phi_{m, j}^{F L O}}{n_{j}^{F L O}}$ 
and $\phi_{i, j}^{F T U S A}<\frac{a_{j}+\sum_{m \in\left(I_{j}^{F T U S A} \backslash\{i\}\right)} \phi_{m, j}^{F T U S A}}{n_{j}^{F T U S A}}$, from Proposition 1)

In this case, since firm $(i, j)$ does not sell fair trade products under FLO, $q_{i, j}^{F L O}$ equals zero and $q_{i, j}^{F T U S A}$ is positive. Then, from $\S 3.3$, the profits of firm $(i, j)$ under FLO and FTUSA are the following:

$$
\begin{aligned}
\Pi_{i, j}^{F L O} & =\bar{\pi}_{i, j}^{R}-\gamma_{i, j} \cdot D_{j}^{F L O}, \text { and } \\
\Pi_{i, j}^{F T U S A} & =\bar{\pi}_{i, j}^{R}-\gamma_{i, j} \cdot D_{i, j}^{F T U S A}+\gamma_{i, j} \cdot q_{i, j}^{F T U S A}+\left(p_{j}^{F T U S A}-\phi_{i, j}^{F T U S A}\right) q_{i, j}^{F T U S A},
\end{aligned}
$$

where $\phi_{i, j}^{F T U S A}=\left(c_{i, j}+\gamma_{i, j}+\theta_{j}^{F T U S A} \rho^{F L O}\right)$. Then, the difference between $\Pi_{i, j}^{F L O}$ and $\Pi_{i, j}^{F T U S A}$ is

$$
\begin{aligned}
\Pi_{i, j}^{F L O}-\Pi_{i, j}^{F T U S A} & =\gamma_{i, j}\left(D_{j}^{F T U S A}-D_{j}^{F L O}\right)-\gamma_{i, j} \cdot q_{i, j}^{F T U S A}-\left(p_{j}^{F T U S A}-\phi_{i, j}^{F T U S A}\right) q_{i, j}^{F T U S A} \\
& =\gamma_{i, j} D_{j}^{\text {Diff }}-\gamma_{i, j} \cdot q_{i, j}^{F T U S A}-\left(\frac{a_{j}}{b_{j}}\right)\left(q_{i, j}^{F T U S A}\right)^{2}
\end{aligned}
$$

because from Lemma 1,

$$
\begin{aligned}
\left(p_{j}^{F T U S A}-\phi_{i, j}^{F T U S A}\right) & =\frac{1}{\left(n_{j}^{F T U S A}+1\right)} \cdot\left\{a_{j}+\sum_{m \in I_{j}^{F T U S A}} \phi_{m, j}^{F T U S A}\right\}-\phi_{i, j}^{F T U S A} \\
& =\frac{1}{\left(n_{j}^{F T U S A}+1\right)} \cdot\left\{a_{j}-\left(n_{j}^{F T U S A}+1\right) \phi_{i, j}^{F T U S A}+\sum_{m \in I_{j}^{F T U S A}} \phi_{m, j}^{F T U S A}\right\} \\
& =\left(\frac{a_{j}}{b_{j}}\right) q_{i, j}^{F T U S A} .
\end{aligned}
$$

Hence, $\Pi_{i, j}^{F L O} \geq \Pi_{i, j}^{F T U S A}$ if and only if

$$
D_{j}^{D i f f} \geq q_{i, j}^{F T U S A}+\left(\frac{a_{j}}{b_{j} \cdot \gamma_{i, j}}\right)\left(q_{i, j}^{F T U S A}\right)^{2} .
$$

Case 3. Entering the fair trade market both under FTUSA and FLO (i.e., $\phi_{i, j}^{F L O}<$ $\frac{a_{j}+\sum_{m \in\left(I_{j}^{F L O} \backslash\{i\}\right)} \phi_{m, j}^{F L O}}{n_{j}^{F L O}}$ and $\phi_{i, j}^{F T U S A}<\frac{a_{j}+\sum_{m \in\left(I_{j}^{F T U S A} \backslash\{i\}\right)} \phi_{m, j}^{F T U S A}}{n_{j}^{F T U S A}}$, from Proposition 1)

In this case, both $q_{i, j}^{F L O}$ and $q_{i, j}^{F T U S A}$ are positive. Then, from $\S 3.3$, the profits of firm $(i, j)$ under FLO and FTUSA are the following:

$$
\begin{aligned}
\Pi_{i, j}^{F L O} & =\bar{\pi}_{i, j}^{R}-\gamma_{i, j} \cdot D_{-i, j}^{F L O}+\left(p_{j}^{F L O}-\phi_{i, j}^{F L O}\right) q_{i, j}^{F L O} \text { and } \\
\Pi_{i, j}^{F T U S A} & =\bar{\pi}_{i, j}^{R}-\gamma_{i, j} \cdot D_{-i, j}^{F T U S A}+\left(p_{j}^{F T U S A}-\phi_{i, j}^{F T U S A}\right) q_{i, j}^{F T U S A},
\end{aligned}
$$

where $D_{-i, j}^{F L O}=\left(\sum_{m \in I_{j}^{F L O}} q_{m, j}\right)-q_{i, j}^{F L O}$ and $D_{-i, j}^{F T U S A}=\left(\sum_{m \in I_{j}^{F T U S A}} q_{m, j}\right)-q_{i, j}^{F T U S A}$. Then, the difference between $\Pi_{i, j}^{F L O}$ and $\Pi_{i, j}^{F T U S A}$ is

$$
\Pi_{i, j}^{F L O}-\Pi_{i, j}^{F T U S A}=\left(D_{-i, j}^{F T U S A}-D_{-i, j}^{F L O}\right) \gamma_{i, j}+\left(p_{j}^{F L O}-\phi_{i, j}^{F L O}\right) q_{i, j}^{F L O}-\left(p_{j}^{F T U S A}-\phi_{i, j}^{F T U S A}\right) q_{i, j}^{F T U S A} .
$$


For the easy of analysis, we first calculate two terms, i.e., $\left(D_{-i, j}^{F T U S A}-D_{-i, j}^{F L O}\right)$ and $\left(p_{j}^{F L O}-\right.$ $\left.\phi_{i, j}^{F L O}\right) q_{i, j}^{F L O}-\left(p_{j}^{F T U S A}-\phi_{i, j}^{F T U S A}\right) q_{i, j}^{F T U S A}$ in the following two sub-cases.

Case 3.1. $\left(D_{-i, j}^{F T U S A}-D_{-i, j}^{F L O}\right)$

From Lemma $1, D_{-i, j}^{F L O}$ is

$$
\begin{aligned}
D_{-i, j}^{F L O}= & \frac{b_{j}}{\left(n_{j}^{F L O}+1\right) a_{j}} \cdot\left\{n_{j}^{F L O} \cdot a_{j}-\sum_{m \in I_{j}^{F L O}} \phi_{m, j}^{F L O}\right\} \\
& -\frac{b_{j}}{\left(n_{j}^{F L O}+1\right) a_{j}} \cdot\left\{a_{j}-\left(n_{j}^{F L O}+1\right) \phi_{i, j}^{F L O}+\sum_{m \in I_{j}^{F L O}} \phi_{m, j}^{F L O}\right\} \\
= & \frac{b_{j}}{\left(n_{j}^{F L O}+1\right) a_{j}} \cdot\left\{\left(n_{j}^{F L O}-1\right) \cdot a_{j}+\left(n_{j}^{F L O}+1\right) \phi_{i, j}^{F L O}-2 \sum_{m \in I_{j}^{F L O}} \phi_{m, j}^{F L O}\right\} .
\end{aligned}
$$

Similarly,

$$
D_{-i, j}^{F T U S A}=\frac{b_{j}}{\left(n_{j}^{F T U S A}+1\right) a_{j}} \cdot\left\{\left(n_{j}^{F T U S A}-1\right) \cdot a_{j}+\left(n_{j}^{F T U S A}+1\right) \phi_{i, j}^{F T U S A}-2 \sum_{m \in I_{j}^{F T U S A}} \phi_{m, j}^{F T U S A}\right\} .
$$

Then, the difference between $D_{-i, j}^{F T U S A}$ and $D_{-i, j}^{F L O}$ is

$$
D_{-i, j}^{F T U S A}-D_{-i, j}^{F L O}=2 \cdot D_{j}^{D i f f}-\left(\frac{b_{j}}{a_{j}}\right)\left(\phi_{i, j}^{F L O}-\phi_{i, j}^{F T U S A}\right),
$$

where $D_{j}^{D i f f}=\left(\frac{b_{j}}{a_{j}}\right)\left[\frac{a_{j}\left(n_{j}^{F T U S A}-n_{j}^{F L O}\right)}{\left(n_{j}^{F L O}+1\right)\left(n_{j}^{F T S S A}+1\right)}+\left\{\frac{\sum_{i \in I_{j}^{F L O} \phi_{i, j}^{F O}}}{\left(n_{j}^{F L O}+1\right)}-\frac{\sum_{i \in I_{j}^{F T U S A} \phi_{i, j}^{F U S A}}}{\left(n_{j}^{F T U S A}+1\right)}\right\}\right]$.

Case 3.2. $\left(p_{j}^{F L O}-\phi_{i, j}^{F L O}\right) q_{i, j}^{F L O}-\left(p_{j}^{F T U S A}-\phi_{i, j}^{F T U S A}\right) q_{i, j}^{F T U S A}$

From Lemma 1 , the term $\left(p_{j}^{F L O}-\phi_{i, j}^{F L O}\right) q_{i, j}^{F L O}$ is

$$
\begin{aligned}
\left(p_{j}^{F L O}-\phi_{i, j}^{F L O}\right) q_{i, j}^{F L O}= & {\left[\frac{1}{\left(n_{j}^{F L O}+1\right)} \cdot\left\{a_{j}+\sum_{m \in I_{j}^{F L O}} \phi_{m, j}^{F L O}\right\}-\phi_{i, j}^{F L O}\right] } \\
& \cdot \frac{b_{j}}{\left(n_{j}^{F L O}+1\right) a_{j}} \cdot\left\{a_{j}-\left(n_{j}^{F L O}+1\right) \phi_{i, j}^{F L O}+\sum_{m \in I_{j}^{F L O}} \phi_{m, j}^{F L O}\right\} \\
= & \frac{b_{j}}{\left(n_{j}^{F L O}+1\right)^{2} a_{j}} \cdot\left\{a_{j}-\left(n_{j}^{F L O}+1\right) \phi_{i, j}^{F L O}+\sum_{m \in I_{j}^{F L O}} \phi_{m, j}^{F L O}\right\}^{2} .
\end{aligned}
$$

Similarly,

$$
\left(p_{j}^{F T U S A}-\phi_{i, j}^{F T U S A}\right) q_{i, j}^{F T U S A}=\frac{b_{j}}{\left(n_{j}^{F T U S A}+1\right)^{2} a_{j}} \cdot\left\{a_{j}-\left(n_{j}^{F T U S A}+1\right) \phi_{i, j}^{F T U S A}+\sum_{m \in I_{j}^{F T U S A}} \phi_{m, j}^{F T U S A}\right\}^{2} .
$$


Then, the difference between $\left(p_{j}^{F L O}-\phi_{i, j}^{F L O}\right) q_{i, j}^{F L O}$ and $\left(p_{j}^{F T U S A}-\phi_{i, j}^{F T U S A}\right) q_{i, j}^{F T U S A}$ is

$$
\begin{aligned}
& \left(p_{j}^{F L O}-\phi_{i, j}^{F L O}\right) q_{i, j}^{F L O}-\left(p_{j}^{F T U S A}-\phi_{i, j}^{F T U S A}\right) q_{i, j}^{F T U S A} \\
& =\left(\frac{b_{j}}{a_{j}}\right) \\
& \cdot\left[\frac{\left\{a_{j}-\left(n_{j}^{F L O}+1\right) \phi_{i, j}^{F L O}+\sum_{m \in I_{j}^{F L O}} \phi_{m, j}^{F L O}\right\}}{\left(n_{j}^{F L O}+1\right)}+\frac{\left\{a_{j}-\left(n_{j}^{F T U S A}+1\right) \phi_{i, j}^{F T U S A}+\sum_{m \in I_{j}^{F T U S A}} \phi_{m, j}^{F T U S A}\right\}}{\left(n_{j}^{F T U S A}+1\right)}\right] \\
& \cdot\left[\frac{\left\{a_{j}-\left(n_{j}^{F L O}+1\right) \phi_{i, j}^{F L O}+\sum_{m \in I_{j}^{F L O}} \phi_{m, j}^{F L O}\right\}}{\left(n_{j}^{F L O}+1\right)}-\frac{\left\{a_{j}-\left(n_{j}^{F T U S A}+1\right) \phi_{i, j}^{F T U S A}+\sum_{m \in I_{j}^{F T U S A}} \phi_{m, j}^{F T U S A}\right\}}{\left(n_{j}^{F T U S A}+1\right)}\right] \\
& =\left(q_{i, j}^{F L O}+q_{i, j}^{F T U S A}\right)\left\{D_{j}^{D i f f}-\left(\frac{b_{j}}{a_{j}}\right)\left(\phi_{i, j}^{F L O}-\phi_{i, j}^{F T U S A}\right)\right\}\left(\frac{a_{j}}{b_{j}}\right),
\end{aligned}
$$

where $D_{j}^{D i f f}=\left(\frac{b_{j}}{a_{j}}\right)\left[\frac{a_{j}\left(n_{j}^{F T U S A}-n_{j}^{F L O}\right)}{\left(n_{j}^{F L O}+1\right)\left(n_{j}^{F T U S A}+1\right)}+\left\{\frac{\sum_{i \in I_{j}^{F L O} \phi_{i, j}^{F L O}}}{\left(n_{j}^{F L O}+1\right)}-\frac{\sum_{i \in I_{j}^{F T U S A} \phi_{i, j}^{F T U S A}}}{\left(n_{j}^{F T U S A}+1\right)}\right\}\right]$. Hence, from Cases 3.1 and 3.2, the profit difference under FLO and FTUSA is

$$
\begin{aligned}
\Pi_{i, j}^{F L O}-\Pi_{i, j}^{F T U S A}= & \left(D_{-i, j}^{F T U S A}-D_{-i, j}^{F L O}\right) \gamma_{i, j}+\left(p_{j}^{F L O}-\phi_{i, j}^{F L O}\right) q_{i, j}^{F L O}-\left(p_{j}^{F T U S A}-\phi_{i, j}^{F T U S A}\right) q_{i, j}^{F T U S A} \\
= & \left\{2 \cdot D_{j}^{\text {Diff }}-\left(\frac{b_{j}}{a_{j}}\right)\left(\phi_{i, j}^{F L O}-\phi_{i, j}^{F T U S A}\right)\right\} \gamma_{i, j} \\
& +\left(q_{i, j}^{F L O}+q_{i, j}^{F T U S A}\right)\left\{D_{j}^{\text {Diff }}-\left(\frac{b_{j}}{a_{j}}\right)\left(\phi_{i, j}^{F L O}-\phi_{i, j}^{F T U S A}\right)\right\}\left(\frac{a_{j}}{b_{j}}\right) \\
= & \left\{D_{j}^{\text {Diff }}+\left(q_{i, j}^{F L O}-q_{i, j}^{F T U S A}\right)\right\} \gamma_{i, j}+\left(q_{i, j}^{F L O}+q_{i, j}^{F T U S A}\right)\left(q_{i, j}^{F L O}-q_{i, j}^{F T U S A}\right)\left(\frac{a_{j}}{b_{j}}\right) .
\end{aligned}
$$

Therefore, $\quad \Pi_{i, j}^{F L O} \geq \Pi_{i, j}^{F T U S A} \quad$ if and only if $\left(\phi_{i, j}^{F L O}-\phi_{i, j}^{F T U S A}\right) \leq$ $\left(\frac{a_{j}}{b_{j}}\right) D_{j}^{\text {Diff }}\left\{1+\frac{\gamma_{i, j}}{\gamma_{i, j}+\left(a_{j} / b_{j}\right)\left(q_{i, j}^{F O}+q_{i, j}^{F U S A}\right)}\right\}$.

From Cases 1, 2, and 3, we prove that $\Pi_{i, j}^{F L O} \geq \Pi_{i, j}^{F T U S A}$ if and only if

$$
\left(\phi_{i, j}^{F L O}-\phi_{i, j}^{F T U S A}\right) \leq\left(\frac{a_{j}}{b_{j}}\right) D_{j}^{D i f f}\left\{1+\frac{\gamma_{i, j}}{\gamma_{i, j}+\left(a_{j} / b_{j}\right)\left(q_{i, j}^{F L O}+q_{i, j}^{F T U S A}\right)}\right\} .
$$

This is because 1) when $\phi_{i, j}^{F L O}$ and $\phi_{i, j}^{F T U S A}$ are the same (i.e., Case 1), (19) always holds; 2) when $q_{i, j}^{F L O}=0$ in (19), (19) is reduced to (18).

(iii) In this part, we explore preference of consumers by comparing consumer surplus under FLO and FTUSA. From Proposition $6, D_{j}^{F T U S A} \geq D_{j}^{F L O}$ and $p_{j}^{F T U S A} \leq p_{j}^{F L O}$. Hence, the consumer surplus under FTUSA is greater than that under FLO. Therefore, consumers always prefer FTUSA.

Proof of Corollary 4. To prove this corollary, we consider two cases: single- and multi-ingredient markets in what follows.

(i) In the single-ingredient market, since $\theta_{S}^{F L O}=\theta_{S}^{F T U S A}=1$ and the same $\rho$ is implemented by 
either organization, the premium to farmer $(i, S)$ under FLO is greater than that under FTUSA if and only if $q_{i, S}^{F L O}>q_{i, S}^{F T U S A}$. Hence, from Proposition 6 , the premium to farmer $(i, S)$ under FLO is greater than that under FTUSA if and only if $\left(\phi_{i, S}^{F L O}-\phi_{i, S}^{F T U S A}\right) \leq \frac{a_{S}}{b_{S}} \cdot\left(D_{S}^{F T U S A}-D_{S}^{F L O}\right)$.

ii) In the multi-ingredient market, the minimum fraction standard by FTUSA is either equal to or less than $\bar{\theta}_{M}$ (see, Corollary 3). Then, we investigate the two cases in the following.

Case 1. $\theta_{M}^{F T U S A}=\bar{\theta}_{M}$ (i.e., $m_{M}^{F T U S A} \geq 2 \rho^{F L O}$ )

In this case, $\theta_{M}^{F T U S A}=\theta_{M}^{F L O}=\bar{\theta}_{M}$. Hence, the premium to farmer $(i, M)$ under FLO is greater than that under FTUSA if and only if $q_{i, M}^{F L O}>q_{i, M}^{F T U S A}$. Hence, from Proposition 6, the premium to farmer $(i, M)$ under FLO is greater than that under FTUSA if and only if $\left(\phi_{i, M}^{F L O}-\phi_{i, M}^{F T U S A}\right) \leq$ $\frac{a_{M}}{b_{M}} \cdot\left(D_{M}^{F T U S A}-D_{M}^{F L O}\right)$.

Case 2. $\theta_{M}^{F T U S A}<\bar{\theta}_{M}$ (i.e., $m_{M}^{F T U S A}<2 \rho^{F L O}$ )

In this case, the premium to farmer $(i, M)$ under FLO is greater than that under FTUSA if and only if $q_{i, M}^{F L O} \theta_{M}^{F L O}>q_{i, M}^{F T U S A} \theta_{M}^{F T U S A}$, i.e., $q_{i, M}^{F L O}\left(\frac{\theta_{M}^{F L O}}{\theta_{M}^{F T U S A}}\right)>q_{i, M}^{F T U S A}$. Then, the difference of the following two terms (i.e., $\left.\left(\frac{a_{M}}{b_{M}}\right) q_{i, M}^{F L O}\left(\frac{\theta_{M}^{F L O}}{\theta_{M}^{F T U S A}}\right)-\left(\frac{a_{M}}{b_{M}}\right) q_{i, M}^{F T U S A}\right)$ is, from Lemma 1,

$$
\begin{aligned}
& \left(\frac{a_{M}}{b_{M}}\right)\left\{q_{i, M}^{F L O}\left(\frac{\theta_{M}^{F L O}}{\theta_{M}^{F T U S A}}\right)-q_{i, M}^{F T U S A}\right\} \\
& =\left(\frac{\theta_{M}^{F L O}}{\theta_{M}^{F T U S A}}\right) \frac{1}{\left(n_{M}^{F L O}+1\right)} \cdot\left\{a_{M}-\left(n_{M}^{F L O}+1\right) \phi_{i, M}^{F L O}+\sum_{m \in I_{M}}^{F L O} \phi_{m, M}^{F L O}\right\} \\
& -\frac{1}{\left(n_{M}^{F T U S A}+1\right)} \cdot\left\{a_{M}-\left(n_{M}^{F T U S A}+1\right) \phi_{i, M}^{F T U S A}+\sum_{m \in I_{M}^{F T U S A}} \phi_{m, M}^{F T U S A}\right\} \\
& =\left(\frac{\theta_{M}^{F L O}}{\theta_{M}^{F T U S A}}\right) \frac{a_{M}}{\left(n_{M}^{F L O}+1\right)}-\frac{a_{M}}{\left(n_{M}^{F T S A}+1\right)}+\left(\frac{\theta_{M}^{F L O}}{\theta_{M}^{F T U S A}}\right) \frac{\sum_{m \in I_{M}^{F L O}} \phi_{m, M}^{F L O}}{\left(n_{M}^{F L O}+1\right)}-\frac{\sum_{m \in I_{M}^{F U S A}} \phi_{m, M}^{F T U S A}}{\left(n_{M}^{F T U S A}+1\right)} \\
& -\left\{\left(\frac{\theta_{M}^{F L O}}{\theta_{M}^{F T U S A}}\right) \phi_{i, M}^{F L O}-\phi_{i, M}^{F T U S A}\right\} \\
& =\frac{a_{M}}{\left(n_{M}^{F L O}+1\right)}-\frac{a_{M}}{\left(n_{M}^{F T S A}+1\right)}+\frac{\sum_{m \in I_{M}^{F L O}} \phi_{m, M}^{F L O}}{\left(n_{M}^{F L O}+1\right)}-\frac{\sum_{m \in I_{M}^{F U S A}} \phi_{m, M}^{F T U S A}}{\left(n_{M}^{F T U S A}+1\right)} \\
& +\left(\frac{\theta_{M}^{F L O}}{\theta_{M}^{F T S A}}\right) \frac{\sum_{m \in I_{M}^{F L O}} \phi_{m, M}^{F L O}}{\left(n_{M}^{F L O}+1\right)}-\frac{\sum_{m \in I_{M}^{F O}} \phi_{m, M}^{F L O}}{\left(n_{M}^{F L O}+1\right)}+\left(\frac{\theta_{M}^{F L O}}{\theta_{M}^{F T U S A}}\right) \frac{a_{M}}{\left(n_{M}^{F L O}+1\right)}-\frac{a_{M}}{\left(n_{M}^{F L O}+1\right)} \\
& -\left\{\phi_{i, M}^{F L O}-\phi_{i, M}^{F T U S A}+\left(\frac{\theta_{M}^{F L O}}{\theta_{M}^{F T U S A}}\right) \phi_{i, M}^{F L O}-\phi_{i, M}^{F L O}\right\} \\
& =\frac{a_{M}}{\left(n_{M}^{F L O}+1\right)}-\frac{a_{M}}{\left(n_{M}^{F T U S A}+1\right)}+\frac{\sum_{m \in I_{M}^{F L O}} \phi_{m, M}^{F L O}}{\left(n_{M}^{F L O}+1\right)}-\frac{\sum_{m \in I_{M}^{F U S A}} \phi_{m, M}^{F T U S A}}{\left(n_{M}^{F T U S A}+1\right)}-\left(\phi_{i, M}^{F L O}-\phi_{i, M}^{F T U S A}\right) \\
& +\left\{\left(\frac{\theta_{M}^{F L O}}{\theta_{M}^{F T U S A}}\right)-1\right\}\left\{\frac{a_{M}}{\left(n_{M}^{F L O}+1\right)}-\phi_{i, M}^{F L O}+\frac{\sum_{m \in I_{M}^{F O}} \phi_{m, M}^{F L O}}{\left(n_{M}^{F L O}+1\right)}\right\} \\
& =\frac{a_{M}}{\left(n_{M}^{F L O}+1\right)}-\frac{a_{M}}{\left(n_{M}^{F T S A}+1\right)}-\frac{\sum_{m \in I_{M}^{F U S A}} \phi_{m, M}^{F T U S A}}{\left(n_{M}^{F T U S A}+1\right)}+\frac{\sum_{m \in I_{M}^{F L O}} \phi_{m, M}^{F L O}}{\left(n_{M}^{F L O}+1\right)}-\frac{\sum_{m \in I_{M}^{F T U S A}} \phi_{m, M}^{F T U S A}}{\left(n_{M}^{F T S A}+1\right)}
\end{aligned}
$$




$$
-\left(\phi_{i, M}^{F L O}-\phi_{i, M}^{F T U S A}\right)+\left\{\left(\frac{\theta_{M}^{F L O}}{\theta_{M}^{F T U S A}}\right)-1\right\}\left(\frac{a_{M}}{b_{M}}\right) q_{i, M}^{F L O}
$$

Hence, the premium to farmer $(i, M)$ under FLO is greater than that under FTUSA if and only if

$$
\begin{aligned}
& \left(\phi_{i, M}^{F L O}-\phi_{i, M}^{F T U S A}\right)-\left\{\left(\frac{\theta_{M}^{F L O}}{\theta_{M}^{F T U S A}}\right)-1\right\}\left(\frac{a_{M}}{b_{M}}\right) q_{i, M}^{F L O} \\
& \leq\left(\frac{\sum_{m \in I_{M}^{F O} \phi_{m, M}^{F L O}}}{\left(n_{M}^{F L O}+1\right)}-\frac{\sum_{m \in I_{M}^{F T U S A}} \phi_{m, M}^{F T U S}}{\left(n_{M}^{F T U S A}+1\right)}\right)+a_{M}\left\{\frac{1}{\left(n_{M}^{F L O}+1\right)}-\frac{1}{\left(n_{M}^{F T U S A}+1\right)}\right\} \\
& =\left(\frac{a_{M}}{b_{M}}\right) D_{j}^{\text {Diff }}=\left(\frac{a_{M}}{b_{M}}\right)\left(D_{M}^{F T U S A}-D_{M}^{F L O}\right) .
\end{aligned}
$$

Proof of Proposition 8. By combining Proposition 7 and Corollary 4, we can show Proposition 8. In detail, first, consumers always prefer FTUSA, see Proposition 7(iii). Second, firm (i,j) prefer FLO if and only if (4) in Proposition 7(ii) (in the manuscript) holds. Third, smallholder farmers in the single-ingredient market prefer FLO if and only if (5) in Corollary 4(i) (in the manuscript) holds. Similarly, smallholder farmers in the multi-ingredient market prefer FLO if and only if (6) in Corollary 4(ii) (in the manuscript) holds. We remark on three things: 1) the case of " $\neg$ (4) and (5)" is impossible because $\gamma$ (which is defined in Proposition 7(ii)) is positive; 2) the condition of (7) in Corollary 4(ii) (in the manuscript) is not considered in Proposition 8 because this is closed to the single-ingredient case (i.e., (5) in Corollary 4(i)); 3) plantations always prefer FTUSA (see, Proposition 7(i)). 